\title{
Digital Game-Based Learning in Crisis Management Decision-Making:
}

Unobtrusive Assessment Measures and Intervention Evaluation 



\section{DIGITAL GAME-BASED LEARNING IN CRISIS MANAGEMENT DECISION-MAKING: \\ UNOBTRUSIVE ASSESSMENT MEASURES \\ AND INTERVENTION EVALUATION}

Johannes Steinrücke 



\title{
DIGITAL GAME-BASED LEARNING IN CRISIS MANAGEMENT DECISION-MAKING:
}

\author{
UNOBTRUSIVE ASSESSMENT MEASURES \\ AND INTERVENTION EVALUATION
}

\section{DISSERTATION}

to obtain

the degree of doctor at the University of Twente, on the authority of the rector magnificus,

prof. dr. ir. A. Veldkamp

on account of the decision of the Doctorate Board,

to be publicly defended

on Friday the $10^{\text {th }}$ of September 2021 at 16:45 hours

by

\section{Johannes Steinrücke}

born on the $11^{\text {th }}$ of January 1994

in Bergisch-Gladbach, Germany 
This dissertation has been approved by the promotors:

prof. dr. A.J.M. de Jong

prof. dr. ir. B.P. Veldkamp

Cover design: Johannes Steinrücke

Printed by: Ipskamp Printing

Lay-out: Sandra Schele

ISBN: $\quad$ 978-90-365-5194-6

DOI: $\quad 10.3990 / 1.9789036551946$

(c) 2021 Johannes Steinrücke, The Netherlands.

All rights reserved. No parts of this thesis may be reproduced, stored in a retrieval system or transmitted in any form or by any means without permission of the author.

Alle rechten voorbehouden. Niets uit deze uitgave mag worden vermenigvuldigd, in enige vorm of op enige wijze, zonder voorafgaande schriftelijke toestemming van de auteur. 


\section{Graduation COMmitTeE}

Chair: prof. dr. T.A.J. Toonen - University of Twente

Promotors: prof. dr. A.J.M. de Jong - University of Twente prof. dr. ir. B.P. Veldkamp - University of Twente

Members: $\quad$ prof. dr. M.D. Endedijk - University of Twente dr. H. van Oostendorp - Utrecht University prof. dr. V.J. Shute - Florida State University prof. dr. ir. P. Spronck - Tilburg University prof. dr. D.K.J. Heylen - University of Twente 


\section{ACKNOWLEDGEMENTS}

This research was funded by the NWO program professional games for professional skills as part of the Data2Game: enhanced efficacy of computerized training via player modeling and individually tailored scenarios research project under project number 055.16.114.

\section{UNIVERSITY OF TWENTE.}

VEILIGHEIDSWAEs

TWENTE
THALES

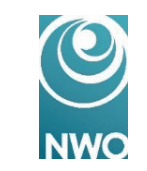




\section{FOREWORD}

More than 9 years ago I visited the campus of the University of Twente for the first time, at least when it comes to anything else than football. I visited the Bachelor open days at the University, where I joined the Psychology program. Long story short, this one day on campus, made me register for the language course in July and the BSc program in Psychology immediately, starting my personal Twente journey.

Therefore, a couple of months later, in July 2012, I started learning Dutch. That was when my first real campus experience started. After one month of successful binge learning, the language was mastered just well enough for studying Psychology at the University of Twente, starting in September 2012. Three years later I graduated from the University of Twente, with my bachelor's degree in the pocket. But instead of leaving, I followed a joined research master's program by the University of Twente and Utrecht University, this time in Methodology and Statistics. I spare you from the full name now, but let us abbreviate it with MSBBSS (you get the idea).

When finishing my Masters, I realized that I still did not get enough. Not enough of Twente, not enough of research, not enough of learning. I was lucky enough to be able to start this position, becoming a $\mathrm{PhD}$ candidate in the field(s) I am enthusiastic about: serious games, educational measurement, and statistics. My bachelor's thesis, my master's thesis and now also my dissertation focus on assessment in serious games. While the details differ, the general field remained the same.

My interest was guided by three things: First, I was amazed by the idea of using games, which I love myself, to deliver learning content in a fun, engaging way. Second, I was annoyed by the traditional way of learning. Albeit useful in certain cases, I prefer the idea of learning by experiencing. Third and last, I do not think that learning should always be assessed by traditional exams or tests. These are the reasons why I want to contribute to the research in this field.

Through all these years, I was supported by people close to me. Friends, family, promotors, colleagues, you name it.

First, I want to start by thanking my promotors, Ton and Bernard. For four years you guided me and helped me grow as an independent researcher. You showed me trust, you encouraged me to think outside the box, you kept reading and reading and reading all the versions of my papers, submissions and of this dissertation. Whenever I ran into problems or issues, I could always count on your expertise, experience, and guidance. 
Second, I want to thank all the participants and members of Veiligheidsregio Twente who were willing to spend time to provide me with information, brainstorm, prepare and participate in the studies. Thank you for giving me the opportunity to gain insight into the functioning of the crisis organization in Twente. Special thanks go to Mark Groenen, Ymko Attema and Jaqueline ten Voorde who were mainly responsible for helping me with the development of the materials and getting us in contact with the participants.

Third, I want to thank all the involved people from HBA-lab by Thales (formerly T-Xchange). Thank you, Thomas, Rafal and Tije for your continuous support in preparing the various versions of the Dilemma (or previous Mayor) game for the data collections, replying to my many e-mails, and helping me sort out technical things when needed.

Fourth, a big thank you goes to all my colleagues at the department of Instructional Technology. From day one you welcomed me as your new colleague. Throughout the four years it was always pleasant to work, discuss or just chat with all of you. Thank you for making my PhD journey fun and exciting. Thanks to all the PhD's who worked in our department, the ProIST sessions were always something I looked forward to. Thanks to Sandra, who always had a listening ear, always was supportive and always made sure that everyone at the office felt welcome and like 'home'. Thanks to my project mates Judith and Paris for the good collaboration and the fun times before, during and after our project meetings. Of course, I also want to thank Mariët, for being in charge and leading the project to where it is now.

Thanks to all my friends, for all the fun times, for taking my mind off work (even if it was just briefly). Thank you Heni, for being there for me over the past years, for listening to my complaints, and for always having my back. Thank you Koen, thank you Jenny, thank you Michel, thank you Tobias, thank you Vera, thank you Dieuwert, thank you Lisa, thank you Serena and all the others who cheered me up, listened to my complaints, and who were always up for a drink and some fun times over the last four years (and longer). Special thanks go out to my paranymphs, Michel and Koen. Both of you know the struggles of a PhD project, and I am glad that you were part of my $\mathrm{PhD}$ journey and agreed to be my paranymphs.

And last, I want to thank my family, and this I do, in German. Danke Mama, danke Oma, danke Papa, danke Opa. Ihr habt mich in meinen Entscheidungen unterstützt, und ihr habt alles dafür getan, dass ich meine Ziele so gut es geht erreichen kann und konnte. Ich konnte mich immer auf euch verlassen. Dafür bin ich euch unendlich dankbar. Danke für alles. Besonders du Mama, du hast mir immer mit Rat und Tat zur Seite gestanden. Du hast immer ein offenes Ohr gehabt, und mir oft aus der gedanklichen Zwickmühle geholfen. Danke Oma, du 
hast für einen nie-endenden Kuchen-Lieferservice gesorgt (den ich übrigens sehr vermissen würde, würde er jemals abbrechen), und du hast immer sichergestellt, dass ich auch mal abschalten konnte. Danke Papa, dass ich dich immer erreichen konnte, wenn ich Ablenkung brauchte. Opa, auch wenn du mich bereits durch mein gesamtes Studium von oben beobachtet hast, warst du immer ein Teil meiner Reise, und dafür bin ich dir unendlich dankbar. Ihr alle habt mich zu dem gemacht der ich heute bin, danke.

Johannes 


\section{TABLE OF CONTENTS}

\section{Chapter 1: General introduction}

General introduction ......................................... 2

Problem statement \& dissertation outline...................... 8

References................................................. 13

\section{Chapter 2: Stress resistance \& analytical skills}

Determining the effect of stress on analytical skills performance in digital decision games: Towards an unobtrusive measure of experienced stress in gameplay scenarios

Abstract.................................................. 18

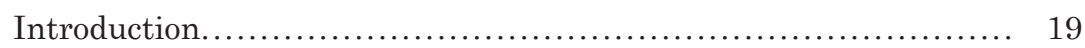

Method....................................................... 24

Results ......................................................... 30

Discussion............................................... 37

References........................................................................... 41

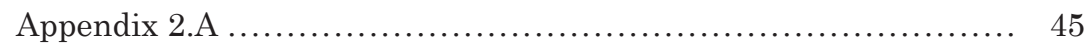

Appendix 2.B .............................................. 46

Appendix 2.C .......................................... 47

\section{Chapter 3: Information literacy}

Information literacy skills assessment in digital crisis management training for the safety domain: Developing an unobtrusive method

Abstract................................................... 50

Introduction.............................................. 51

Method...................................................... 54

Analysis \& results .......................................... 59

Discussion.............................................. 67

References............................................... 71

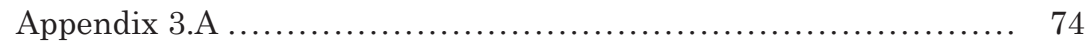

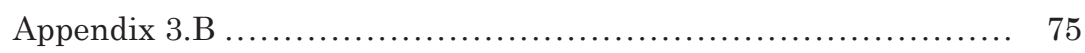

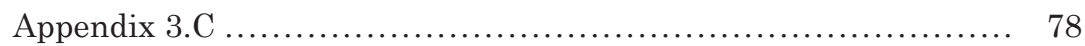




\section{Chapter 4: Self-reflection}

Abstract ..................................................... 82

Introduction ............................................... 83

Method ................................................... 85

Analysis \& results ......................................... 93

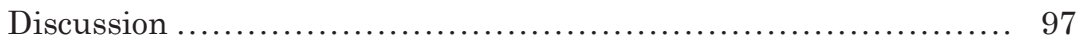

References ................................................. 101

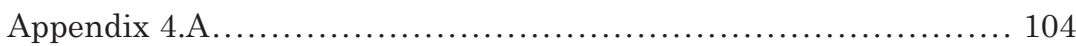

Appendix 4.B............................................. 105

\section{Chapter 5: General discussion}

Introduction .................................................... 108

Discussion of the conducted studies ........................... 108

Unobtrusive assessment in digital game-based learning ............ 113

Keeping learners motivated.................................. 116

Concluding notes ........................................... 117

References .................................................. 119

\section{Chapter 6: English summary}

Introduction .................................................... 125

Overview of conducted studies ................................ 125

Conclusion................................................... 127

\section{Chapter 7: Nederlandse samenvatting}

Introductie....................................................... 129

Overzicht van de uitgevoerde studies .......................... 129

Conclusie....................................................... 131

\section{Chapter 8: Deutsche Zusammenfassung}

Einleitung .................................................. 133

Übersicht über die durchgeführten Studien ..................... 133

Fazit ......................................................... 135 


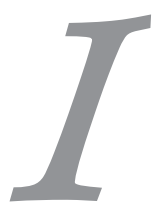

General introduction 


\section{GENERAL INTRODUCTION}

In the year 2000, crisis managers had to quickly take action in a fireworks explosion in the Netherlands, which had a severe impact on society (Kuttschreuter et al., 2011). The involved crisis professionals had to take decisions under uncertainty, extreme stress and time pressure, often within a few seconds of arriving at the scene. While being able to take into account some of the contextual information (e.g., the color of the smoke), the urgency of the event prevented crisis professionals from considering all contextual information when making decisions or taking action (e.g., placement of containers containing dangerous goods), forcing operational staff to risk their own lives trying to extinguish the fire. Unfortunately, due to issues in the communication chain some of the valuable and important decisions by the crisis professionals (e.g., requesting as many units as possible) were not executed immediately, which was one of many factors contributing to the severity of this disaster (Commissie Onderzoek Vuurwerkramp, 2001).

The above-described crisis evolved rather quickly end was of relatively short duration. In short crises like this, crisis managers usually do not have the opportunity to adjust and fine-tune their decisions. They have to act quickly, often under time-constraints and uncertainty. However, crisis can also be long-lasting, over time new knowledge is gained, uncertainty is reduced, and decisions and measures can be adjusted and fine-tuned.

For example, nearly the entire world went into a mode of crisis throughout 2020 because of COVID-19. Countries all over the world were struggling with the disease, forcing governments and crisis managers in different parts of the world to impose different measures to stop the spread of the virus, with some countries being more successful and other countries initially being less successful (Comfort et al., 2020). In the latter case, decisions and measures taken in early stages of the pandemic that the public believed to be effective, were viewed as less effective retrospectively (Meier et al., 2020). While initially made decisions were found to mitigate negative economic consequences in the short run, it remains uncertain that this also holds for medium- and long-term consequences (Naumann et al., 2020). In other words, decisions that were considered the best possible option given the knowledge available at the time, might turn out to be rather suboptimal at a later point.

Both examples demonstrate that crisis management is an important, highly context dependent and complex task, where rather small mistakes or delays can have rather big consequences and in which information gathering and management are crucial aspects in the decision-making process. Therefore, it is important that professionals in crisis management receive proper training, such 
that the public can depend on the expertise of the professionals handling the crisis. In the Netherlands alone, crisis management organizations received 1.2 billion euros in 2019 (Ministerie van Justitie en Veiligheid, 2020), which is used for, among others, training crisis management decision-making.

\section{Crisis management decision-making}

As seen in above examples, the expertise of the crisis managers in charge, their decisions, and the way these decisions were made are crucial in crisis management. However, there is no one-fits-them-all solution to decision-making in crisis management. Decisions often have to be made in a limited amount of time, under limited availability of information, and under difficult circumstances (Crichton et al, 2000). Furthermore, crisis management decision-making situations often are dilemmas: All possible decision options come with their own advantages and disadvantages, which might be different for each involved stakeholder, while there is no correct decision to make, making it even more important for the decision-makers to ensure a high-quality decision-making process (Veiligheidsregio Twente, 2016a).

In this context, decision-makers may be tempted to take an intuitive approach to decision-making, which might cause rather suboptimal decisions (Mezey, 2004). This could be prevented by taking a more analytical, but time consuming, approach to decision-making. However, since crisis situations, and therefore the decision-making process, can become complex rather quickly and because the situation is often urgent (van der Hulst et al., 2014), decision-makers are forced to make an appropriate decision in a relative short time. In this dissertation we investigate how combining an intuitive with an analytical approach can lead to optimal decision-making under time constraints.

\section{Training crisis management decision-making}

To guarantee that the crisis is handled as good as possible and to prevent suboptimal decisions, training crisis management decision-making situations is of utmost importance (Crichton \& Flin, 2001). Real-life training sessions can, especially when multiple stakeholders are involved, become very time consuming and therefore costly. Also, these training sessions require meticulous planning, since trainees and locations have to be available, and training scenarios and locations have to be prepared (Veiligheidsregio Twente, 2016a, 2016b).

A potential alternative to these real-life training sessions is (digital) game-based learning. Digital training environments can be used by individual people at their own preferred times. They also offer the opportunity to automize certain processes within the training session, to standardize training and thereby save a lot of time. In comparison to real-life training, which cannot be done often, digital game-based 
learning environments allow the trainees to train more frequently, which has shown to be useful for decision-making processes (Stonebraker, 2016). Last, as

discussed by Crichton et al. (2000) and Crichton and Flin (2001), game-based learning environments are suitable to implement, and therefore train, decisionmaking in dilemma-like crisis situations, which stands in focus in this dissertation.

\section{Digital game-based learning}

Next to these potential advantages, digital game-based learning (DGBL) environments also offer various conceptual advantages over traditional learning and training environments (e.g., An \& Bonk, 2009; Susi et al., 2007). Whenever real-life training sessions are not feasible (e.g., due to time constraints), DGBL environments allow the learner to participate in complex learning activities in an engaging and realistic manner. Theoretical knowledge and practical knowledge can be incorporated into the main story of the game, such that learning of theoretical knowledge and practical skills is achieved by following the storyline and playing the game: Trainees can experiment with the functionalities the game offers, such that they can better connect practice and theory. Even complex scenarios, which would be impossible to experience in real-life scenarios due to cost, safety, or other reasons, become accessible. Summarizing, as Susi et al. (2007) state, "learning takes place within a context that is meaningful to the game". Furthermore, the authors state that learning environments are not as effective when this meaningful context is missing.

Further, using a DGBL environment makes an adaptive learning experience available. Instructional interventions can be introduced at adaptive points in time based on the players actions and their context. As An and Bonk (2009) discuss, a well-designed DGBL environment enables learners to use pauses to reflect on their behavior. Reflection can be stimulated in various ways, one of which is through feedback. Feedback on the learning process however is only achievable when the current skill (or, in more general terms, competency) state of the learner is known to the DGBL environment. Hence, we need an efficient assessment system to obtain the needed information.

\section{Assessment in digital game-based learning}

To make an adaptive learning experience possible, the DGBL needs to be able to assess the current skill level of the trainees. Two widely used assessment design frameworks are the assessment and feedback lifecycle (Jisc, 2020) and the fourprocess architecture for assessment delivery (Mislevy \& Riconscente, 2005). While the former is rather specific and designed for traditional course settings, the latter is defined in much more general terms, and can therefore be adapted in DGBL (e.g., Shute \& Wang, 2015). The four-process architecture for assessment delivery, 
depicted in Figure 1.1 (Mislevy \& Riconscente, 2005, p. 25), is usually used as part of the evidence-centered design approach to assessment (Almond et al., 2002; Mislevy \& Riconscente, 2005), which is a top-down approach to educational assessment design intended to guarantee relevance and validity (Mislevy et al., 2003).

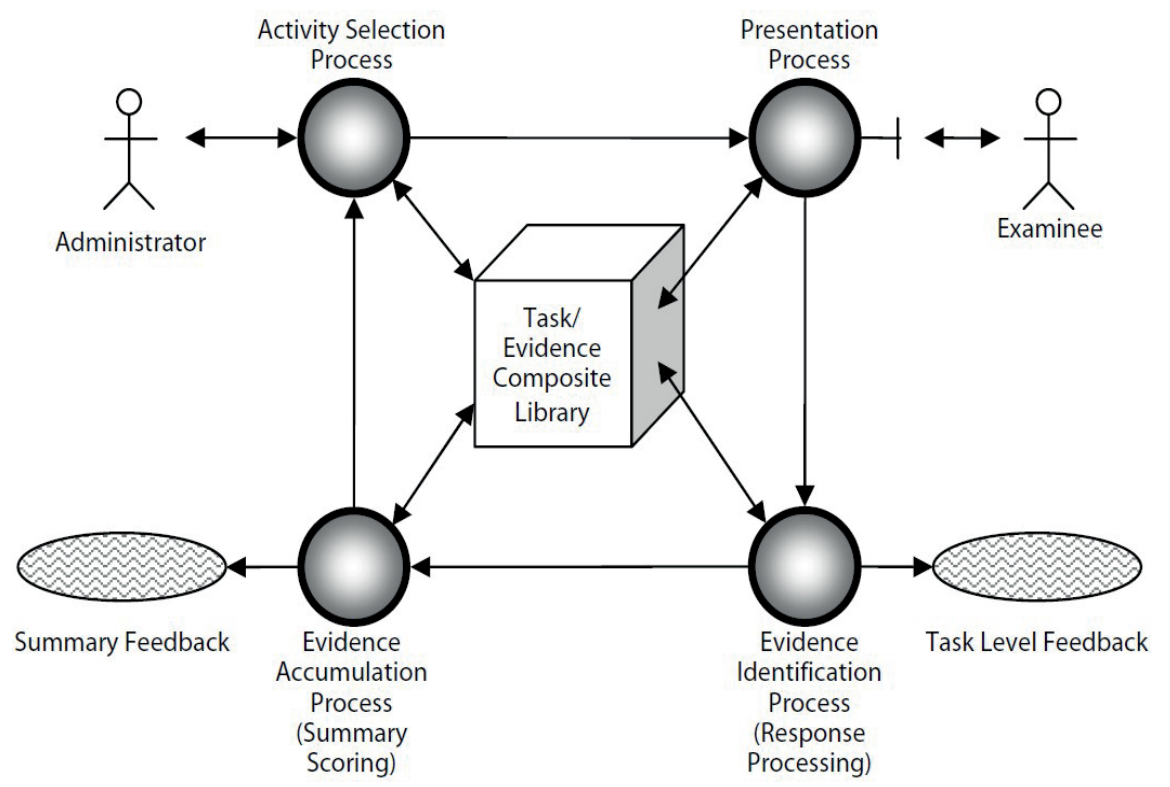

Figure 1.1. The four-process architecture for assessment delivery. From "Evidencecentered assessment design: Layers, structures, and terminology"

by R.J. Mislevy and M. Riconscente, 2005, SRI International Copyright 2005 by SRI International. Reprinted with permission.

As the name suggests, the four-process architecture describes four principal processes to assessment (Mislevy et al., 2003), explained in the following example:

In a traditional exam, the teacher would choose relevant questions for the exam (activity selection process), hand out the exam sheets to learners (presentation process), evaluate if learners gave correct answers (evidence identification process) and compute the score on that exam (evidence accumulation process). In a DGBL environment these processes all can be automated. For example, to assess the problem-solving skill of the player we could employ a puzzle of a certain difficulty (activity selection process). Then this puzzle could be presented just like a real puzzle would be presented, only digitally (presentation process). The DGBL environment then could track the number of attempts needed to solve the puzzle as evidence (evidence identification process), such that a score can be computed (evidence accumulation process). 
In DGBL environments we can weave these four processes into the game itself. The activity selection process and the presentation process would already be defined while developing the game. Considering the natural measurement opportunities of a digital game, it is possible to process all interactions the player makes, with the exact time stamps. In doing so, an underlying scoring algorithm can be employed to trigger moments of feedback and provide said feedback. Integrating the assessment in the game itself has major advantages, as DGBL allows the assessment to be gamified, unobtrusive, and designed in such a way that flow is maintained (Shute, 2011). Furthermore, it is argued that, for example, test anxiety is a much smaller problem in these unobtrusive kinds of assessments than compared to traditional assessment scenarios (Shute, 2011; Shute \& Wang, 2016; Wang et al., 2015). This is because learners are not aware of being tested, due to the assessment being seamlessly incorporated into the gameplay.

In other words, unobtrusive assessment means that the assessment (i.e., task presentation, data collection and analysis) is a natural part of the game, that it does not interrupt the gameplay flow of the player (Ifenthaler et al., 2012). For example, Shute and Wang (2015) applied stealth assessment in a videogame called 'Portal 2', where the player has to solve enigmas or puzzles to progress in the game. The authors argue that the problem-solving skills of the player can be assessed using this game. Once the task has been presented, the learner interacts with the environment or game. Regarding the evidence identification process this means, that all interactions from the learner with the DGBL environment are tracked, and that all relevant information of the task are associated with learners' interactions. The raw data is logged and later analyzed in the process of evidence accumulation. Information about the skill level of the learner is gained by employing a statistical framework which fits the goal of the learning environment. Simple methods like score computation (VanLehn et al., 2011), but also more advanced techniques like Bayesian network algorithms (Shute et al., 2016) are just two applicable examples.

\section{Instructional intervention}

As already scraped upon, using a DGBL environment offers the opportunity to adaptively adjust the game to the players, such that they can exercise in an environment that is fit to their specific needs. For example, a low performing player would receive more support or (initially) simpler problems and tasks. Therefore, a high performing player would receive less support or (earlier) more complex problems and tasks (An \& Bonk, 2009). Next to adjusting the tasks players have to perform in the game, the game could also adaptively prompt instructional interventions. This too can improve the learning effect over what is achieved by simple exercising alone (i.e., playing a serious game in a DGBL environment). In conclusion, adaptivity can improve the learning effect compared 
to the same DGBL environment without adaptivity (Cocea \& Weibelzahl, 2007; Lopes \& Bidarra, 2011).

To achieve adaptivity, the DGBL environment needs to be aware of the player's current in-game (i.e., gameplay) behavior, for example by assessing the player. Following the previously described architecture by Mislevy and Riconscente (2005), assessment methods offer the opportunity to provide task level feedback to the DGBL environment itself. When this assessment is unobtrusive, assessment takes place without interrupting the gameplay, therefore reducing bias due to interruption. That means, on top of providing direct feedback to the learner only, we can also provide feedback to the DGBL environment, so that it can adapt to meet the learner's needs. For example, this feedback to the DGBL environment could be used to trigger instructional interventions when certain conditions, like specific in-game behavior or a reduction or stagnation in performance respectively skill level of the player, are met. The DGBL environment could monitor these conditions by constantly evaluating the player's skill level, performance or in-game behavior using unobtrusive assessment methods (Bellotti et al., 2013). Alternatively, if these conditions do not occur, the instructional intervention can still be offered after a pre-defined amount of time.

As Wouters and van Oostendorp (2013) discuss, there are plenty of different interventions that can be used in such environments (e.g., reflection, collaboration, or personalization), next to task-level feedback to the player. The instructional intervention should be relevant to the player (Keller, 1999; Keller, 2000; Albrecht \& Karabenick, 2018), suggesting that trainees should engage in similar thinking strategies as in practice. For example, if in real exercises the trainees are used to debriefings where they can reflect on their own performance and receive some external feedback, the instructional intervention in a DGBL environment should be designed similarly. Therefore, we chose to employ a dashboard-supported self-reflection in the game in Study 3, which is described in detail in Chapter 4.

\section{Data2Game}

This dissertation was written as part of the "Data2Game: Enhanced Efficacy of Computerised Training via Player Modelling and Individually Tailored Scenarios" (D2G) research project. The main goal of D2G was to investigate different techniques and methods to individually tailor a digital serious game to the individual player. The project was performed in close collaboration with HBA-Lab (formerly T-Xchange) by Thales Nederland, who provided the infrastructure for the digital serious game, and Veiligheidsregio Twente (VRT; Twente Safety Region). The research in $\mathrm{D} 2 \mathrm{G}$ was performed by three $\mathrm{PhD}$ candidates, of which two were positioned at the University of Twente and one at Tilburg University. 
The individual subprojects were carried out mostly independent from another, with the target group and the used digital serious game as the most important common factors (Data2Game, 2020).

\section{Problem Statement \& Dissertation OUTLINE}

\section{Crisis management at Veiligheidsregio Twente}

VRT is the regional crisis management organization in the Dutch region of Twente. In case a crisis evolves that involves multiple municipalities and that reaches a certain level of severity, usually involving multiple municipalities, the crisis team of VRT is called in. In this crisis team, professionals are supposed to discuss and make decisions about how to deal with the crisis. Among others, they discuss approaches to solve the crisis at its core, approaches to keep the public safe and informed, and more issues that require a just and critical decisionmaking process (Veiligheidsregio Twente, 2016b). The crisis team is composed of professionals from different fields, like the fire department, the police, the health department, mental health care, crisis communication, administrative consultants and often representatives from the in the crisis involved parties (i.e., companies or civilians). Professionals from these fields, excluding the representatives of the involved parties, who already are, or have the option to become, members of the "crisis team", are the intended target population of the entire Data2Game project.

These professionals were also the main participants in the current dissertation. However, in Chapter 2 the sample comes from a student body of the University of Twente. This was done, because the arrangements to collect data from a large enough number of professionals from VRT were not yet made. As further described in Chapter 3 and Chapter 4, collecting data from VRT professionals proved challenging even with these arrangements. The main issue was that the approximately 150 prospective participants often struggled to find enough time, did not see added value, or simply ignored the multiple invitations. As for the study described in Chapter 4, the time issue became more and more prominent because of the COVID-19 pandemic throughout 2020.

\section{Crisis management training at Veiligheidsregio Twente}

VRT views crisis management as a combined skill (see Figure 1.2). Depending on the crisis managers specific background (e.g., police vs communication), the crisis manager has to be proficient on certain skills. Together, as the crisis team, the crisis managers from their different backgrounds should cover all the in Figure 1.2 depicted skills: There is at least one person that is proficient on each skill. 


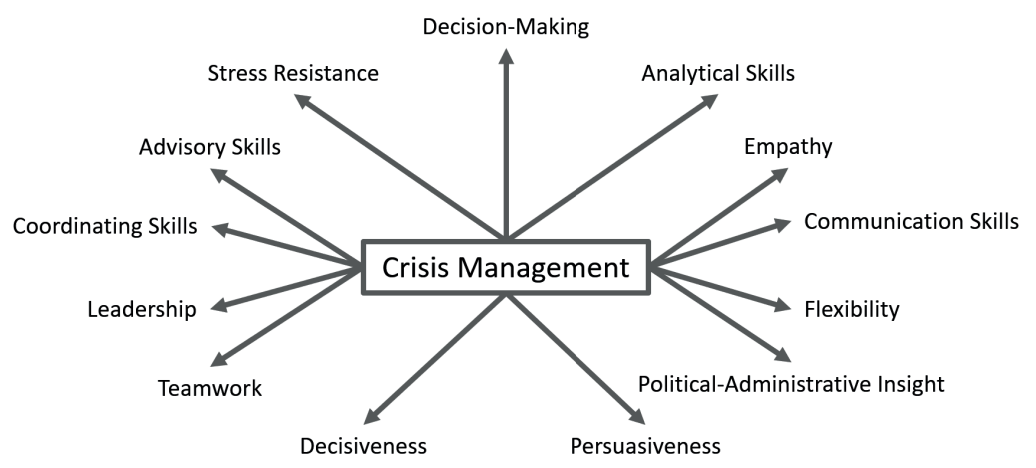

Figure 1.2. Crisis management as combined skill as described in internal VRT documents

While there is a large overlap between all the listed competencies, VRT considers two to be particularly important in crisis management: Stress Resistance and Analytical Skills, which are crucial for facilitating a high-quality decision-making process in crisis management. VRT describes Stress Resistance as the competency to perform calm even under difficult, uncertain conditions, to have insight into one's own physical and mental capacities, to reduce pressure by creating oversight, to remain concentrated even under high pressure and to not get carried away by emotions. Analytical Skills are being described as the competency to distinguish between facts and assumptions, to distinguish between relevant and irrelevant information, to connect individual pieces of information to obtain the bigger picture, to decide who the relevant stakeholders are, to collect and obtain information and to think ahead based on the available information and the context of the situation.

To train the crisis management skills, VRT periodically holds so called Systeemoefeningen (system exercises), where fictional crises (e.g., terroristic attack, power failure for multiple days, big accidents in production facilities) are being handled. Members of the individual organizations within VRT, as well as civilian organizations are involved in these exercises. Next to trying to solve the crises, VRT also performs a detailed debriefing after the exercise is completed, where they discuss what was handled well and what was not handled well by the trainees. Trainees are asked to reflect on their own performance, to name points of improvement and to name what they did well. The system exercises usually take at least half a day to complete and take place approximately once a month (Veiligheidsregio Twente, 2016a, 2016b). However, it is time consuming to plan and execute these system exercises. Therefore, to be able to exercise more frequently and to receive additional training of crisis management decisionmaking, a DGBL environment as described in the following section could be used. 


\section{Game-based learning environment}

The goal of this dissertation is to investigate unobtrusive assessment and an instructional intervention (i.e., a dashboard-supported self-reflection) in a DGBL environment for additional training of crisis management decision-making. To reach this goal, we made use of the Mayor, respectively Dilemma, Game in all studies that are described in this dissertation.

The Dilemma Game is a further developed version of the Mayor Game, which was developed by T-Xchange (now Thales HBA-lab). Both the Mayor and Dilemma Game focus on training decision-making skills in crisis situations. While they originally were designed to be used by administrators (e.g., mayors) to train and evaluate their policing and decision-making styles, the Mayor and Dilemma Game did not focus on training specific parts of crisis management decision-making ( $\mathrm{T}$ Xchange, 2020; van de Ven et al., 2014), and therefore were adjusted, together with the developers, to tailor the game to the specific context of the studies described in this dissertation. Furthermore, the general set-up of the Mayor and the Dilemma Game is similar to the crisis team set-up of VRT, where the decisionmaker can consult multiple experts to gain additional information about the situation. In the following paragraphs, we describe the game as we used it in the individual studies. In the first study, we used a modified version of the Mayor Game. In studies two and three, the Dilemma Game was used, in its most recent version of the time of the respective studies.

\section{The Mayor Game in Study 1}

In the first study we employed the Mayor Game which was running on the SDM (strategic decision-making) game engine by T-Xchange. In the game, the player had to make a decision in a fictional crisis situation. To do so, the player was asked to consult all the advisors present on the screen, which all provided one piece of information. They player had to answer a total of eight dilemmas. After answering a dilemma, the player was asked to indicate which of the read pieces of information were in line with the made decision.

\section{The Dilemma Game in Study 2}

In our second study the Mayor Game was further developed, and now called the Dilemma Game. The Dilemma Game was running on the DDM (dynamic decisionmaking) game engine by T-Xchange. In this study, each advisor was offering two pieces of information per dilemma: one was offered actively (the advisors had a pop-up to indicate that they have to offer information), while the other had to be "asked" for (done by a click on the advisors without a pop-up). For each advisor holds that the second piece of information became only available when the first piece of information has already been read. 


\section{The Dilemma Game in Study 3}

Due to the COVID-19 pandemic the third experiment was conducted online. Because the Flash player is not supported on all devices, the game in the third study was a slightly updated version of the Dilemma Game, ported to HTML5. In doing so, we were able to collect data fully online, since no compatibility issues arose. Aside from slight optical changes the functionalities of the game remained the same as in the second study.

The studies \& discussion

As the name of this dissertation "Game-based learning: assessment and instructional interventions" already suggests, studies with two different aims are performed. First, it is investigated if and how competencies of a user of a digital game-based learning environment can be assessed, without administering a test directly to the player. Ideally, the player is evaluated based solely on how the game is played. Second, it is investigated whether instructional interventions, that are related to these evaluations, can be used to influence the players approach to the game, which in the end might promote learning.

\section{Study 1}

In the first study, we focused on two competencies that were relevant in crisis management according to VRT: stress resistance and analytical skills. The study aimed to answer two research questions: First, whether a change in experienced stress influences the players' in-game performance for analytical skills. Second, whether we can employ in-game behavior to make predictions about the measured level of stress of a player. As described, we employed a version of the Mayor Game running on the SDM game engine by T-Xchange. This study is described in Chapter 2.

\section{Study 2}

Given that unobtrusively measuring the players stress seemed too complex to achieve with the Mayor game, the focus for the second study shifted towards Information Literacy skills assessment. Information Literacy generally describes many of the by VRT listed competencies in crisis management. In this study, we aimed to develop an unobtrusive measure of information literacy using the Dilemma game. To validate any possible unobtrusive measure, we also let participants fill in an Information Literacy questionnaire, which was developed in collaboration with two information specialists at the University of Twente. This study is described in Chapter 3. 


\section{Study 3}

After conducting two studies on unobtrusive assessment of different skills in a digital game-based learning environment, in the third study the focus was set on evaluating the effect of one instructional intervention, which according to the literature fits the target population and the context of game-based learning: selfreflection in combination with a dashboard promoting self-comparison. This study is described in Chapter 4.

\section{General discussion}

In the general discussion we reflect on the work conducted in the three main studies. Lessons learned are discussed, reflecting on different approaches to assessment (i.e., top-down vs. bottom-up). Further, the results of the studies are put into perspective, considering the initial goal that was set out for this subproject of Data2Game. Finally, it will also be discussed how the results of this subproject fit into Data2Game as a whole and how the project turned out in general. Problems, obstacles, and their solutions are described. The discussion is provided in Chapter 5. 


\section{REFERENCES}

Albrecht, J. R., \& Karabenick, S. A. (2018). Relevance for learning and motivation in education. The Journal of Experimental Education, 86, 1-10. https://doi.org/10.1080/00220973.2017.1380593

Almond, R., Steinberg, L., \& Mislevy, R. (2002). Enhancing the design and delivery of assessment systems: A four-process architecture. The Journal of Technology, Learning and Assessment, 1. https://ejournals.bc.edu/index.php/jtla/article/view/1671

An, Y. J., \& Bonk, C. J. (2009). Finding that special place: Designing digital game-based learning environments. TechTrends: Linking Research and Practice to Improve Learning, 53. 43-48.

Bellotti, F., Kapralos, B., Lee, K., Moreno-Ger, P., \& Berta, R. (2013). Assessment in and of serious games: An overview. Advances in Human-Computer Interaction, 2013. https://doi.org/10.1155/2013/136864

Cocea, M., \& Weibelzahl, S. (2007). Eliciting motivation knowledge from log files towards motivation diagnosis for adaptive systems. In C. Conati, K. McCoy, \& G. Paliouras (Eds.), User modeling 2007 (pp. 197-206). Springer. https://doi.org/10.1007/978-3540-73078-1_23

Comfort, L. K., Kapucu, N., Ko, K., Menoni, S., \& Siciliano, M. (2020). Crisis decisionmaking on a global scale: Transition from cognition to collective action under threat of COVID-19. Public Administration Review, 80, 616-622. https://doi.org/10.1111/puar.13252

Commissie Onderzoek Vuurwerkramp. (2001). De vuurwerkramp: Eindrapport [The fireworks disaster: Final report]. https://dloket.enschede.nl/loket/sites/default/files/ DOC/Eindrapport\%20Commissie\%20Oosting\%20compleet.pdf.

Crichton, M. T., \& Flin, R. (2001). Training for emergency management: Tactical decision games. Journal of Hazardous Materials, 88, 255-266. https://doi.org/10.1016/s0304-3894(01)00270-9

Crichton, M. T., Flin, R., \& Rattray, W. A. R. (2000). Training decision makers - Tactical decision games. Journal of Contingencies and Crisis Management, 8, 208-217. https://doi.org/10.1111/1468-5973.00141

Data2Game. (2020, November). What is DATA2GAME. https://data2game.nl/project/

Ifenthaler, D., Eseryel, D., \& Ge, X. (2012). Assessment for game-based learning. In D. Ifenthaler, D. Eseryel \& X. Ge (Eds.), Assessment in game-based learning: Foundations, innovations, and perspectives (pp. 1-8). Springer.

Jisc. (2020) Transforming assessment and feedback with technology. https://www.jisc.ac.uk/full-guide/transforming-assessment-and-feedback

Keller, J. M. (1999). Using the ARCS motivational process in computer-based instruction and distance education. New Directions for Teaching and Learning, 1999, 37-47. https://doi.org/10.1002/tl.7804 
Keller, J. (2000). How to integrate learner motivation planning into lesson planning: The ARCS model approach. Paper presented at VII Semenario, Santiago, Cuba, 19-21 October.

Kuttschreuter, M., Gutteling, J. M., \& de Hond, M. (2011). Framing and tone-of-voice of disaster media coverage: The aftermath of the Enschede fireworks disaster in the Netherlands. Health, Risk \& Society, 13, 201-220. https://doi.org/10.1080/13698575. 2011.558620

Lopes, R., \& Bidarra, R. (2011). Adaptivity challenges in games and simulations: A survey. IEEE Transactions on Computational Intelligence and AI in Games, 3, 85-99. https://doi.org/10.1109/TCIAIG.2011.2152841

Meier, K., Glatz, T., Guijt, M. C., Piccininni, M., van der Meulen, M., Atmar, K., Jolink, A.-T. C., Kurth, T., Rohmann, J. L., Zamanipoor Najafabadi, A. H. (2020). Public perspectives on protective measures during the COVID-19 pandemic in the Netherlands, Germany and Italy: A survey study. PLOS ONE, 15, e0236917. https://doi.org/10.1371/journal.pone.0236917

Mezey, G. (2004). Crisis management decision making. AARMS, 3, 267-288.

Mislevy, R. J., Almond, R. G., \& Lukas, J. F. (2003). A brief introduction to evidence centered design. ETS Research Report Series, 2003, i-29. https://doi.org/10.1002/j.2333-8504.2003.tb01908.x

Mislevy, R. J., \& Riconscente, M. (2005). Evidence-centered assessment design: Layers, structures, and terminology (Tech. Rep.). SRI International.

Naumann, E., Möhring, K., Reifenscheid, M., Wenz, A., Rettig, T., Lehrer, R., Krieger, U., Juhl, S., Friedel, S., Fikel, M., Cornesse, C., \& Blom, A. G. (2020). COVID-19 policies in Germany and their social, political, and psychological consequences. European Policy Analysis, 6, 191-202. https://doi.org/10.1002/epa2.1091

Ministerie van Justitie en Veiligheid. (2020, September 29). Veiligheidsregio's. Veiligheidsregio's en crisisbeheersing, Rijksoverheid.nl. https://www.rijksoverheid. nl/onderwerpen/veiligheidsregios-en-crisisbeheersing/veiligheidsregios

Shute, V. J. (2011). Stealth assessment in computer-based games to support learning. Computer games and instruction, 55, 503-524.

Shute, V. J., \& Wang, L. (2015). Measuring problem solving skills in Portal 2. In P. Isaías, J. M. Spector, D. Ifenthaler, \& D. G. Sampson (Eds.), E-learning systems, environments and approaches: Theory and implementation (pp. 11-24). Springer. https://doi.org/10.1007/978-3-319-05825-2_2

Shute, V. J., \& Wang, L. (2016). Assessing and supporting hard-to-measure constructs in video games. In A. A. Rupp \& J. P. Leighton (Eds.), The Wiley handbook of cognition and assessment (pp. 535-562). John Wiley \& Sons, Inc. https://doi.org/10.1002/9781118956588.ch22

Stonebraker, I. (2016). Toward informed leadership: Teaching students to make better decisions using information. Journal of Business \& Finance Librarianship. 21, 229-238. https://doi.org/10.1080/08963568.2016.1226614 
Susi, T., Johanneson, M., \& Backlund, P. (2007). Serious games - An overview (Tech. Rep.). School of Humanities and Informatics, University of Skövde. http://urn.kb.se/resolve?urn=urn:nbn:se:his:diva-1279

T-Xchange. (2020, February 21). Dilemma. https://www.txchange.nl/ dilemma/

van de Ven, J. G. M., Stubbé, H., \& Hrehovcsik, M. (2014). Gaming for policy makers: It's serious!. In A. De Gloria (Eds.), Games and learning alliance: Second international conference, GALA 2013 (pp. 376-382). Springer. https://doi.org/10.1007/978-3-31912157-4_32

van der Hulst, A. H., Muller, T. J., Buiel, E., Gelooven, D. V., \& Ruijsendaal, M. (2014). Serious gaming for complex decision making: Training approaches. International Journal of Technology Enhanced Learning, 6, 249-264. https://doi.org/10.1504/IJTEL.2014.068364

VanLehn, K., Burleson, W., Echeagary, H., Christopherson, R., Sanchez, J., Pontet, Y., Muldner, K., \& Zhang, L. (2011). The level up procedure: How to measure learning gains without pre- and post-testing. In Proceedings of the 19th international conference on computers in education, icce 2011 (pp. 96-100).

Veiligheidsregio Twente. (2016a). Overview crisisorganisatie 2016. https://vrtwente.nl/ media/351300/overview-crisisorganisatie-2016-def.pdf

Veiligheidsregio Twente. (2016b). Regionaal Crisisplan Veiligheidsregio Twente - Deel 1. http://www.vrtwente.nl/media/227908/regionaal-crisisplan-veiligheidsregiotwente-deel-1.pdf

Wang, L., Shute, V., \& Moore, G. R. (2015). Lessons learned and best practices of stealth assessment. International Journal of Gaming and Computer-Mediated Simulations, 7, 66-87. https://psycnet.apa.org/doi/10.4018/IJGCMS.2015100104

Wouters, P., \& van Oostendorp, H. (2013). A meta-analytic review of the role of instructional support in game-based learning. Computers \& Education, 60, 412425. https://doi.org/10.1016/j.compedu.2012.07.018 
Chapter 1 


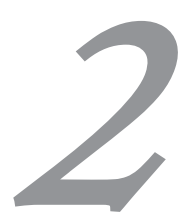

\title{
Stress resistance \& analytical skills
}

\author{
Determining the effect of stress on analytical skills \\ performance in digital decision games: \\ Towards an unobtrusive measure of experienced stress \\ in gameplay scenarios
}

This chapter is based on:

Steinrücke, J., Veldkamp, B. P., \& de Jong, T. (2019). Determining the effect of stress on analytical skills performance in digital decision games towards an unobtrusive measure of experienced stress in gameplay scenarios. Computers in Human Behavior, 99, 144-155. https://doi.org/10.1016/j.chb.2019.05.014 


\section{Abstract}

This study aims to develop an unobtrusive measure for experienced stress in a digital serious gaming environment involving decision-making in crisis management, using only in-game measures in a digital decision game called the Mayor Game. Research has shown that stress has an influence on a decisionmaker's behavior, and also on the learning experience in training scenarios. Being able to assess unobtrusively the level of stress experienced would allow manipulation of the game so as to improve the learning experience. An experiment was conducted with two conditions, one paced and one non-paced. In the paced condition, participants were exposed to in-game changes that aimed to induce stress by creating information overload, uncertainty and time pressure. While pacing caused differences between the conditions with respect to in-game performance for analytical skills, several simple unobtrusive in-game measures were not consistent enough to serve as indicators for experienced stress. Further, physiological measurements of stress did not show significant differences between the conditions, indicating that the employed methods to induce stress did not work sufficiently. These results call for testing of more sophisticated methodologies to unobtrusively assess experienced stress in the given type of serious game. 


\section{INTRODUCTION}

"Hasty, often unwise decisions" are induced by stress (Cooper, 2007, p. 21). This statement highlights the influence of stress on the quality of decision-making processes and was confirmed by later findings describing the effect of stress on decision-making (Starcke \& Brand, 2012). It is also related to the Yerkes-Dodson law (Yerkes \& Dodson, 1908), which indicates that people perform worse under higher than optimal stress conditions. The Yerkes-Dodson law, describing a curvilinear (U-shaped) relationship between stress and performance, further implies that a slight level of experienced stress is nonetheless beneficial compared to experiencing no stress at all (Yerkes \& Dodson, 1908). This relationship is of paramount importance when a high-quality decision-making process is needed, such as decision-making in the context of crisis management. In some crisis situations the decisions to be taken are similar to dilemmas: No matter what exact decision is made, the result is never perfect for all parties involved. In these situations, it is crucial to have a high-quality decision-making process, thereby ensuring that decisions are not hasty and unwise, but well thought through, and that important factors are considered (Crichton et al., 2000).

One of the crucial aspects of crisis management is situation assessment, in which the available information and its meaning are examined and evaluated (Mezey, 2004). A thorough analysis of the crisis situation is also crucial for situational awareness (SA; Endsley, 2000), about which the author stated: "Most simply put, SA is knowing what is going on around you" (p. 2). Knowing that, we can reasonably conclude that situational awareness and situation assessment are key in decision-making in crisis management (Mezey, 2004; van der Hulst et al., 2014; Veiligheidsregio Twente, 2016). Further looking at the role of stress, Mezey (2004) explained that stress can be produced in crisis situations, which would influence the crisis manager's performance. This stress could also influence the assessment of the crisis situation by decreasing the quality of the situation assessment and in the end reducing the quality of the decision-making process (Cooper, 2007). As Kowalski-Trakofler and Vaught (2003) described in the context of managing emergencies, stressed persons rely on different patterns of reasoning for coming to a conclusion than non-stressed persons, who more often rely on in-depth analysis of the situation. The authors further explained that decision-makers often narrow their attention to focus on critical issues and elements when under stress, letting them ignore or miss other (additional) useful information about the situation. In the next section we explain how this relationship between stress and analytical skills is viewed and handled by Veiligheidsregio Twente, a regional Dutch crisis organization, which also provides the practical context for this study. 


\section{Analytical skills and stress at Veiligheidsregio Twente}

Veiligheidsregio Twente ${ }^{1}$ (VRT; Twente Safety Region) is an organization consisting of people from the fire department, the police department, the medical emergency response team, and local government, responsible for coordination and response to crises in the Dutch region of Twente. VRT usually involves two different types of crisis professionals in such crisis situations: First, there is the operational staff. These are, for example, the firefighters who go to the place of an incident and work on extinguishing the fire. Second, there is the strategic staff. They focus on the more administrative part of crisis management, which includes, for example, coordinating the different emergency services, specifying strategies and communicating facts within the organization and to the public. More complex crisis situations, where both types of crisis managers are involved, are only trained for about one afternoon once a month because of time and cost reasons. Consequently, training all important competencies (VRT names 13 different competencies: stress resistance, analytical skills, empathy, leadership, teamwork, flexibility, decisiveness, persuasiveness, coordinating, communication, advisory skills, political administrative insight, decision-making) and focusing on all of them is not feasible. Hence, VRT has searched for an additional way to train their crisis managers on some of these competencies, for example, by a digital serious game that focuses on decision-making processes.

As laid out before, the two competencies of Analytical Skills and Stress Resistance lie at the core of the decision-making process: VRT (personal communication, April 16, 2018) describes Analytical Skills as the competency to discriminate between facts and assumptions, relevant and irrelevant information, to make connections based on available information, to gather and consult information as well as the ability to apply scenario-based thinking. Sarpong and Maclean (2011) define scenario-based thinking as the "use of scenarios to stimulate innovative solutions for a possible future context” (p. 1155). VRT (personal communication, April 16, 2018) describes Stress Resistance, on a slightly different level. While the main point of being stress resistant is that the crisis manager does not get carried away by emotions, the description also implies that a stress-resistant crisis manager behaves similarly when under stress and when not under stress. This includes the requirement that the crisis manager maintains concentration and still puts things into perspective. According to VRT, time pressure is not only among the most important stressors for crisis managers, but they also have to deal with time pressure during crisis situations, which does not allow them to discuss all matters in as much detail as possibly needed.

1 http://www.vrtwente.nl 
To ensure that the crisis managers of VRT are capable of doing just that, more complex crisis situations thus need to be trained more often, for example, by means of a digital serious game. The experienced stress level of the crisis managers should be kept at medium intensity during training, which is where fastest learning can be expected according to Raudys and Justickis (2003), along with best performance as implied by the Yerkes-Dodson law. Knowing the player's current level of experienced stress would thus allow manipulation of the serious game to ensure that players experience the optimal stress level for learning, for example, by adjusting the pace of the game.

\section{Decision games}

Serious games are often categorized based on their application context (Susi et al., 2007) or on the game's genre (Connolly et al., 2012; Sniezek et al., 2001). Since the current study was conducted within a crisis management and decision-making domain, the serious game to be used in this research would be categorized as a military or government game based on the scheme described by Susi et al. (2007). In both categories, managing crisis situations, making decisions and running scenarios repeatedly are among the most important game characteristics. However, this basic categorization does not spell out the specific nature of what a game fitting this research's context should look like.

As Connolly et al. (2012) and Sniezek et al. (2001) described many serious games and games for learning can be categorized as simulation games. In simulation games the goal is to model or mimic a realistic (crisis) scenario, for example, by using scenarios and/or dilemmas based on past, elapsed real-life crisis situations. In that sense, simulation games are well suited for training for decision-making in crisis management. Just as VRT already does in an analog manner, a serious game should mimic the situation for decision-makers using realistic scenarios and dilemmas. As in real situations, the decision-makers need to differentiate between pros and cons for a specific decision, in order to make a decision based on the available information. Sniezek et al. (2001) extended this description with the notion that in crisis (management) training contexts, "a simulation is realistic if it induces the same psychological processes in the training context that are experienced during an actual crisis" (p. 3), which remains one of the greatest challenges for such simulations to accomplish. Accordingly, we prefer to employ a serious game that mimics the to-be-trained-for situation in an authentic way, being aware that a simulation close to the real-life situation is difficult to implement.

What fits with the above categorizations, the context of our research, and also the structure of VRT, is what Crichton et al. (2000) and Crichton and Flin (2001) described as tactical decision games, which are designed for practicing decisionmaking skills. Such games illustrate decision-making strategies, "boost expertise in 
decision-making and judgement" (p. 260), but also allow practicing of situation awareness and stress management (Crichton \& Flin, 2001). Further, the players must deal with the fact that there is no 'correct' decision to be made; the players are confronted with dilemmas. Players in such games also have only limited information available, in line with what occurs during actual crisis situations where decision-makers must make a decision based on the available information, which sometimes is not much (Crichton et al., 2000). The Mayor Game, which is the digital serious gaming application used in this study, is focused on the process of making a decision, and functions similarly to what was just described in this section.

\section{The Mayor Game}

The Mayor Game is a digital web-based serious game used to train Dutch mayors for dealing with crisis situations. The Mayor Game provides training on various important competencies for decision-making in crisis management, for example, environmental consciousness, decisiveness, anticipation, and judgment. The Mayor Game is played by many mayors all across the Netherlands, who in general value the game (Jong, 2017) . In the game, players must handle a realistic crisis situation (called a scenario) by responding to a number of dilemmas. To help the players decide on what answer to give, a number of advisors offer additional information to the player, which the players can also mark as relevant. Next to additional information, each advisor also provides a clear recommendation on what to decide (yes or no). The game's focus does not lie on deciding correctly, given that there is no correct decision to make; instead, the Mayor Game focuses on the decisionmaking process, rather than on the actual decision. All dilemmas can be responded to in multiple ways, which will affect only the feedback the players receive after they have finished the scenario. See Figure 2.1 for a screenshot taken in the Mayor Game, showing one dilemma.

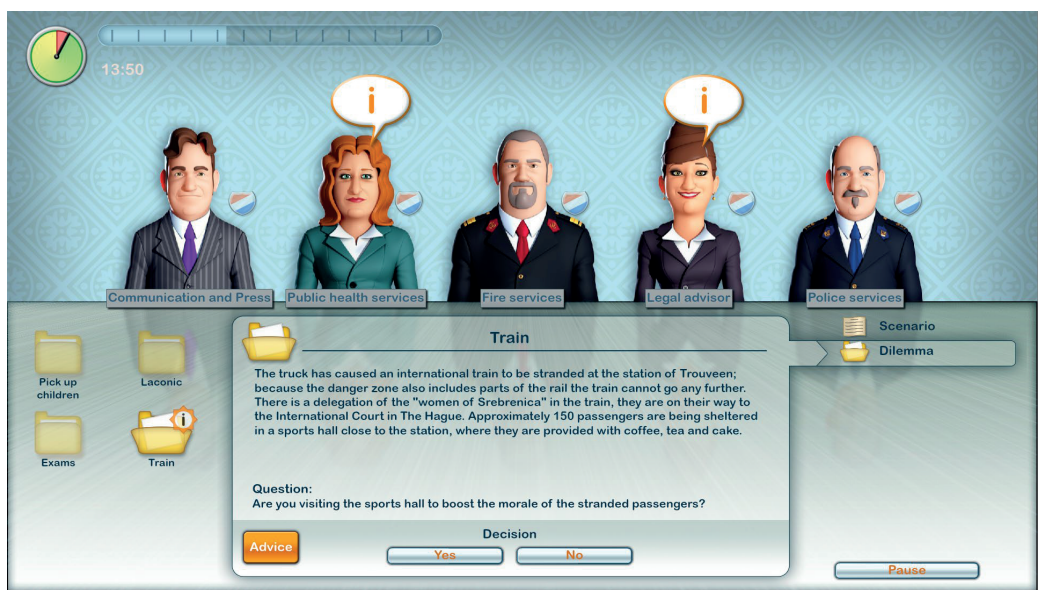

Figure 2.1. Screenshot of the Mayor Game 
The feedback is about how the players handled the situation, what the players took into account and how the players scored on, for example, scales for different leadership styles (T-Xchange, 2018; van de Ven et al., 2014). Tweaked versions of one game scenario in the Mayor Game, as described in the next section, were used in the experiment described in this study.

\section{An unobtrusive measure of stress in decision games}

Unobtrusively assessing players' stress levels in serious games has various advantages over more obtrusive in-game assessment methods such as questionnaires or external, out-of-game measures such as wearable sensors to measure physiological indicators of stress. For example, Shute (2011) stated that keeping the players in a so-called flow state by not interrupting or disturbing the gameplay to assess the players is beneficial to the learning process. The players are allowed to simply play the game, while unobtrusive in-game assessment methods can be used to induce adaptivity by changing the game depending on the outcomes of that assessment (Bellotti et al., 2013), which in turn increases the efficiency of the learning process for which the serious game was originally designed (Lopes \& Bidarra, 2011). Further, the authors stated that adaptivity is supposed to increase how the game appeals to the players, which Cocea and Weibelzahl (2007) framed as follows: The more appealing the game, the more motivated the players, which in turn leads to increased learning.

To assess the players unobtrusively, the assessment must be woven into the natural gameplay (Shute \& Kim, 2014). Consequently, the interactions of the players with the game need to be used, in such a way that conclusions can be drawn about the players' experienced stress level. For example, we could just look at the percentage of correct decisions players have made up to a certain point. However, when a serious game is designed to improve the quality of processes and not the quality of their product, we cannot look only at the percentage of correct decisions or actions. Instead, we have to take into account other interactions from the player with the game that the player took in working towards said product.

Looking back at what has been described thus far, the current study aims to find an unobtrusive measure for experienced stress in crisis management-related decision-making using different in-game measures in a digital game-based learning environment. The study is conducted in the context of VRT and the Mayor Game, a decision-based digital serious game.

\section{Research questions}

Finding an unobtrusive measure for a player's experienced level of stress is only useful when stress indeed has an influence on in-game performance. Therefore, we investigate on the effect of induced stress on in-game performance first. Given 
that it is crucial for decision-makers in crisis management to maintain the quality of their decision-making process while under stress, in the case of VRT, the ability to analyze information, in particular, should not suffer under greater experienced stress. This gives rise to the research question: Does a change in experienced stress influence the players' in-game performance for analytical skills? Based on the definitions stated by VRT, it is expected that persons experiencing too much stress will score lower on analytical skills, which is in line with Yerkes and Dodson's (1908) theory that a higher than optimal level of experienced stress causes worse performance. Answering this research question will help to identify effects of induced stress on players' performance for analytical skills in decision games that provide training on crisis management skills, thereby highlighting the importance of stress in the crisis managers' everyday work.

Next, in line with the Yerkes-Dodson law, which describes a curvilinear (Ushaped) relationship between the players' stress levels and their performance (Cohen, 2011; Yerkes \& Dodson, 1908), stress levels that differ from what is optimal are expected to have a negative influence on a person's response behavior (e.g., Cheng, 2018; Sniezek et al., 2001). Assuming that the level of experienced stress indeed has an influence on the players' in-game performance, the second research question of this study is: Can we employ in-game behavior to make predictions about the measured level of stress of a player? Answering this research question serves the general aim of this study to find an unobtrusive measure for experienced stress in crisis management-related decision-making in a digital game-based learning environment. This unobtrusive measure could be used as input to statistical models that can evaluate the experienced level of stress to make the game adaptive. Thereby, the unobtrusive measure allows to guide the game to be more effective and efficient: After a calibration scenario, to obtain base levels of the player's stress level, the game can adjust the following scenarios based on a comparison of the current stress level of the player as measured by the unobtrusive in-game measure and the earlier set baseline.

In the current study, participants will be placed in two conditions, one control and one experimental condition, to gain insight into how stress affects their ingame behavior and their performance for analytical skills. Gameplay log data, questionnaire data, and physiological sensor data will be used to address the research questions.

\section{METHOD}

\section{Participants}

In total, 82 participants took part in this study, 43 in the control condition and 39 in the experimental condition. Participants were randomly assigned to condition, 
but due to short-term cancellations the group sizes ended up different. Two participants in the experimental condition did not complete the experiment and were thus removed from the dataset. The remaining 80 participants (43 in the control condition and 37 in the experimental condition) came from two different programs of study at the University of Twente, Psychology (59; 73.75\%) and Communication Science $(21 ; 26.25 \%)$. The majority of the participants were female (53; 66.25\%). Participants had various nationalities, the two most common being German (58; 72.5\%) and Dutch $(15 ; 18.75 \%)$. The remaining seven participants were scattered among five different nationalities, so they were grouped under Other (7; 8.75\%). The great majority of participants were between 18 and 24 years old (75; 93.75\%), where only five participants were 24 or older $(6.25 \%)$.

\section{Game scenario}

Participants played one scenario in the Mayor Game: A tanker truck transporting highly flammable and toxic chemicals was involved in an accident and threatens to explode. The scenario consisted of eight dilemmas; participants decided about each dilemma with either Yes or No. In the dilemmas the players had to make decisions about how to handle different situations. For example, the first dilemma, named "Pick up Children", was to decide whether parents should be allowed to pick up their children from a school within the evacuation radius. The other dilemmas were called "Laconic", "Exams", "Train", "Tight Curve", "Laboratory", "Youth News" and "Explosion". "Laconic" is a dilemma about how to deal with residents in the wider area who do not listen to the instructions made by the police. The third dilemma, "Exams", asked whether final exams taken in a school lying in the evacuation area should be stopped. The fourth dilemma, "Train", confronted the players with the question whether a shelter hall where stranded passengers are held should be visited by the mayor of the fictional town in which the truck accident took place. Dilemma five, "Tight Curve", challenged the players to deal with a statement that was published by a third party, trying to explain how the accident could happen in the first place. Dilemma six, "Laboratory", confronted the players with deciding on whether a laboratory experimenting with viruses should receive additional protection against the smoke and dust coming from the burning truck. "Youth News" was a dilemma asking the players to handle the press, which focuses on explaining the situation to a younger audience. In the eighth and last dilemma, "Explosion", the tanker truck exploded, so the players faced the challenge of deciding how the death of three firefighters should be communicated to their respective families.

Five different advisors (police services, fire service, public health services, legal advisor, communication and press) could help the players with making their decisions by providing additional information on each dilemma. Each advisor 
provided one information item per dilemma, adding up to five information items available to the players per dilemma and consequently 40 in total. Each could be read multiple times before responding to the dilemma. Although the eight dilemmas were offered to the players in a pre-specified order, the players were not forced to play them in this particular order. Participants were asked to mark the information corresponding with the decision that they made, to indicate which information implied that same decision. As an example, we provide a detailed description of one dilemma and the five information items offered for this dilemma in Appendix 2.A.

\section{Conditions}

Participants in this study were assigned to one of two conditions. In the control condition participants were given 15 minutes to complete the scenario. Dilemmas and information provided by the five advisors appeared at fixed time intervals, which were the same in all dilemmas. For example, when a participant opened the first dilemma, information items became available every two to four seconds. Additionally, a recommendation on whether an advisor would vote yes or no appeared every 20 seconds, with two being available from the start. That resulted in a well-suited game pace, where a new action became available whenever the players finished thoroughly reading information items or descriptions of the situation.

A heightened stress level can be created by inducing information overload and time pressure (see Cheng, 2018; Sniezek et al., 2001), which is in line with the in section 1.1 described information provided by VRT. Thus, participants in the experimental condition were given twelve minutes to complete the scenario, three minutes less than in the control condition, but still enough time to complete the scenario without skipping information. To further increase the experienced stress level, information given by the advisors appeared faster. Furthermore, the preferred decisions of the advisors were available much later in the experimental condition, so that uncertainty was created if the participant had not yet made a choice. Uncertainty is also used to increase the experienced stress level (Sniezek et al., 2001). Cheng (2018) also stated that a (large) alarm clock, visible and/or audible to the participant, might also increase time pressure. In accordance with this suggestion, a large alarm clock was presented on a screen on location, along with a verbal statement of the time left made at two-minute intervals.

Along with time pressure, an equivalent to peer pressure was induced. Kim et al. (2004) used simple statements such as: "The participants before you all did well and finished relatively fast" to increase the stress level of the participant. Consequently, a similar statement was made in the experimental condition, before the participants started the gameplay scenario. The content of the scenario was not altered in comparison to the control condition, so that possible differences in gameplay behavior and stress levels between the conditions were fully explainable by the 
artificially induced time and peer pressure. By inducing time pressure, changes in decision-making processes would be expected to occur (Maule et al., 2000).

\section{Measures}

\section{Analytical performance measure}

According to the definition provided earlier for analytical skills, interpreting available information correctly given the situational context is of utmost importance. In the context of the Mayor Game, available information items point towards either Yes or No. In some cases, the information items are vaguer and, in some cases, less vague, but they are always relevant to the situation. This leaves the players to interpret the information, and later to indicate which information corresponded with the decision they made. In doing so, the players indicated that the available information was correctly understood, and the main message of this information item was grasped. Consequently, if players read all available information, they had to mark those information items as corresponding that implied the decision they made for that specific dilemma. When an information item did not support the player's decision, the player was expected not to indicate this item as corresponding. In line with the definitions of crisis management skills, any information that was not read was considered to be wrongly interpreted, because requesting information to reduce uncertainty is also part of these crisis management skills (Mezey, 2004; Veiligheidsregio Twente, 2016).

Players received one point for each information item correctly marked as corresponding and one point for each information item correctly non-marked, adding up to a maximum score of five points per dilemma equal to the amount of available information. Again, when information was not read it was considered as wrongly interpreted. Some of the information were vaguer than other, which besides simply computing scores also must be taken into account. For this reason, we used an Item-Response Theory (IRT) model, the Rasch model (Baker, 2001; Rasch, 1960), thereby bringing the person's ability and the item difficulty (here vagueness of information) onto the same scale. In this way we can estimate the person-level ability parameter for each person for each dilemma, taking into account the vagueness of the information items.

\section{Behavior variability as unobtrusive stress measure}

Since the same competency, analytical skills, was measured in all dilemmas, under normal conditions the observed ability of a person is expected to remain stable throughout a single gameplay scenario in the Mayor Game. Participants under stress are expected to be less accurate in interpreting the information items and more inconsistent in playing the game, possibly leading to larger variability in terms of overall performance and gameplay behavior. Therefore, we expect 
larger variability throughout the scenario to be an indicator for induced stress. To assess the variability of the analytical ability parameter, the variance between the per dilemma parameter estimates can be computed per person. The resulting within-person variances are consequently considered to be an indicator of the variability of the ability parameter. We hypothesized that a more stressed person shows more inconsistent behavior; hence, we expect the within-person variances to be higher in the experimental condition than in the control condition. In line with this expectation, the within-person variances of three in-game measures were considered: of the average number of information items read, of the average time an information item was kept open relative to the total playtime, and of the performance on analytical skills throughout the gameplay.

\section{Validation of the unobtrusive stress measure}

\section{Sensor data}

To obtrusively measure experienced stress, sensor data was collected to validate possible in-game measures, so that in an actual practical application the sensors would not be needed to infer the player's level of experienced stress. To objectively measure experienced stress, we used the Shimmer GSR+ sensors, which capture heart rate data and also skin conductance data. Both have shown to be valid predictors of physiological arousal (e.g., Mandryk et al., 2006; Shi et al., 2010; Yannakakis \& Hallam, 2008), which in turn can serve as an indicator for experienced stress (Holmgård et al., 2015).

More specifically, Holmgård et al. (2015) found different measures extracted from sensor data that were significantly correlated to experienced stress: maximum heart rate, heart rate at last measurement point, heart rate standard deviation, heart rate range (the difference between maximum and minimum heart rate), skin conductance range and skin conductance at the first measurement point. The authors also found physiological measures that were statistically significant only with $a=0.1$. These measures were the average skin conductance throughout gameplay, maximum and minimum skin conductance, standard deviation of skin conductance and shift in heart rate throughout the game (the difference between first and last measurement of heart rate), all of which we will consider in our analysis. Taking into account that the Yerkes-Dodson law also suggests a Ushaped relationship between analytical ability (respectively the within-person variances of analytical ability) and (physiological) arousal, curvilinear as well as linear relationships between gameplay performance and sensor data were tested.

\section{Self-report questionnaire}

A self-report questionnaire was administered right after the participants finished the gameplay scenario. Here we followed the same idea as with the collected 
sensor data, using two brief (perceived) arousal scales as indicators for the stress level that was experienced. The Perceived Arousal Scale (Anderson, 1995; Anderson et al., 1995) and the Affect Grid (Russell et al., 1989) were used. Besides demographic characteristics and the arousal scales, participants were also asked to describe how they felt about the pace of the game in an open question format. The Perceived Arousal Scale is a 24-item questionnaire, where participants must indicate how much they felt a specific emotion or feeling using a five-point Likert scale, with one being not at all and five meaning extremely. The Affect Grid is a single item questionnaire measuring two dimensions, arousal and pleasure. The participants here must indicate how aroused they were and how much pleasure they felt during the gameplay session, this time on a nine-point Likert scale. The pleasure dimension was disregarded in this study.

\section{Procedure}

Participants were first familiarized with the game they were about to play. Important gameplay mechanics and features of the game were presented. The sensors were put on and immediately turned on, right after the participants were familiarized with the game. Next, the participants played the gameplay scenario. Once the participants were finished playing the gameplay scenario, they started completing the self-report questionnaire, while still wearing the sensors. Recording of the sensor data was stopped after the participants completed the selfreport questionnaire. The researchers were present in the room during the entire time of the study to ensure that the participants followed the instructions; participants were able to ask for assistance in case of technical difficulties. Ethical approval for this research was provided by the ethics committee of the University of Twente in February 2018. All participants provided active consent before starting the study.

Data were collected using three main types of source. First, gameplay data from the Mayor Game were gathered. Second, sensor data about the heart rate and the galvanic skin response of participants was gathered using the Shimmer GSR+ sensors. Third, a self-report questionnaire was employed. The sensor data and the self-report data were collected for validation purposes.

\section{Analysis}

Data were analyzed with respect to the two formulated research questions. First, we compared the analytical skills performance between groups, on a per dilemma basis. This was done based on simple sum scores, as derived from the scheme described in Appendix 2.B and as explained in Section 2.3.1. To correct for differences in the vagueness of the available information, a one-parameter logistic (Rasch) model was employed. Given that only five observations per dilemma per 
person were available, we employed a Bayesian application of the Rasch model, making sure that the results are meaningful even with few(er) data points (McNeish, 2016; van de Schoot et al., 2015). Here we made use of an Importance Sampling (Wasserman, 2004) based procedure, as described in Appendix 2.C. These analyses serve to address our first research question.

The second research question was answered using regression analyses. We started by comparing in-game performance and in-game behaviors between groups. Following that, simple regression models employing only one in-game measure and one physiological measure were used to gain insight into possible linear or curvilinear relationships between in-game data and physiological arousal data, that can serve as an indicator for experienced stress. We ran the same analyses for the in-game measures and the self-report data, where we also looked into the reliability of said self-reports. Lastly, we checked relationships between sensor and self-report data.

\section{RESULTS}

\section{The effect of stress level on "analytical skills"}

All participants were scored for analytical skills according to the scheme ${ }^{2}$ described in Section 2.3.1. The lowest observed per dilemma score was zero, and the highest observed per dilemma score was five. The lowest observed total score was 14 and the highest was 40, meaning that at least one participant interpreted all information correctly. Table 2.1 displays the mean scores and standard deviations (SD) for all dilemmas and the total score, per condition. Levene's test for equality of variances between conditions for the total score gave a significant result, with $F=5.903$ and $p=0.017$, meaning the variances are not equal between groups, which indicated that the Welch-Satterthwaite adjustment method should be used on the degrees of freedom. Running a one-tailed $t$-test on the total score, using this adjustment method, gave a significant difference in total scores between conditions $(t=2.777 ; d f=64.638 ; p=0.0035)$, indicating that the average score in the experimental condition was lower compared to the normal condition. Although this difference might seem interesting at first, it must be noted with caution: Because participants in the experimental condition were forced to work faster than participants in the control condition, some were not able to complete the gameplay scenario. Consequently, analyses should be carried out that take into account that some dilemmas might not have been accessed.

\footnotetext{
2 Provided in detail in Appendix 2.B.
} 
Table 2.1

Mean sum scores and standard deviations of dilemma and total scores per condition; Onetailed t-test statistic with fitting adjustment method for degrees of freedom

\begin{tabular}{lcccccc}
\hline \multirow{2}{*}{ Dilemma } & \multicolumn{2}{c}{ Control } & \multicolumn{2}{c}{ Experimental } & \multicolumn{2}{c}{$t$-test statistic } \\
& Mean & $(S D)$ & Mean & $(S D)$ & $t(d f)$ & $p$-value \\
\hline 1. Pick up children & 3.74 & $(1.432)$ & 3.65 & $(1.602)$ & $0.282(78)$ & 0.390 \\
2. Laconic & 4.14 & $(1.082)$ & 3.54 & $(1.095)$ & $2.455(78)$ & $0.008^{* *}$ \\
3. Exams & 4.60 & $(0.695)$ & 4.22 & $(0.947)$ & $2.063(65.115)$ & $0.022^{* *}$ \\
4. Train & 4.26 & $(0.902)$ & 4.00 & $(1.000)$ & $1.203(78)$ & 0.117 \\
5. Tight curve & 4.07 & $(0.936)$ & 3.73 & $(1.217)$ & $1.411(67.084)$ & $0.086^{*}$ \\
6. Laboratory & 3.72 & $(1.368)$ & 3.49 & $(1.539)$ & $0.721(78)$ & 0.237 \\
7. Youth news & 3.86 & $(1.246)$ & 3.32 & $(1.796)$ & $1.527(62.755)$ & $0.066^{*}$ \\
8. Explosion & 3.26 & $(1.720)$ & 2.32 & $(1.857)$ & $2.328(78)$ & $0.011^{* *}$ \\
Total Score & 31.65 & $(4.956)$ & 27.27 & $(6.332)$ & $2.628(67.811)$ & $0.006^{* *}$ \\
\hline
\end{tabular}

Note. ${ }^{*} \mathrm{p}<0.1 ; * * \mathrm{p}<0.05$.

Following the order used in Table 2.1, from top to bottom, the first four dilemmas were completed by all 80 participants. The fifth dilemma was completed by 79 (43 control, 36 experimental) participants. The sixth, seventh and eighth dilemma were completed by 76 (42 control, 34 experimental), 73 (41 control, 32 experimental), and 68 (38 control, 30 experimental) participants respectively. Of the 12 participants who did not complete the eighth and final dilemma, five came from the control and seven from the experimental condition. However, not all of the 68 participants completing all eight dilemmas actually read all available information items. As already described, what information was not accessed could be determined from the log files, and it was considered as wrongly interpreted.

Excluding those participants who did not finish the scenario (all dilemmas) from the analyses gives a more accurate understanding. As described, in the control condition, 38 participants out of 43 total completed the scenario. In the experimental condition, 30 out of 37 participants completed the scenario. A onetailed $t$-test on the total scores of these 68 participants, again using the WelchSatterthwaite adjustment method on the degrees of freedom $(F=5.875 ; p=0.018)$, showed that participants scored significantly higher in the control condition than in the experimental condition $(t=2.178 ; d f=50.455 ; p=0.017)$. The per dilemma differences in scores between conditions are visualized in Figure 2.2.

At the dilemma level, significant differences between conditions in the second, third, and last dilemma were found. These findings are partly in line with the feedback given by participants. In the experimental condition, participants 
reported that especially for the last dilemma, when they realized they would not finish the scenario in time at their current speed of working, they skimmed faster through the available information, not having as much time to think about what the information implied. Consequently, these participants made more mistakes in indicating which information also implied their decisions. However, this does not explain the significant differences in dilemmas two and three.

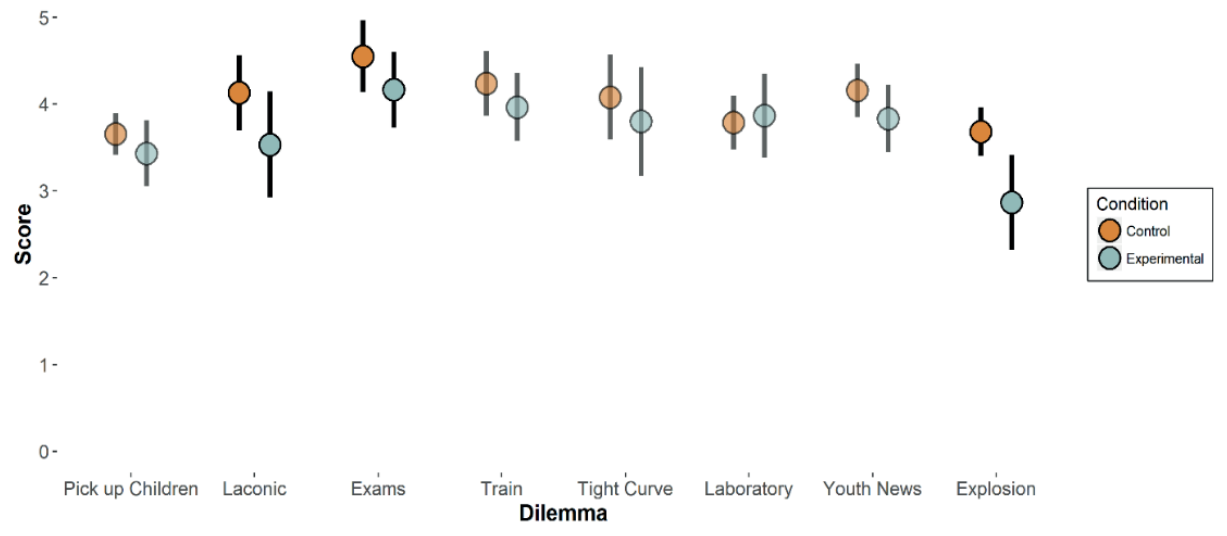

Figure 2.2. Comparison of scores per dilemma between conditions

As already discussed, IRT analyses can be employed to account for differences in difficulty/vagueness of available information. By taking into account the complexities of the different information items, the Rasch model gives more accurate estimates of how well players performed and is more informative when it comes to drawing conclusions about the current ability levels of the players compared to score-based measures that do not take into account item difficulty. The difficulty of the information items was estimated using a Rasch model (e.g., Hambleton \& Swaminathan, 1985), prior to feeding the values into the analyses presented in this study. All analyses were carried out using the data of the 68 participants who finished all dilemmas.

On average, participants performed better in the control condition than in the experimental condition. T-tests comparing the per dilemma person ability parameters between conditions supported the earlier findings based on per dilemma scores, thereby confirming that the experimental manipulation indeed led to a difference in in-game performance for analytical skills between the two conditions. Person ability parameters, estimated using the Rasch model, are visualized in Figure 2.3, again per dilemma and per condition. The IRT analyses confirmed the earlier score-based findings. By correcting for the item difficulty and bringing person ability and item difficulty onto the same scale, the IRT analyses introduced a "cleaned-up" ability estimate, that we can use to assess the 
variability of the analysis scores throughout the scenario. A 2-parameter logistic model (2PLM) or a 3-parameter logistic model (3PLM) might lead to even more accurate estimates of the person ability parameter. However, because of the relatively small size of the data set for estimating the item parameters, we chose to report the Rasch model analyses. Furthermore, an analysis conducted using a 2PLM resulted in issues in terms of model fit, while it also did not lead to meaningfully different results.

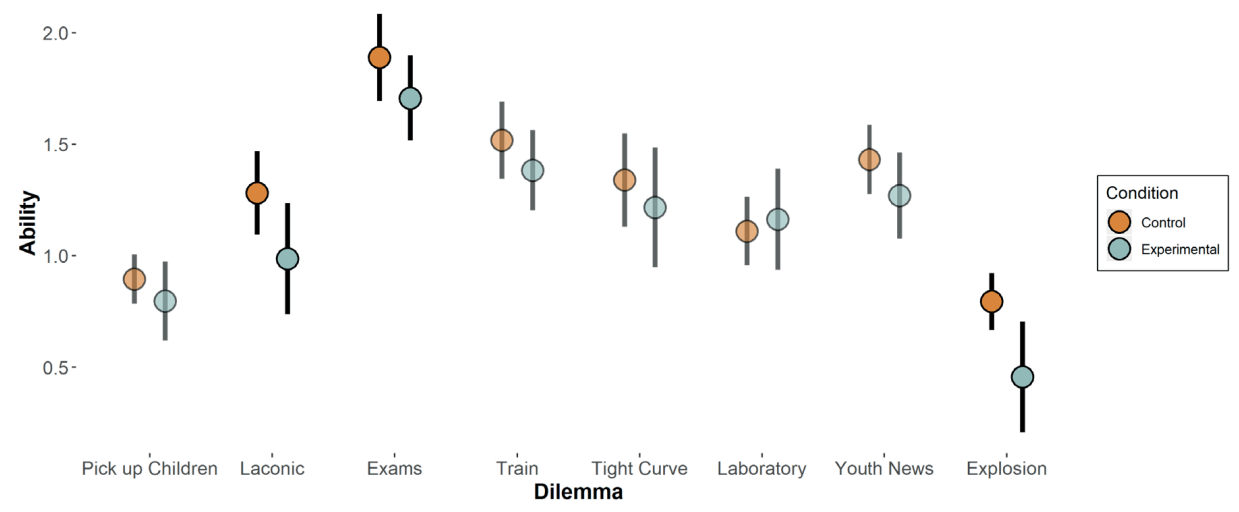

Figure 2.3. Comparison of person ability parameters per dilemma between conditions

\section{Unobtrusively assessing "stress resistance"}

Differences in (variability of) gameplay behavior between conditions

As a measure of experienced stress, higher within-person variances in the experimental than in the control condition were hypothesized. The within-person variances in the person ability parameter per condition are visualized in Figure 2.4. To test for significance, linear regression or $t$-tests are not applicable, since the variance is not normally or $t$-distributed. In Bayesian solutions, often inverse gamma distributions are used to sample from the variance of a normal distribution (Lynch, 2007). Accordingly, a generalized linear model using an inverse gamma link, from here on referred to as inverse gamma regression, was used to test for between-condition differences in the within-person variances. Condition was found to have no significant effect on within-person variances $\left(\beta_{1}=\right.$ $-0.4134 ; t=-1.111 ; d f=65 ; p=0.271)$. Hence, in the next section we used the collected sensor data to test for possible relationships between within-person variances and experienced stress level. 


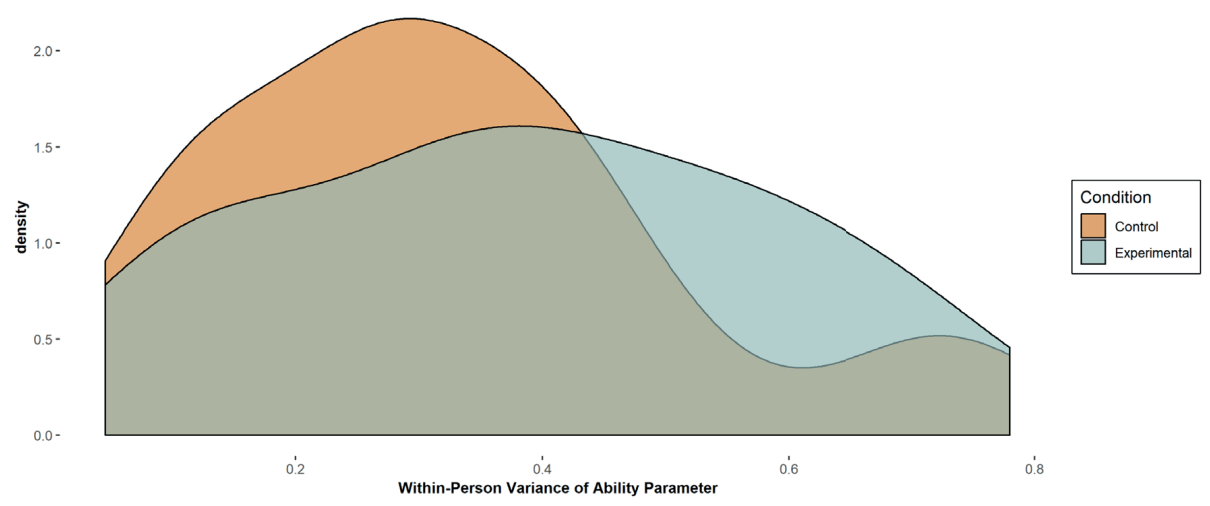

Figure 2.4. Sample distributions of within-person variances in the ability parameter per condition

To further explore differences in (variability of) gameplay behavior, we chose to extract more data from the game logfiles, keeping in mind that we expected differences in gameplay behavior between different levels of induced stress. One variable that could also differ between different levels of stress is the amount of time an information item was kept open and its variance. The average open time was computed per dilemma to take into account that more vague information was kept open much longer than less vague information. To correct for the difference in open time that we induced by our design (12 minutes available in the experimental condition for 40 information items compared to 15 minutes in the control condition), we corrected the individual open times for the total playtime of that respective player: all open times were converted to a percentage of total time needed to finish the gameplay scenario. In this way, we took out the by-design differences between conditions and the individual working speed of players. As visualized by the greater height of the blue curve in Figure 2.5, participants in the experimental condition seemed to have an overall smaller within-person variance in open times than participants in the control condition. Using an inverse-gamma regression, the difference between conditions was found to be statistically significant $\left(\beta_{1}=2.0696 ; t=2.328 ; d f=66 ; p=0.023\right)$, indicating that participants in the experimental condition divided the available used time on each dilemma more evenly throughout the scenario.

Given that players had the opportunity to reopen already read information in order to read it again, the within-person variances of the average per dilemma counts for this were also compared between conditions. The inverse-gamma regression to test for effects of condition on the within-person variance of the average per dilemma counts of read information gave no significant result for condition effects $\left(\beta_{1}=4.7532 ; t=1.533 ; d f=56 ; p=0.131\right)$. 


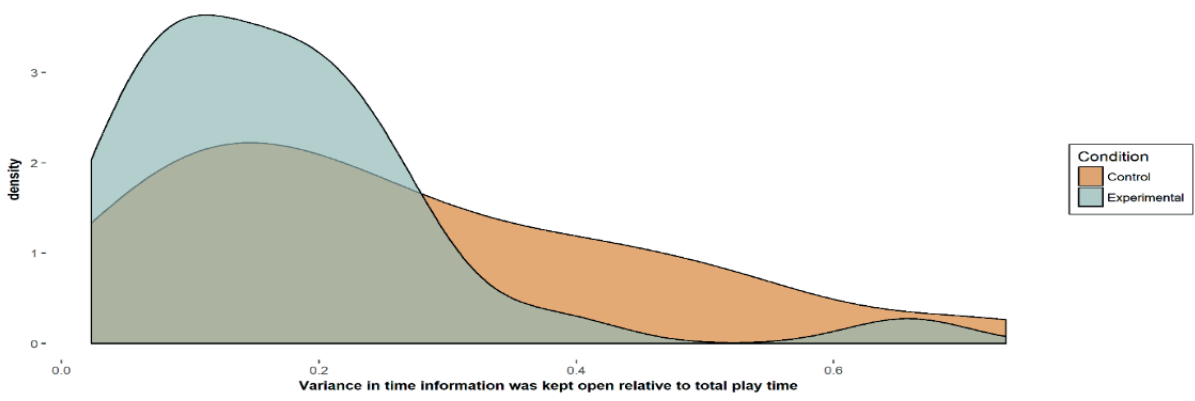

Figure 2.5. Sample distributions of within-person variances of the time an information item was open per condition

\section{Sensor data}

Only two out of 11 measures derived from the sensor data revealed significant differences at $a=0.05$ between the conditions: the difference between the maximum and minimum skin conductance $\left(\beta_{1}=1.6816 ; t=2.335 ; d f=66 ; p=\right.$ $0.0226)$ was bigger, and the maximum skin conductance throughout the gameplay $\left(\beta_{1}=1.1891 ; t=2.241 ; d f=66 ; p=0.0284\right)$ was higher in the experimental condition. The minimum skin conductance showed a significant relationship with $\alpha=0.1\left(\beta_{1}\right.$ $=-0.4925 ; t=1.897 ; d f=66 ; p=0.0623$ ), being lower in the experimental condition. Although only these three sensor measures differed between the two conditions, we investigated (curvi-) linear relationships between sensor and in-game data. To test these relationships between sensor and in-game data, significant differences between conditions are not necessarily needed, although they would be useful in finding relevant predictors for experienced stress using in-game data.

The within-person variance computed from the person ability parameters was not a significant predictor for any of the measures identified by Holmgård et al. (2015); no linear or curvilinear relationships were found. Looking at the measures that Holmgård et al. found to be statistically significant at $a=0.1$, but not at $\alpha=0.05$, none showed significant linear relationships with the within-person variance of the ability parameter. Neither were any curvilinear relationships found. As described, players were able to reopen already read information and read it again. Accordingly, the counts of how often information items were opened on average were correlated to the sensor features using regression analyses, as was the within-person variance of the per dilemma counts. The same was done for the average time an information item was kept open and the within-person variance of this. However, only the initial skin conductance was significantly related to the average time an information item was kept open $\left(\beta_{1}=-2.638 ; t=-2.208 ; d f=66\right.$; $p=0.031$ ). At $\alpha=0.1$, the last measurement of heart rate was also significantly related to the average time an information item was kept open $\left(\beta_{1}=8.973 ; t=\right.$ $1.862 ; d f=66 ; p=0.067)$. 


\section{Self-report questionnaire}

Out of the 80 participants, 75 participants completed the perceived arousal scale in the self-report questionnaire entirely. Four of the five participants who did not entirely complete the self-report only missed a few values. The fifth participant who did not complete the self-report was excluded from further analyses that included the self-report data. But first, the reliability of the Perceived Arousal Scale (PAS) was checked. Cronbach's alpha was 0.82 for that scale, and Lambda2 was 0.835, suggesting that the reliability of the Perceived Arousal Scale is satisfactory. Since the Affect Grid (AG) is a single-item questionnaire, reliability analyses are not applicable. Alternatively, the correlation between the AG and the PAS was tested to assess whether this scale is reliable. The AG score was not significantly correlated to the score on the perceived arousal scale $(r=0.181 ; t=$ 1.578; $d f=73 ; p=0.119$ ), meaning that results based on AG scores must be viewed with caution, because the AG did not seem to measure arousal consistently in our sample. To be complete, we still tested possible relationships involving the AG scores. Given the high reliability of the PAS, the few missing data points of the four participants who did not give a response on some items of the Perceived Arousal Scale were imputed, so that the maximum number of participants could be used in all analyses involving the self-report and gameplay data. Table 2.2 summarizes the mean scores and standard deviations for both scales per condition, as well as a one-tailed $t$-test statistic testing whether the scores are lower in the control than in the experimental condition, showing that there were no significant differences between the conditions on both scales. Note, only the self-report data of the 67 participants who completed both the scenario and the self-report was used.

Table 2.2

Mean and standard deviations of Perceived Arousal Scale and Affect Grid scores per condition; One-tailed $t$-test statistic with fitting adjustment method for degrees of freedom

\begin{tabular}{|c|c|c|c|}
\hline & Control & Experimental & $t$-test statistic \\
\hline Neare & Mean (SD) & Mean (SD) & $(d f ; p)$ \\
\hline Perceived Arousal Scale & $86.42 \quad(10.485)$ & $89.41 \quad(8.317)$ & $-1.263(65 ; 0.1055)$ \\
\hline Affect Grid & $6.55 \quad(1.350)$ & $6.83 \quad(0.966)$ & $-0.930(65 ; 0.1775)$ \\
\hline
\end{tabular}

The relationships between both perceived arousal scales and sensor data were also tested. A significant linear relationship was found between maximum skin conductance and the total PAS score $\left(\beta_{1}=-0.0536 ; t=-2.237 ; d f=64 ; p=0.0288\right)$, when also taking between-condition differences into account. Further, a significant linear relationship was found between skin conductance range and the total PAS total score $\left(\beta_{1}=-0.06874 ; t=-1.999 ; d f=64 ; p=0.0499\right)$, also taking 
into account between-condition effects. No significant linear or curvilinear relationships were found between sensor data and the AG scores.

A possible relationship between the PAS and AG scores and the within-person variance in the ability parameter was also tested using regression analysis; in both cases, the results were not significant (PAS: $\beta_{1}=-5.800, t=-1.948, d f=64$, $p=0.347$ AG: $\left.\beta_{1}=-0.3853, t=-0.502, d f=64, p=0.617\right)$. Neither were any curvilinear relationships found. However, relating the within-person variance per dilemma of how often information was read to the PAS and AG scores showed higher correlations. The within-person variance of the per dilemma count of opened information was significantly correlated to the PAS score at $a=0.1$, correcting for between-condition effects $\left(\beta_{1}=-1.691 ; t=-1.755 ; d f=64 ; p=0.084\right)$. Furthermore, the average count of opened information was significantly correlated to the AG score $\left(\beta_{1}=-0.841 ; t=-2.31 ; d f=64 ; p=0.0241\right)$ and the within-person variance of the per dilemma count was significantly correlated to the AG score $\left(\beta_{1}=-0.348 ; t=-3.023 ; d f=64 ; p<0.01\right)$, both taking into account the between-condition effects. The self-report data were neither linearly nor curvilinearly related to the average time an information item was kept open relative to the total play time, nor to the within-person variance in that measure.

\section{DisCUSSION}

The general aim of this study was to find an unobtrusive measure for experienced stress in a digital serious game, by using different in-game measures. The unobtrusive measure we used for experienced stress was based on the variation in observed performance levels for analytical skills throughout the gameplay. To find indications of the validity of this way of measuring experienced stress, the gameplay data were related to condition, sensor and self-report data. While differences in analysis scores were found between the two conditions, finding an unobtrusive measure for experienced stress was less successful. The collected physiological arousal data offered only few measures that correlated with in-game measures. The chosen (simple) measures to unobtrusively assess experienced stress were, at least in our sample, not able to reliably measure the participants' stress levels.

\section{Effect of induced stress on in-game performance}

The first research question questioned whether we can observe a difference between the conditions with respect to the players' performance on the analytical skills competency. The analyses confirmed that this is the case. Changing the game pace influenced how well the information items offered in the game were analyzed, thereby being in line with available literature suggesting that decisionmaking can be both calm and thought-through (strategic), but also spontaneous 
and intuition-guided (intuitive) (Cooper, 2007; Endsley, 2000). Participants in the experimental condition indeed seemed to play the game differently than participants in the control condition. Participants in the experimental condition seemed to follow a more intuition-guided, not thought-through, decision-making strategy, which in turn might be less accurate due to a lack of situational awareness presumably caused by a heightened stress level, thereby leading to biases in judgment (Tversky \& Kahneman, 1974).

Despite possibly following a more intuition-guided decision-making strategy, participants in the experimental conditions in general spent a similar amount of time on each dilemma, while participants in the control condition varied more with respect to time needed per dilemma. In the experimental condition the participants were provided with a large alarm clock and regular announcements about the amount of time left until the scenario was over; these changes could have resulted in higher awareness of time. This was particularly interesting to find, since it is in contrast to the higher within-person variances for participants in the experimental condition that we initially expected. Looking at only the participants who completed the entire scenario, the regular announcements and the large clock seemed to help to better plan ahead for the rest of the scenario, and thus proceed to the next dilemma on time, so that they were able to finish all of the upcoming dilemmas.

This more decisive, but intuitive, decision-making strategy actually is desirable up to a certain degree (Veiligheidsregio Twente, 2016). Quite often crisis managers struggle to be decisive, meaning that they tend to spend more than the necessary time on one single problem. In real-life crisis situations, the world does not stand still while the decision-makers gather and analyze information. The crisis evolves, so that the crisis managers must make decisions and cannot afford to think about a single dilemma for too long. Still, they must keep it in mind to base their decisions on a thorough analysis of the available information, so being too decisive also can have its downsides when information is missed or wrongly interpreted. For example, just as in real-life crisis scenarios, making decisions before all information is considered and analyzed forces the decision-makers to more often follow an intuition-guided, less accurate, decision-making strategy. The available information might be vague, not directly implying the decision to make, so the decision-maker could be unable to correctly interpret the main message of the information. Hence, the quality of the decision-making process may decrease when decision-makers act too decisively.

Analytical skills were not measured unobtrusively, as this was not the aim of this study. It might be useful to develop an unobtrusive measure for this competency as well. In real-life crisis situations, the crisis managers do not specifically indicate what the available information implies. Crisis managers read or listen to 
information, interpret it, and then move on with the process. An unobtrusive measure for analytical skills would allow game developers to develop an even more realistic serious game, thereby simulating realistic situations in even greater detail. Additionally, in line with Shute's (2011) statement about keeping players in a flow state to improve the learning experience, the game could help do so by employing unobtrusive assessment methods for analytical skills.

\section{Unobtrusive assessment of experienced stress}

The second research question stated whether we are able to find relationships between in-game measures and (physiological) stress measures to be able to unobtrusively assess the experienced stress of a player. As described earlier, knowing the current level of experienced stress can help with improving the learning experience of a player, by adjusting the game to the player's actual state. Being able to unobtrusively assess the experienced stress level is crucial for accomplishing that in a digital serious gaming context. However, in this study the in-game measures for experienced stress were rather simple, and for the most part they did not significantly correlate with the physiological arousal data. Only the average time an information item was kept open relative to the total playtime was significantly related to the heart rate at the last measurement point and the first measurement of skin conductance. Relating the self-report data to the in-game measures also was not too insightful. Only the counts of information items read and the within-person variance of these counts were significantly correlated with participants' Affect Grid scores. Reading information less often and a smaller variance in these counts, respectively, were associated with higher Affect Grid scores. Overall, these results do not provide sufficient evidence for the self-report measures to serve as an unobtrusive measure of experienced stress, given that a significant relationship was found with only two out of 11 physiological measures.

These results could be explained through different means: First, the variance in the available sensor measures was relatively low, making it difficult to find meaningful relationships with the more variable gameplay data. The (physiological) sensor measurements differed between conditions in only three out of 11 cases. This raises a question as to whether the manipulation was effective enough to cause the desired differences between the conditions with respect to experienced stress. Second, the self-report measures were in line what the sensor data already implied. Both the Affect Grid and the Perceived Arousal Scale scores showed no significant differences between the two conditions. Third, we chose to employ rather simple methodologies. More sophisticated methods could be more effective in finding relevant indicators for the experienced level of stress. For example, Bayesian networks, as a popular probabilistic method in unobtrusive assessment (e.g., Shute, 2011; Wang, Shute, \& Moore, 2015), could make better 
use of the logged in-game data than the simple statistical models employed in this research. Additional log-data to be considered could be, for example, patterns of requesting information from only a few advisors (for example, only police services and fire services), or patterns of ignoring one advisor in particular. Fourth, based on the obtained results it seems that we also induced a direct effect on performance, just because participants in the experimental condition had less time to finish the scenario. Although this was meant to be a stress-inducing factor, we do not have a clear indication of whether this was the case, or whether the shorter time itself caused the performance drop. Checking whether this was the case could be subject of an additional experiment using two conditions with the same amount of available time. Based on our study, we can conclude that the manipulation caused differences in interacting with the game, which is a promising insight for possible future research into this topic. Last, it would be interesting to dive into similar research with active professionals in the crisis management domain, to gain insight into how the same mechanisms work in a closer-to-practice setting and also to test more sophisticated methodologies. 


\section{REFERENCES}

Anderson, C. A. (1995). Perceived arousal scale. http://public.psych.iastate.edu/caa/scales/ PerArous.pdf

Anderson, C. A., Deuser, W. E., \& DeNeve, K. M. (1995). Hot temperatures, hostile affect, hostile cognition, and arousal: Tests of a general model of affective aggression. Personality and Social Psychology Bulletin, 21, 434-448. https://doi.org/10.1177/0146167295215002

Baker, F. B. (2001). The basics of item response theory (2nd ed.). ERIC Clearinghouse on Assessment and Evaluation.

Bellotti, F., Kapralos, B., Lee, K., Moreno-Ger, P., \& Berta, R. (2013). Assessment in and of serious games: An overview. Advances in Human-Computer Interaction, 2013. https://doi.org/10.1155/2013/136864

Cheng, S.-Y. (2018). Evaluation of effect on cognition response to time pressure by using EEG. Paper presented at the conference on Advances in Human Factors and Ergonomics in Healthcare and Medical Devices. https://doi.org/10.1007/978-3-31960483-1_5

Cocea, M., \& Weibelzahl, S. (2007). Eliciting motivation knowledge from log files towards motivation diagnosis for adaptive systems. In C. Conati, K. McCoy, \& G. Paliouras (Eds.), User modeling 2007 (pp. 197-206). Springer. https://doi.org/10.1007/978-3540-73078-1_23

Cohen, R. A. (2011). Yerkes-Dodson law. In J. S. Kreutzer, J. DeLuca, \& B. Caplan (Eds.), Encyclopedia of clinical neuropsychology (pp. 2737-2738). Springer. https://doi.org/10.1007/978-0-387-79948-3

Connolly, T. M., Boyle, E. A., MacArthur, E., Hainey, T., \& Boyle, J. M. (2012). A systematic literature review of empirical evidence on computer games and serious games. Computers \& Education, 59, 661-686. https://doi.org/10.1016/j.compedu.2012.03.004

Cooper, H. H. A. T. (2007). Decision making in a crisis. Journal of Police Crisis Negotiations, 7, 5-28. https://doi.org/10.1300/J173v07n02_02

Crichton, M. T., \& Flin, R. (2001). Training for emergency management: Tactical decision games. Journal of Hazardous Materials, 88, 255-266. https://doi.org/10.1016/s03043894(01)00270-9

Crichton, M. T., Flin, R., \& Rattray, W. A. R. (2000). Training decision makers - Tactical decision games. Journal of Contingencies and Crisis Management, 8, 208-217. https://doi.org/10.1111/1468-5973.00141

Endsley, M. R. (2000). Theoretical underpinnings of situation awareness: A critical review. In M. R. Endsley \& D. J. Garland (Eds.), Situation awareness analysis and measurement (pp. 3-32). Lawrence Erlbaum Associates.

Hambleton, R. K., \& Swaminathan, H. (1985). Item response theory: Principles and applications. Springer. https://doi.org/10.1007/978-94-017-1988-9 
Holmgård, C., Yannakakis, G. N., Martínez, H. P., Karstoft, K.-I., \& Andersen, H. S. (2015). Multimodal PTSD characterization via the StartleMart Game. Journal on Multimodal User Interfaces, 9, 3-15. https://doi.org/10.1007/s12193-014-0160-5

Jong, W. (2017, August 13). Burgemeestersgame [Blog Post]. https://www.burgemeesters.nl/ content/1308-burgemeestersgame

Kim, K. H., Bang, S. W., \& Kim, S. R. (2004). Emotion recognition system using shortterm monitoring of physiological signals. Medical and Biological Engineering and Computing, 42, 419-427. https://doi.org/10.1007/BF02344719

Kowalski-Trakofler, K. M., \& Vaught, C. (2003). Judgment and decision making under stress: An overview for emergency managers. International Journal of Emergency Management, 1, 278-289. https://dx.doi.org/10.1504/IJEM.2003.003297

Lopes, R., \& Bidarra, R. (2011). Adaptivity challenges in games and simulations: A survey. IEEE Transactions on Computational Intelligence and AI in Games, 3(2), 85-99. https://doi.org/10.1109/TCIAIG.2011.2152841

Lynch, S. M. (2007). Basics of Bayesian statistics. In S. M. Lynch (Ed.), Introduction to spplied Bayesian statistics and estimation for social scientists (pp. 47-75). Statistics for social and behavioral sciences. https://doi.org/10.1007/978-0-38771265-9_3

Mandryk, R. L., Inkpen, K. M., \& Calvert, T. W. (2006). Using psychophysiological techniques to measure user experience with entertainment technologies. Behaviour \& Information Technology, 25, 141-158. https://doi.org/10.1080/01449290500331156

Maule, A., Hockey, G. J., \& Bdzola, L. (2000). Effects of time-pressure on decision-making under uncertainty: Changes in affective state and information processing strategy. Acta Psychologica, 104, 283-301. https://doi.org/10.1016/s0001-6918(00)00033-0

McNeish, D. (2016). On using Bayesian methods to address small sample problems. Structural Equation Modeling: A Multidisciplinary Journal, 23, 750-773. https://doi.org/10.1080/10705511.2016.1186549

Mezey, G. (2004). Crisis management decision making. AARMS, 3, 267-288.

Rasch, G. (1960). Probabilistic models for some intelligence and attainment tests. Danish Institute for Educational Research.

Raudys, S., \& Justickis, V. (2003). Yerkes-Dodson law in agents' training. In F. M. Pires \& S. Abreu (Eds.), Progress in artificial intelligence (pp. 54-58). Springer.

Russell, J. A., Weiss, A., \& Mendelsohn, G. A. (1989). Affect grid: A single-item scale of pleasure and arousal. Journal of Personality and Social Psychology, 57, 493-502. https://psycnet.apa.org/doi/10.1037/0022-3514.57.3.493

Sarpong, D., \& Maclean, M. (2011). Scenario thinking: A practice-based approach for the identification of opportunities for innovation. Futures, 43, 1154-1163. https://doi.org/10.1016/j.futures.2011.07.013

Shi, Y., Nguyen, M., Blitz, P., French, B., Frisk, S., De la Torre, F., Smailagic, A., Siewiorek, D. P., al' Absi, M., Ertin, E., Kamarck, T., \& Kumar, S. (2010). 
Personalized stress detection from physiological measurements. In Proceedings of the 2nd international symposium on quality of life technology.

Shute, V. J. (2011). Stealth assessment in computer-based games to support learning. Computer games and instruction, 55, 503-524.

Shute, V. J., \& Kim, Y. J. (2014). Formative and stealth assessment. In J. M. Spector, M. D. Merrill, J. Elen, \& M. J. Bishop (Eds.), Handbook of research on educational communications and technology (pp. 311-321). Springer. https://doi.org/10.1007/ 978-1-4614-3185-5

Sniezek, J. A., Wilkins, D. C., \& Wadlington, P. L. (2001, Jan). Advanced training for crisis decision making: Simulation, critiquing, and immersive interfaces. In Proceedings of the 34th Annual Hawaii International Conference on System Sciences. https://doi.org/10.1109/HICSS.2001.926337

Starcke, K., \& Brand, M. (2012). Decision making under stress: A selective review. Neuroscience \& Biobehavioral Reviews, 36, 1228-1248. https://doi.org/10.1016/ j.neubiorev.2012.02.003

Susi, T., Johanneson, M., \& Backlund, P. (2007). Serious games - An overview (Tech. Rep.). School of Humanities and Informatics, University of Skövde. http://urn.kb.se/resolve?urn=urn:nbn:se:his:diva-1279

Tversky, A., \& Kahneman, D. (1974). Judgment under uncertainty: Heuristics and biases. Science, 185, 1124-1131. https://doi.org/10.1126/science.185.4157.1124

T-Xchange. (2018). Mayors game. Retrieved February 15, 2018, from http://www.txchange.nl/ portfolio-item/mayors-game/

van de Ven, J. G. M., Stubbé, H., \& Hrehovcsik, M. (2014). Gaming for policy makers: It's serious! In A. De Gloria (Eds.). Games and learning alliance: Second international conference, GALA 2013 (pp. 376-382). Springer. https://doi.org/10.1007/978-3-31912157-4_32

van der Hulst, A. H., Muller, T. J., Buiel, E., van Gelooven, D., \& Ruijsendaal, M. (2014). Serious gaming for complex decision making: Training approaches. International Journal of Technology Enhanced Learning, 6, 249-264. https://doi.org/10.1504/ IJTEL.2014.068364

van de Schoot, R., Broere, J. J., Perryck, K. H., Zondervan-Zwijnenburg, M., \& van Loey, N. E. (2015). Analyzing small data sets using Bayesian estimation: The case of posttraumatic stress symptoms following mechanical ventilation in burn survivors. European Journal of Psychotraumatology, 6, 25216. https://doi.org/10.3402/ejpt. v6.25216

Veiligheidsregio Twente. (2016b). Regionaal Crisisplan Veiligheidsregio Twente - Deel 1. http://www.vrtwente.nl/media/227908/regionaal-crisisplan-veiligheidsregio-twentedeel-1.pdf

Wang, L., Shute, V., \& Moore, G. R. (2015). Lessons learned and best practices of stealth assessment. International Journal of Gaming and Computer-Mediated Simulations, 7, 66-87. https://psycnet.apa.org/doi/10.4018/IJGCMS.2015100104 
Wasserman, L. (2004). Simulation methods. In L. Wasserman, All of statistics: A concise course in statistical inference (pp. 403-433). Springer. https://doi.org/10.1007/9780-387-21736-9_24

Yannakakis, G. N., \& Hallam, J. (2008). Entertainment modeling through physiology in physical play. International Journal of Human-Computer Studies, 66, 741-755. https://doi.org/10.1016/j.ijhcs.2008.06.004

Yerkes, R. M., \& Dodson, J. D. (1908). The relation of strength of stimulus to rapidity of habit-formation. Journal of Comparative Neurology and Psychology, 18, 459-482. https://doi.org/10.1002/cne.920180503 


\section{APPENDIX 2.A}

Table 2.A.1

Description of the fourth dilemma, "Train", and the five respective information items offered

Dilemma Text "Train" The truck has caused an international train to be stranded at the station of Trouveen; because the danger zone also includes parts of the rail the train cannot go any further. There is a delegation of the "women of Srebrenica" in the train, they

\section{Dilemma}

Information item are on their way to the International Court in The Hague. Approximately 150 passengers are being sheltered in a sports hall close to the station, where they are provided with coffee, tea and cake.

Question Text Are you going to visit the sports hall to boost the morale of the stranded passengers?

Police Services You should remain inside the city hall. That way you are easily available for the operational leader. This is the best for the sake of this crisis.

Fire Services

The situation is stable, but precarious. A captain has to stay on board. In other words: your presence is desired in the crisis team now.

Public Health Services If you would just show up in the shelter hall, that would also give a boost to the staff at the municipality.

Legal Advisor Nobody is indispensable. Your role in the crisis team can be fulfilled by the deputy mayor. You can afford to leave for half an hour.

Communication and It is good to show your involvement to the Press stranded travelers also. You have to fulfill your role as figurehead. 


\section{APPENDIX 2.B}

Table 2.B.1

Correspondence markers for competency "Analytical Skills" for response 'Yes'

\begin{tabular}{lccccc}
\hline & $\begin{array}{c}\text { Communication } \\
\text { and Press }\end{array}$ & $\begin{array}{c}\text { Public health } \\
\text { services }\end{array}$ & $\begin{array}{c}\text { Fire } \\
\text { services }\end{array}$ & $\begin{array}{c}\text { Legal } \\
\text { advisor }\end{array}$ & $\begin{array}{c}\text { Police } \\
\text { services }\end{array}$ \\
\hline $\begin{array}{l}\text { Pick up } \\
\text { children }\end{array}$ & 1 & 0 & 1 & 0 & 1 \\
Laconic & 0 & 0 & 1 & 1 & 1 \\
Exams & 0 & 0 & 1 & 0 & 1 \\
Train & 1 & 1 & 0 & 1 & 0 \\
Tight curve & 1 & 0 & 1 & 0 & 0 \\
Laboratory & 1 & 1 & 0 & 1 & 0 \\
Youth news & 1 & 0 & 0 & 1 & 0 \\
Explosion & 1 & 1 & 1 & 1 & 1
\end{tabular}

The table displays the correct correspondence marker, given that the response on the dilemma was 'yes'. If the decision was 'no' all values are inverted. If a participant decides 'yes' on the dilemma 'pick up children', the participant should mark the information from the 'communication and press', 'fire services' and 'police services' advisors as corresponding, while leaving the information of the 'public health services' and 'legal advisor' unmarked. If the participant does exactly this, the resulting score would be five. Hence, if the participant does the opposite while still answering 'yes', the resulting score would be zero. For each correctly set correspondence marker the participant receives one point. The dilemmas are scored individually. When the participant did not read an information item, the item is considered as wrongly interpreted. 


\section{APPENDIX 2.C}

The person ability parameters were estimated by continuously computing the marginal likelihood of the data under multiple hypotheses. For each hypothesis, the marginal likelihoods were computed using an importance sampling-based procedure with 10,000 samples from the proposed parameter distribution of the posterior.

The initial proposal distribution of the ability parameter $\theta$ was a normal distribution $N(0,0.1)$. Three hypotheses were compared:

- $H_{a 0}:-0.1<\theta<0.1$

- $H_{a 1}: \Theta>0.1$

- $H_{a 2}: \theta<-0.1$

This first comparison only gives a first direction of where a parameter value might be. To find the correct value, the hypotheses are adjusted, and testing is repeated. Hence, if $H_{a 1}$ turned out to be the most probable hypothesis, we now would test the hypotheses:

- $H_{b 0}: 0<\theta<0.2$

- $H_{b 1}: \theta>0.2$

- $H_{b 2}: \theta<0$

Also, the distances between the tested parameters are decreased when two hypotheses are about equally probable. This serves to find an accurate value of the parameter. Hence, later hypotheses to test could be:

- $H_{c 0}: 0.5<\theta<0.55$

- $H_{c 1}: \theta>0.55$

- $H_{c 2}: \theta<0.5$

The procedure was repeated until the third decimal of $\theta$ was found. 
Chapter 2 


\section{Information literacy}

Information literacy skills assessment in digital crisis
management training for the safety domain:
Developing an unobtrusive method

This chapter is based on:

Steinrücke, J., Veldkamp, B. P., \& de Jong, T. (2020). Information literacy skills assessment in digital crisis management training for the safety domain: Developing an unobtrusive method. Frontiers in Education. 5. https://doi.org/10.3389/feduc.2020.00140 


\section{Abstract}

This study aims to develop an unobtrusive assessment method for information literacy in the context of crisis management decision-making in a digital serious game. The goal is to only employ in-game indicators to assess the players' skill level on different facets of information literacy. In crisis management decision-making it is crucial to combine an intuitive approach to decision-making, build up by experience, with an analytical approach to decision-making, taking into account contextual information about the crisis situation. Situations like these have to be trained frequently, for example by using serious games. Adaptivity can improve the effectiveness and efficiency of serious games. Unobtrusive assessment can enable game developers to make the game adapt to the players current skill level without breaking the flow of gameplay. Participants played a gameplay scenario in the Dilemma Game. Additionally, participants completed a questionnaire that was used as a validation measure for the in-game information literacy assessment. Using latent profile analyses, unobtrusive assessment models could be identified, most of which correlate significantly to the validation measure scores. Although inconsistencies in correlations between the information literacy standards, which call for broader testing of the identified unobtrusive assessment models, have been observed, the results display a good starting point for an unobtrusive assessment method and a first step in the development of an adaptive serious game for information literacy in crisis management decision-making. 


\section{INTRODUCTION}

Professionals in crisis management decision-making in the safety domain have to take well-informed and appropriate actions in an often very short time frame. For making these decisions they may rely on their experiences and known heuristics. However, this approach to decision- making may lead to decisions based on biases in the decision-making process. Consequently, this rather intuitive approach may cause suboptimal decisions (Mezey, 2004). Alternatively, decision-makers may engage in a more analytical approach characterized by an elaborate information analytical process, implying that they interpret and analyze information (often brought to them by experts) thoroughly before making a decision.

Both approaches are important for making sound decisions in the context of crisis management, where the decision-making process can become complex rather quickly (van der Hulst et al., 2014). In such situations, decision-makers cannot rely solely on their own experiences, while at the same time they do not have sufficient time to analyze and interpret every detail of the situation. Therefore, managing crisis situations asks decision-makers to properly combine and use the more intuitive and more analytical approach in their decision-making processes: According to the analytical approach, decision-makers need to gather, comprehend, and interpret information, which they also have to retain to be able to make predictions about possible future events. Besides, the intuitive approach implies that previous experiences of decision-makers are a crucial factor in performing this "analysis" effectively and accurately.

The skillset needed in such a decision-making process is well described by what is called Information Literacy (IL). IL is defined as the competency of being able to recognize the need of information, to locate information, to evaluate information and its sources, to interpret and to use the information. Lastly, IL also is about integrating information into one's own knowledge base, so that in future situations new information can be handled more efficiently. Another skillset to be considered could be Data Literacy (DL). Based on, among others, the work of Mandinach and Gummer (2016), Kippers et al. (2018, p. 22) define DL as the "educator's ability to set a purpose, collect, analyze, interpret data and take instructional action." Furthermore, the authors state that DL is an important skill in data-based decision-making. While both DL and IL convene on the importance of collecting and interpreting new data, respectively information, in decisionmaking processes, IL extends the definition of DL by also including the importance of the decision-makers experience. Relating this to the earlier described context of crisis management decision-making, we recognize that experience plays a crucial role in the decision-making process. Therefore, we will refer to IL in the remainder of this study. 
Endsley (2000) stated that having more data (i.e., available new information) does not necessarily equal having more information, thereby emphasizing the importance of being information literate. Stonebraker (2016) clarified that more data can offer more information, but only if the data is "analyzed" properly and put into perspective. In other words, the same piece of information can imply different meanings, depending on what else is known about the situation: It is highly dependent on the situation how a specific piece of information feeds into the decision-making process (Veiligheidsregio Twente, 2015).

In this study, we cooperate with the regional crisis management organization in the Dutch region of Twente, Veiligheidsregio Twente (VRT; Twente Safety Region). They state that gathering and interpreting information, creating awareness of the situation, reducing uncertainty, and performing scenario thinking as a form of risk assessment are among the most crucial skills in complex crisis situations on a strategic level. VRT uses the term analytical skills to refer to all these competencies (Veiligheidsregio Twente, 2016), which are in line with what we described in the context of IL.

Complex crisis situations, where being information literate is highly important, occur on a non-frequent, irregular basis. Still, the strategic crisis managers of VRT need to be able to handle these situations whenever they arise. Therefore, VRT trains complex crisis situations by simulating real-life crisis situations and going through the complete process of solving the situation. Here it is noteworthy that decisions made on the strategic level are usually neither correct nor incorrect: The decision-makers have to deal with situations similar to dilemmas. This experiential learning approach is among the most effective approaches to train skills important in decision-making in crisis management (Cesta et al., 2014). However, the real-life training sessions are complex and expensive to organize, so VRT sticks to training on a monthly basis (Veiligheidsregio Twente, 2016, 2018). Hence, we focus on games for training the interpretation and comprehension of information, since they can be used more frequently (Mezey, 2004; van der Hulst et al., 2014; Veiligheidsregio Twente, 2016).

\section{Digital serious games as training applications}

Stonebraker (2016) highlights the added usefulness of repeatedly training for integrating information into decisions. Making use of digital applications like serious games appears to be promising in training information literacy skills, which again is important in decision-making in crisis management. Furthermore, according to Smale (2011) (digital) serious games are already popular in information literacy instruction in academic library contexts. Here positive outcomes over more traditional information literacy instruction have been observed, which raises interest to also employ such serious games in non-academic and/or nonlibrary environments, like crisis management decision-making. 
Scenario based serious games, which make use of dilemmas and where the decision-making process stands in focus, are well suited to mimic and train such crisis situations on a strategic level (Crichton et al., 2000; Crichton \& Flin, 2001; Susi et al., 2007). Serious games are often considered to be simulation games (Connolly et al., 2012; Sniezek et al., 2001), trying to mimic realistic scenarios. This is similar to the training method currently used by VRT, only that using a digital serious game offers a number of advantages, with being able to train more often as the most apparent one (Stonebraker, 2016). Serious games aiming to train the player on decision-making and decision-making strategies can be defined as tactical decision games (Crichton et al., 2000; Crichton \& Flin, 2001). In tactical decision games, players must handle problems like uncertainty or information overload. Further, time pressure or other distractions can be implemented in such games. Hence, digital decision games are well suited for strategic decision-makers of VRT to use as an additional form of training.

\section{Unobtrusive in-game assessment of information literacy skills}

To make a serious game, and thereby the learning process, more effective and more efficient, the game should adapt to the player's current skill level (Lopes \& Bidarra, 2011). To achieve that, the game needs to measure the skill level of the player in-game. Making this assessment unobtrusive, thus woven into the natural gameplay (Shute \& Kim, 2014), can keep the flow of the game (Shute, 2011), allowing the game to react to the current skill level of the player on the fly. As a result, the game could provide immediate feedback on the player's performance and/or introduce instructional interventions (Bellotti et al., 2013), like for example self-reflection moments (Wouters \& van Oostendorp, 2013), to further enhance the learning process. Next to the learning related advantages, adaptivity also makes the game more appealing by challenging the player appropriately, which again can improve the learning process (Cocea \& Weibelzahl, 2007). Last, since crisis management decision-makers cannot just pause the crisis in real-life, a serious game using an unobtrusive assessment not interrupting the flow of the crisis better supports the experiential training method already used by VRT.

When an assessment is unobtrusive, we have to employ the interactions between the player and the game to build an assessment model so that we can make claims about the player's skill level, rather than using a classical testing procedure. If valid, an unobtrusive assessment method can enrich serious games by enabling them to adapt to the individual player.

This study aims to develop an unobtrusive assessment measure for IL in a digital decision game to be used by professionals in the crisis management domain. The focus lies on the strategic team of the crisis organization, where high-quality decision-making processes are key to making sound decisions to effectively overcome the crisis situation. 


\section{METHOD}

\section{The Dilemma Game}

A game that mimics crisis situations on a strategic level and is eligible to train decision-making processes, is the Mayor Game (Steinrücke et al., 2019; van de Ven et al., 2014). Originally, the Mayor game is a digital serious game used to train Dutch mayors on how to handle crisis situations, where players handle a realistically designed crisis situation by answering dilemmas. To support the players in their decision-making, they have the opportunity to ask advisors for additional information pointing toward a specific decision. Since the Mayor Game focuses on the decision-making process, and not on the actual decision, there is no correct decision to make (van de Ven et al., 2014). Giving different answers only affects the feedback provided to the player after the scenario. Players receive feedback about how they handled the situation, what information they took into account to come to a decision and how they scored on, for example, scales for different leadership styles (T-Xchange, 2018; van de Ven et al., 2014). Based on this Mayor Game, the Dilemma Game was developed. The gameplay scenario is running on the Dilemma engine by T-Xchange (2020), which is a further developed version of the original game engine as used in the Mayor Game (T-Xchange, 2018). Figure 3.1 displays the main interface of the game, where the player can interact with the different advisors and information items. The exact question and naming of the information items vary per dilemma.

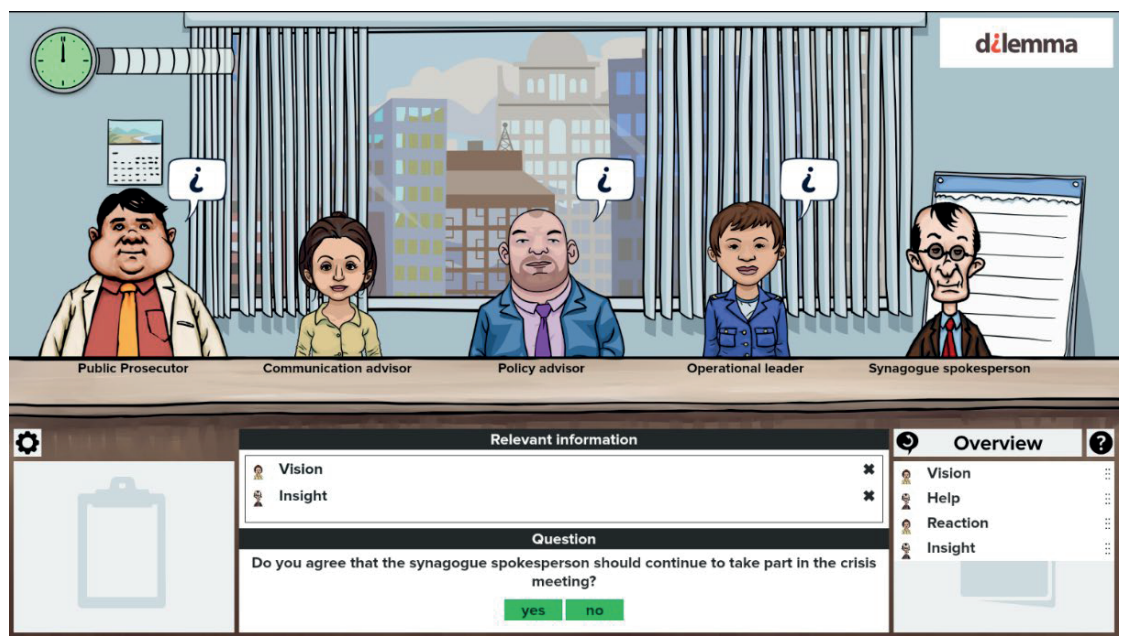

Figure 3.1. Screenshot of Dilemma Game

In the gameplay scenario, the player had to take decisions to manage a fictional crisis situation in a fictional town. The scenario was based on an existing training 
scenario about a possible terroristic attack, as used by VRT. Accordingly, the scenario was developed in close collaboration with two representatives of VRT to assure practical relevance and realism.

\section{Scenario content}

The scenario was about handling a possible terroristic attack, and possible ongoing threat, in a fictional town called "Trouveen". Questions were about how to communicate to the public, what strategy to follow, and whether there is enough expertise available. The scenario consisted of eight dilemmas: "Expertise", "Scale Up", "Victim statistics", "Public buildings", "NL-Alert", "Market", "Protest" and "Visit". The plot starts with the report of a big explosion at Trouveen's synagogue. Soon it becomes apparent that this explosion might not have been an accident. In the following the individual dilemmas are briefly described. As an example, see Appendix 3.A, Table 3.A.1 for full texts of dilemma four "Public buildings".

The first dilemma, "Expertise", deals with the question whether the spokesperson of the synagogue (SY) should join the crisis staff at the strategic table. The SY argues, that he wants to help figuring out what happens. He can provide inside knowledge about the synagogue and thereby maybe support the ongoing investigations.

The second dilemma, "Scale Up", deals with the question whether the crisis organization should raise the risk level. That would provide them with more rights and possibilities, but it also comes with more obligations. Further, scaling up the risk level should not be done if not necessary.

The third dilemma, "Victim statistics", is about whether the number of hurt or deceased people from the accident should be communicated. As pictures and numbers are already to be found on various social networks, the usually obvious decision that the precise number is not to be communicated, is not that obvious anymore.

The fourth dilemma, "Public buildings", asks whether public buildings around the synagogue should be closed. There are rumors that there might be a second culprit. As these are rumors, it is not that easily justified to close off public buildings.

The fifth dilemma, "NL-Alert", deals with the question whether an NL-Alert, an automated message to all mobile phones connected to the Dutch network, should be sent. As for the other dilemmas, there are arguments for and against sending an NL-Alert.

The sixth dilemma, "Market", is about whether the weekly market should be evacuated. As there is still no clear evidence whether or whether not there is second culprit, and there are rumors of a suspicious car in a parking lot. 
The seventh dilemma, "Protest", asks the player how to deal with an ongoing protest by an extremist group. Protesting is not forbidden. However, protests by extremist groups tend to provoke protests by anti-extremist groups.

The eighth dilemma, "Visit", is supposed to wrap up the story. In this dilemma, the player simply has to decide whether the synagogue is visited. The advisors provide information arguing for and against it.

In the Dilemma Game, gameplay data was collected using a gameplay scenario. Participants had to complete this scenario within 30 minutes, however all participants finished earlier probably because they were asked to treat the gameplay scenario as a realistic situation. The gameplay scenario consisted of eight dilemmas. In each dilemma participants received ten information items from the advisors, five of which had to be actively 'asked' for. That means, that for these five information items no indicators appeared to show that they are available. Instead, participants should actively consult the advisor, before they know that a second information item from that particular advisor is available. The players can read each information item multiple times. For each respective first information item, the player is notified about the information's availability.

\section{Unobtrusive in-game assessment}

To assess the players IL skill level, it is crucial to first clearly define information literacy. The American Library Association (ALA) defines important competencies an information literate person must possess using five standards (Information Literacy Competency Standards for Higher Education, 2000). They state that "the information literate student ...":

- “... determines the nature and extend of the information needed."

- “... accesses needed information effectively and efficiently.”

- “... evaluates information and its sources critically and incorporates selected information into his or her knowledge base and value system.”

- “..., individually or as a member of a group, uses information effectively to accomplish a specific purpose.”

- “... understands many of the economic, legal, and social issues surrounding the use of information and accesses and uses information ethically and legally."

In this study we will seek how to classify participants on the first four IL competency standards of the ALA on the basis of in-game behaviors that were collected unobtrusively. We will use the gameplay log data to derive an unobtrusive in-game measure of participants' IL skill level. For this we need to couple participants ingame behaviors to IL levels. Table 3.1 shows available in-game behaviors. 
Table 3.1

In-game indicators available for the operationalization

In-game indicators

Amount of $1^{\text {st }}$ information read

Amount of $2^{\text {nd }}$ information read

Amount of information reopened

Amount of information marked as relevant

Number of advisors consulted

Average reading time $1^{\text {st }}$ information per dilemma

Average reading time $2^{\text {nd }}$ information per dilemma

Response time relative to total playtime

Amount of information read

Average reading time of information per dilemma

Number of how often each individual advisor is consulted

Amount of information of each individual advisor marked as relevant

Average reading time dilemma story

Response to dilemma

Note. Not all of these indicators are used in the final unobtrusive assessment models.

\section{Validation measure}

To validate the unobtrusive assessment models for the IL skill level of the players, an external validation measure is needed. This validation measure, in the form of a questionnaire, was built in close collaboration with representatives of VRT, thereby measuring the practice relevant skill set, and two information specialists at the University of Twente. Participants' scores on this validation measure will be included in the analysis, such that we can verify that our unobtrusive in-game assessment for IL measures what it is supposed to measure.

Given that we were not able to find existing (Dutch) measures applicable to the context of crisis management, we developed a validation measure based on the information literacy competency standards as issued by the ALA (Information literacy competency standards for higher education, 2000) suited for a Dutch target population. The questionnaire was developed with the aim to measure crucial aspects of IL, as described in the information literacy standards 1, 2, 3 and 4 (Information literacy competency standards for higher education, 2000), while also being applicable to the context of VRT and the Dilemma Game. The questionnaire was developed in close collaboration with two information specialists.

The validation measure consists of 20 statements measuring the first four IL competency standards. The first and second standard are measured by five 
statements each, whereas the third and fourth standard are measured by six and four statements respectively. Each statement was answered on a 7-point Likert scale ranging from 'completely disagree' to 'completely agree'. The full, translated, validation measure is provided in Appendix 3.B.

\section{Participants}

In total 48 professionals people participated in this study. Of these 48 participants, seven did not complete the study. They were excluded since they did not follow the guidelines appropriately, or because they were not part of the target population (e.g., interns sent to replace ill colleagues). Due to missing data in the gameplay, caused by technical issues, one further participant was removed from the dataset. That reduced the number of participants to be considered in the data analyses to 40 participants. All participants are associated with VRT, working in a higher function or with the perspective to work in a higher function in the (near) future. Professionals from the police, fire department, public care, health care and crisis communication participated.

\section{Procedure}

As indicated, data was collected using a digital serious game and a validation measure. First, the participants were familiarized with the context of the study and the game they were about to play, for that purpose also an introductory scenario was provided. Second, the participants played the gameplay scenario. Once the participants finalized the last dilemma of the gameplay scenario, they were asked to fill in the validation measure. Ethical approval for this research was provided by the ethics committee of the University of Twente in September 2018. All participants were briefed and provided active consent before starting the study. The entire procedure took 45 to 60 minutes.

\section{Analysis}

With respect to the gameplay data an important notice is, that the first and eighth dilemmas have to be treated differently. The first dilemma naturally serves as an introductory dilemma as well. On the one hand, it introduces and starts the story of the gameplay scenario. On the other hand, the first dilemma is the first moment for many participants to ever play a likewise game without external assistance. Hence, it is to be expected that this dilemma is played somewhat differently by the participants. The eighth dilemma, which is the last dilemma, also serves to wrap up the story and deliver a, hopefully satisfying, ending of the scenario to the player. Since the crisis depicted in the scenario is already solved at this point, we choose to exclude it from further analysis as well. 
Even though we could extract more than 20 performance indicators from the log files, we cannot safely assume that all this data is independent. For example, the number of second information items read strongly depends on whether the first order information items were read. Furthermore, it is not safe to assume that a more information literate person automatically reads more information items, or that this person is faster in making the decision. Therefore, simple linear models might not be applicable.

Among widely used methods to analyze such gameplay interactions are (probabilistic) machine learning or clustering methods, which try to predict an unobserved latent variable (e.g., Shute, 2011; Shute et al., 2016). A clustering method, which can identify clusters respective to how the game is played, is latent profile analysis (LPA; Oberski, 2016). Since we aim to make use of only the gameplay interactions to assess the players' current IL skill level, LPA seems a fitting method. With LPA we can identify different clusters of gameplay behavior corresponding to higher or lower scores on our information literacy survey.

Since the unobtrusive assessment method that we aim to develop is supposed to enable a serious game to be adaptive, we want to be able to sketch an accurate, content-independent picture of the player's current skill level early in the game. Therefore, we will compare the accuracy of assessing the player after one, two, three, four, five or six dilemmas using bootstrap resampling methods. This way, we can investigate how many dilemmas are needed to sketch an accurate picture of the players information literacy skill level. In doing so, we can correlate the IL score and the in the LPA identified classes of gameplay behavior. The accuracy of the unobtrusive assessment models will be further evaluated by computing the correlation between predicted classes and IL score using data of subsequent dilemmas. Again, we employ bootstrap resampling methods to test the correlations despite our small sample size.

\section{ANALYSIS \& RESULTS}

\section{Validation measure}

Descriptive statistics and 95\% confidence intervals for the mean scores per standard (scale 1-7) are provided in Table 3.2. To evaluate the validation measure we considered only the 40 participants who were also eligible for the analysis of the gameplay data. As depicted in Table 3.2, the 95\% confidence intervals for each standard are completely in the upper half of possible mean scores. This entails that multiple participants scored the maximum score (7 out of 7 ) on multiple items, which is in line with our expectations considering the sample from our expert-level target population. 
Table 3.2

Means and $95 \%$ confidence intervals for each standard of IL

\begin{tabular}{lcc}
\hline Standard & Mean (SD) & 95\% Confidence interval \\
\hline Standard 1 & $5.215(0.595)$ & $4.05-6.38$ \\
Standard 2 & $5.375(0.644)$ & $4.11-6.64$ \\
Standard 3 & $5.133(0.452)$ & $4.25-6.02$ \\
Standard 4 & $5.806(0.644)$ & $4.54-7.00$ \\
\hline
\end{tabular}

With exception of Standard 4, scores on all standards are significantly intercorrelated (see Table 3.3). This is not surprising, since the standards are all part of the IL competency. Standard 4, is only significantly correlated to Standard 3. A potential explanation could be that while standards 1,2 and 3 are describing the competency to acquire new information and trying to grasp its main meaning, Standard 4 describes the competency to actually use information to a specific purpose. In other words, standards 1, 2 and 3 are all about knowledge acquisition, and Standard 4 is about applying that knowledge.

Table 3.3

Correlations between IL scores

\begin{tabular}{lcccc}
\hline & Standard 1 & Standard 2 & Standard 3 & Standard 4 \\
\hline Standard 1 & 1 & $0.32^{* *}$ & $0.34^{* *}$ & 0.21 \\
Standard 2 & & 1 & $0.35^{* *}$ & 0.19 \\
Standard 3 & & 1 & $0.36^{* *}$ \\
Standard 4 & & & & 1 \\
\hline
\end{tabular}

Note. ${ }^{* *} \mathrm{p}<0.05$.

\section{Demographic differences}

As part of the survey, we collected multiple demographic characteristics of the participants, these are age, gender, organization they belong to, function and experience. On average, participants were 46.9 years old $(S D=9.56)$. On average, the participants had 11.22 years of experience $(S D=9.37)$ in VRT. $80 \%$ of the participants were male, $20 \%$ were female. 15 participants came from the fire department, 13 from public care, five from health care, five from crisis communication, and two from the police. Five participants were 'general commandants', 18 were 'officers', nine were 'chief officers', one was 'strategic communication advisor', and seven participants had organization specific functions.

Since the four IL scores are inter-correlated, we performed a multivariate analysis of variance (MANOVA) with the four IL scores as dependent variables, and the 
demographic characteristics as independent variables. Only the function within the organization seemed to have a significant influence on the information literacy scores per standard based on the validation measure $(F=1.90 ; d f=16,11 ; p=$ 0.03). Specifically, using pairwise comparisons, we found that with respect to IL Standard 1 'officers' perform worse than 'general commandants' ( $T=3.14$; $d f=$ 28; $p=0.03$ ) and 'chief officers' ( $T=2.76 ; d f=28 ; p=0.07)$, while with respect to Standard 4 the 'general commandants' ( $T=2.87 ; d f=28 ; p=0.05$ ) and 'chief officers' ( $T=3.40 ; d f=28 ; p=0.02$ ) outperformed those participants who had organization specific functions (labelled 'Others'). None of the other demographic variables were found to significantly influence the information literacy score on any of the four standards. Therefore, we decided to treat the respondents as a homogeneous group in the remaining analyses.

\section{Unobtrusive assessment measure}

After comparing multiple operationalization and choosing the best performing, the final operationalization of the IL competency standards 1 through 4 is provided in Table 3.4 .

Table 3.4

Final in-game operationalization of information literacy standards 1 to 4

\begin{tabular}{|c|c|}
\hline Standard & In-game indicator \\
\hline Standard 1 & $\begin{array}{l}\text { Amount of } 1^{\text {st }} \text { information read } \\
\text { Amount of } 2^{\text {nd }} \text { information read } \\
\text { Amount of information reopened } \\
\text { Number of advisors consulted }\end{array}$ \\
\hline Standard 2 & $\begin{array}{l}\text { Amount of } 2^{\text {nd }} \text { information read } \\
\text { Average reading time } 2^{\text {nd }} \text { information per dilemma } \\
\text { Response time relative to total playtime } \\
\text { Number of advisors asked }\end{array}$ \\
\hline Standard 3 & $\begin{array}{l}\text { Response time relative to total playtime } \\
\text { Number of advisors asked } \\
\text { Amount of information reopened }\end{array}$ \\
\hline Standard 4 & $\begin{array}{l}\text { Amount of } 1^{\text {st }} \text { information read } \\
\text { Number of advisors consulted } \\
\text { Amount of information marked as important } \\
\text { Response time relative to total playtime }\end{array}$ \\
\hline
\end{tabular}

The in Table 3.4 defined in-game operationalization of the first four IL competency standards, was tested with LPA using the tidyLPA software package in $\mathrm{R}$ (Rosenberg et al., 2018). First, we estimated latent class models with either three 
or four classes, and with either equal variances and covariances fixed to zero or with equal variances and equal covariances. Then we compared the four possible latent class models using an Analytic Hierarchy Process (AHP; Akogul \& Erisoglu, 2017), which compares models using multiple fit indices. In Appendix 3.C, Table 3.C.1 we provide Akaike's Information Criterion (AIC) and Bayesian Information Criterion (BIC) for all possible models to give an idea of the model fit. The best performing model for each standard was used in any subsequent analysis.

\section{Testing unobtrusive assessment models}

We used LPA to classify participants based on their gameplay behavior. To be able to compute a correlation between the latent classes and the IL score per standard, we labeled the latent classes by their mean IL scores in ascending order. Class 1 is now considered the class with the lowest mean IL score, classes 3 and 4 are the classes with the highest mean IL score. The mean IL scores and standard deviation per class are provided in Table 3.5 for each standard.

Table 3.5

Centroid mean and standard deviation per class for each standard

\begin{tabular}{|c|c|c|c|c|}
\hline Class & $\begin{array}{l}\text { Standard } 1 \\
\text { Mean }(S D)\end{array}$ & $\begin{array}{l}\text { Standard } 2 \\
\text { Mean }(S D)\end{array}$ & $\begin{array}{l}\text { Standard } 3 \\
\text { Mean }(S D)\end{array}$ & $\begin{array}{l}\text { Standard } 4 \\
\text { Mean (SD) }\end{array}$ \\
\hline 1 & $5.11 \quad(0.65)$ & $5.12 \quad(0.65)$ & $4.96 \quad(0.42)$ & $5.44 \quad(0.80)$ \\
\hline 2 & $5.22 \quad(0.52)$ & $5.40 \quad(0.55)$ & $5.25 \quad(0.35)$ & $5.71 \quad(0.71)$ \\
\hline 3 & $5.66 \quad(0.30)$ & $5.68 \quad(0.73)$ & $5.39 \quad(0.37)$ & $6.07 \quad(0.37)$ \\
\hline 4 & - & $5.90 \quad(0.21)$ & $5.59 \quad(0.59)$ & - \\
\hline
\end{tabular}

Given our rather small sample size of 40 participants, we performed a bootstrap resampling-based correlation analysis using the according to the AHP best performing latent class models. We used 100,000 iterations to compute the correlation between the latent classes (in ascending order by the mean IL score per class) and the IL score obtained using the validation measure. The results of the bootstrap correlation analysis are depicted in Table 3.6.

Although utilizing data of more dilemmas leads to higher correlations in some cases, the trade-off between time and accuracy seems to be most efficient after dilemmas two and three. Therefore, we continued our analysis with the respective model parameters obtained when using data of these two dilemmas. Even though all correlations between the latent classes and the IL score are positive, the correlations are quite low for Standard 4. The correlations for Standard 1, Standard 2 and Standard 3 are to a large proportion significant. 
Table 3.6

Bootstrapped correlations of (accumulated) gameplay data and IL score - Final models

\begin{tabular}{lllll}
\hline Dilemma & $\begin{array}{l}\text { Standard 1 } \\
\text { Mean }(S D)\end{array}$ & $\begin{array}{l}\text { Standard 2 } \\
\text { Mean }(S D)\end{array}$ & $\begin{array}{l}\text { Standard 3 } \\
\text { Mean }(S D)\end{array}$ & $\begin{array}{l}\text { Standard 4 } \\
\text { Mean }(S D)\end{array}$ \\
\hline 2 & $0.22(0.17)$ & $0.31(0.14)^{*}$ & $0.39(0.13)^{*}$ & $0.01(0.16)$ \\
$2-3$ & $0.34(0.13)^{*}$ & $0.46(0.09)^{*}$ & $0.49(0.11)^{*}$ & $0.33(0.12)^{*}$ \\
$2-4$ & $0.25(0.13)^{*}$ & $0.34(0.13)^{*}$ & $0.57(0.11)^{*}$ & $0.35(0.11)^{*}$ \\
$2-5$ & $0.37(0.15)^{*}$ & $0.39(0.12)^{*}$ & $0.43(0.14)^{*}$ & $0.27(0.14)$ \\
$2-6$ & $0.43(0.14)^{*}$ & $0.21(0.16)$ & $0.49(0.11)^{*}$ & $0.14(0.14)$ \\
$2-7$ & $0.28(0.16)$ & $0.44(0.13)^{*}$ & $0.49(0.11)^{*}$ & $0.18(0.18)$ \\
\hline
\end{tabular}

Note. * strictly positive correlation; $95 \%$ confidence interval above 0 .

\section{Content independency}

Data of two consecutive dilemmas is used to predict the class membership of each participant for Standard 1, 2, 3 and 4. To check for consistency, class memberships were correlated to the IL score based on the validation questionnaire for every consecutive pair. In performing this sequential test, we intend to rule out content dependency for our unobtrusive assessment measure. The results are depicted in Table 3.7.

Table 3.7

Bootstrapped correlations over two dilemmas using model parameters estimated from dilemma 2 and 3 - Final models

\begin{tabular}{lllll}
\hline Dilemma & $\begin{array}{l}\text { Standard 1 } \\
\text { Mean }(S D)\end{array}$ & $\begin{array}{l}\text { Standard 2 } \\
\text { Mean }(S D)\end{array}$ & $\begin{array}{l}\text { Standard 3 } \\
\text { Mean }(S D)\end{array}$ & $\begin{array}{l}\text { Standard 4 } \\
\text { Mean }(S D)\end{array}$ \\
\hline $2-3$ & $0.34(0.13)^{*}$ & $0.46(0.09)^{*}$ & $0.49(0.11)^{*}$ & $0.33(0.12)^{*}$ \\
$3-4$ & $0.34(0.13)^{*}$ & $0.39(0.12)^{*}$ & $0.43(0.13)^{*}$ & $0.34(0.12)^{*}$ \\
$4-5$ & $-0.04(0.17)$ & $0.28(0.12)^{*}$ & $0.26(0.15)$ & $0.05(0.17)$ \\
$5-6$ & $0.41(0.13)^{*}$ & $0.28(0.12)^{*}$ & $0.31(0.13)^{*}$ & $-0.17(0.13)$ \\
$6-7$ & $0.26(0.14)$ & $0.35(0.12)^{*}$ & $0.37(0.12)^{*}$ & $0.00(0.14)$ \\
\hline
\end{tabular}

Note. * strictly positive correlation; $95 \%$ confidence interval above 0 .

For Standard 1, 2 and 3 we observe significant correlations for the consecutive pairs. Standard 4 seems to not perform as well as the other standards, with only two out of five significant correlations. Even though these results aren't perfect, this seems to indicate that our focus on two consecutive dilemmas seems to work. 


\section{Interpretation unobtrusive assessment models}

Now that we developed (relatively) well working unobtrusive assessment models, we can inspect what the players are exactly doing during gameplay. For all standards, all classes are ordered from lower IL performance (class 1) to higher IL performance (class 3; class 4). All figures in this paragraph show centered and scaled scores.

As we can see in Figure 3.2, for IL standard 1, players who barely read information ( $1^{\text {st }}$ and $2^{\text {nd }}$ information), and do not ask many different advisors, will be classified in class 1. Players who read much information, but do not ask many different advisors, are classified in class 2 . Class 3 includes those players, who consult more different advisors, read a similar number of first information items as players in class 2 , but who read less pieces of second information. Players in class 3 seem to recognize that they have enough information to make a decision. In contrast to that, players in class 2 consult the advisors a second time. Players in class 1 do not seem to recognize that they need (more) information in the first place. They open only few first information items before they make a decision. As the positive correlations in Tables 3.6 and 3.7 indicate, we can assume that gameplay behavior associated with class 3 is associated with a higher ability on IL Standard 1.

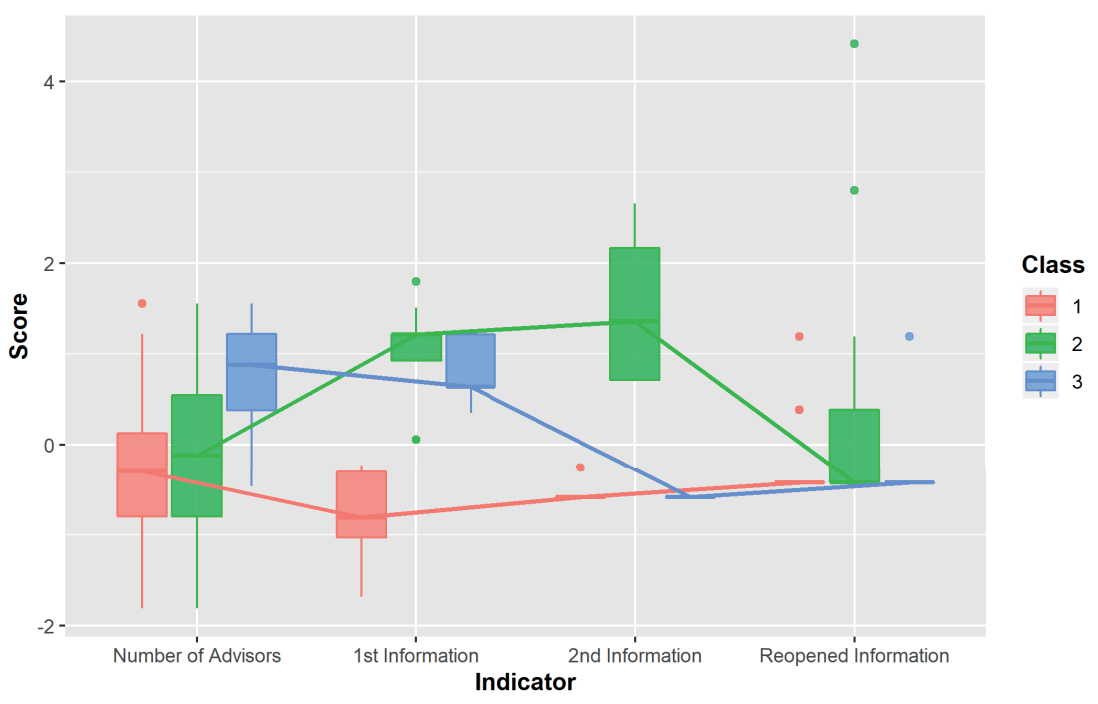

Figure 3.2. Gameplay profiles for Standard 1

The results for IL Standard 2 are depicted in Figure 3.3. In contrast to Standard 1 , four distinct classes have been identified based on the players' gameplay behavior. We observe that class 1 is characterized by a small number of opened second information items, few different advisors asked, and fast response times. 
Players associated with class 2 ask more advisors than those in all other classes, recognizing that they need to consult a variety of sources, while supposedly not differentiating between the perceived relevance of the sources. Asking many second information items is associated with class 3 , whereas participants classified in class 4 seem to better handle the trade-off between asking more information and making a timely decision. Further, the reading time for these second information items seems to be faster for participants in class 4 than for participants in class 3 . Generally, we see that members of higher classes ask slightly more advisors, with the notion that participants in class 4 seem to be better able to distinguish who is to be asked in the first place, therefore acting the most efficient.

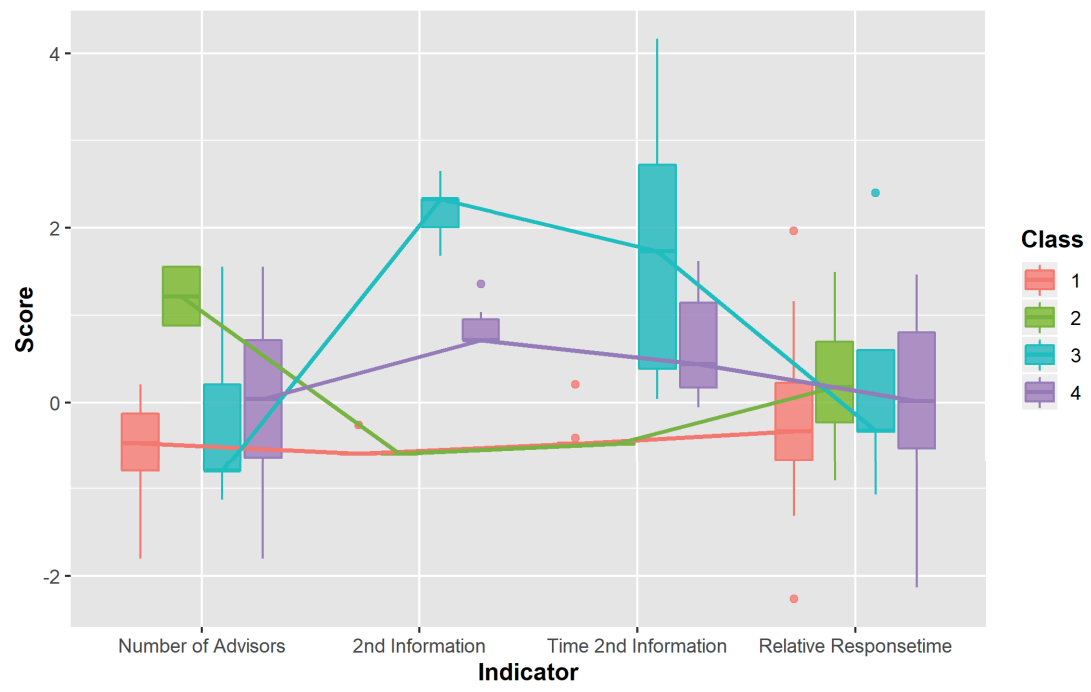

Figure 3.3. Gameplay profiles for Standard 2

Figure 3.4 depicts the identified gameplay profiles associated with Standard 3. Players classified in class 3 or class 4 generally consult more advisors than those classified in lower classes. Classes 3 and 4 are distinguished by the amount of reopened information items, with members of class 4 reopening more information items than members in class 3 . Classes 1 and 2 are distinguished by the number of advisors consulted and the response times relative to total playtime, with members of class 2 consulting fewer advisors and responding faster.

As depicted in Figure 3.5, the best performing unobtrusive assessment model for Standard 4 distinguishes between three different gameplay profiles. Members of class 3 consult more advisors than members from class 1 and two, whereas members of class 1 seem not to make a distinction when it comes to marking an information item as relevant or not. Next, it seems that members of class 3 
carefully evaluate the read information items, as opposed to members of class 1 . While the latter read more first information items, they still respond much faster. The gameplay profile of class 2 is somewhat counterintuitive. Members of this class read fewer information items and mark fewer as relevant. However, looking back at Table 3.7 we also need to be aware that the unobtrusive assessment model for Standard 4 seems not to perform comparable to the other standards.

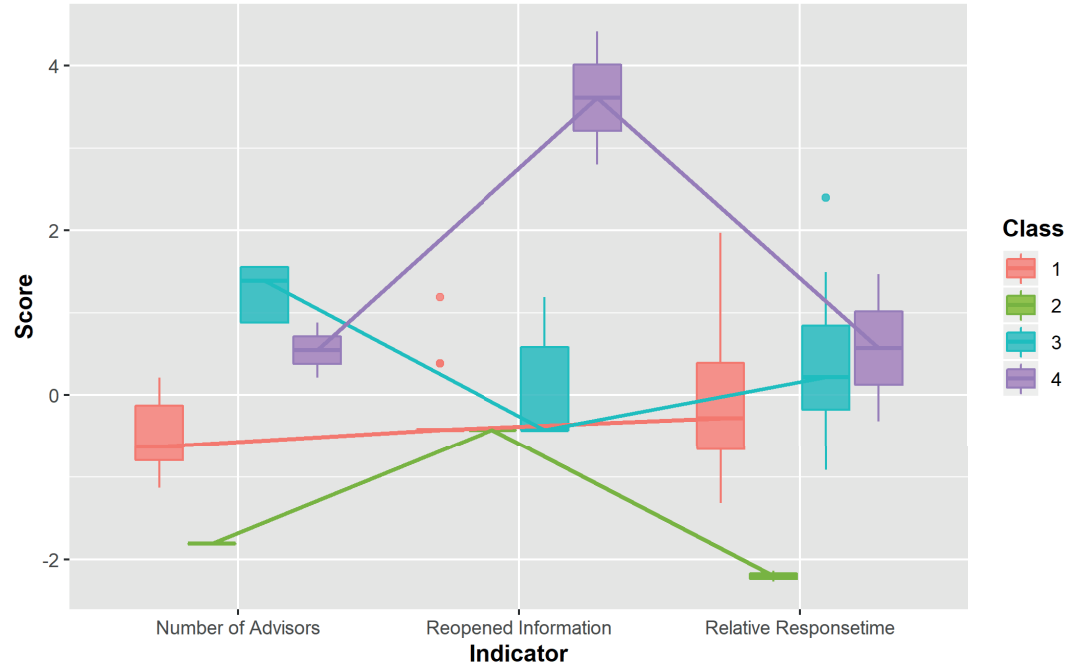

Figure 3.4. Gameplay profiles for Standard 3

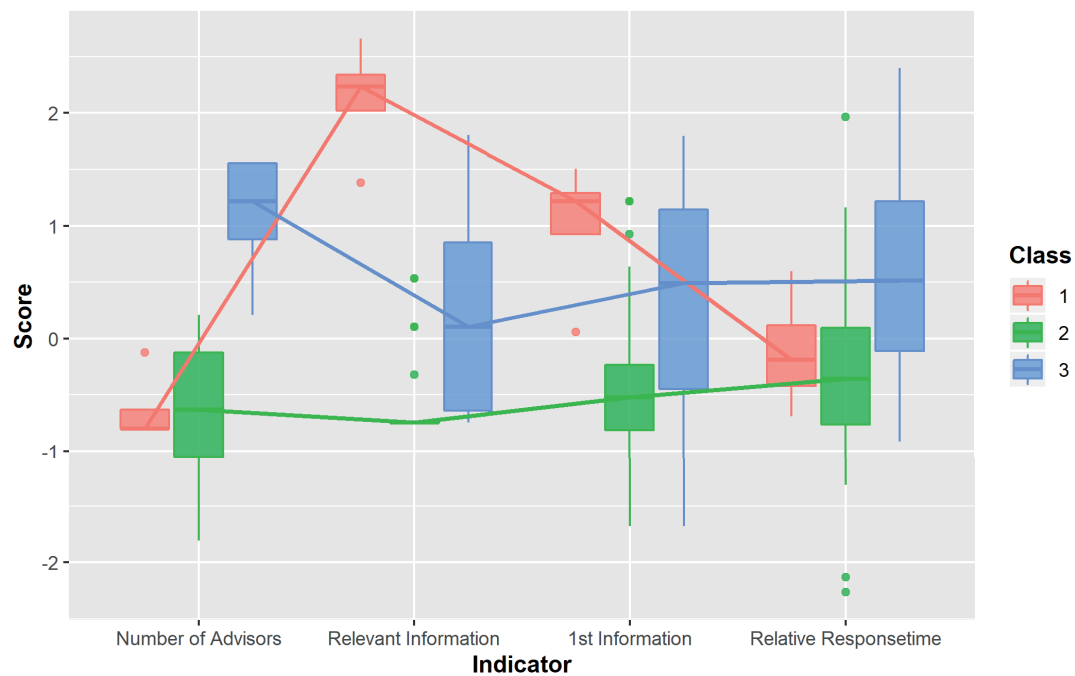

Figure 3.5. Gameplay profiles for Standard 4 


\section{Correlation between latent classes}

Last, we tested the correlation between the classes of the different standards as they all are part of IL competency. An information literate person ideally performs well on all standards; therefore, the unobtrusive assessments should also be positively inter-correlated. As depicted in Table 3.8, we find that classes of all standards except Standard 3 are positively inter-correlated. The classifications for Standard 3 are negatively correlated to the classes of Standard 2 and Standard 4, whereas the correlation between Standard 1 and Standard 3 is negative but not significant. This stays in contrast to the correlations depicted in Table 3.3, where most standards were significantly and positively inter-correlated. This means that, according to gameplay behavior, Standard 3 seems to conceptually differ from the other standards, but that on the basis of the questionnaire, all standards seem to have a common underlying concept, namely IL.

Table 3.8

Correlations between latent classes based on model parameters on dilemmas 2 and 3

\begin{tabular}{lllll}
\hline & Standard 1 & Standard 2 & Standard 3 & Standard 4 \\
\hline Standard 1 & 1 & $0.46^{* * *}$ & -0.21 & $0.42^{* * * *}$ \\
Standard 2 & & 1 & $-0.47^{* * *}$ & $0.79^{* * *}$ \\
Standard 3 & & 1 & $-0.35^{* * *}$ \\
Standard 4 & & & 1
\end{tabular}

Note. ${ }^{* * \mathrm{p}}<0.05 ; * * * \mathrm{p}<0.01$.

\section{DISCUSSION}

In this study, we aimed to develop an unobtrusive assessment for the first four IL competency standards: recognizing the need of (additional) information, accessing information effectively and efficiently, incorporating information in one's own knowledge base, and using information for a specific purpose. This unobtrusive assessment was supposed to only use in-game measures derived from gameplay behavior, such that the flow of the player is not interrupted. We correlated (accumulated) in-game measures with the IL score using bootstrap resampling methods, given that our sample was rather small. After exploratory testing the performance of multiple operationalization, we developed unobtrusive assessment models which performed to a satisfying degree.

\section{Unobtrusive assessment measure}

The correlations between the final unobtrusive assessment models and the IL score were to a large portion significant. Only with respect to Standard 4 (using 
information for a specific purpose) we did not find an operationalization performing on par with the other standards. With respect to standards 1 (recognizing the need of information), 2 (accessing information effectively and efficiently) and 3 (incorporating information into one's own knowledge base) we found well performing unobtrusive assessment models, which could be used to approximate the player's skill level. We already mentioned that Standard 4 differs from standards 1,2 and 3: Standards 1,2 and 3 concern the acquisition of information, whereas Standard 4 concerns the use of information after acquisition.

However, given our expert level target population it is also evident that the identified skill levels are relatively close to another. This does not change the fact, that acquiring the highest possible skill level is desirable, especially in crisis management decision-making. Therefore, we conclude that the unobtrusive assessment models can contribute to building an adaptive serious game for crisis management decision-makers, while for members of a non-expert population, maybe scoring less on the IL questionnaire, the accuracy of the unobtrusive assessment models cannot be guaranteed.

When reviewing the correlations depicted in Table 3.8, Standard 3 seems to fall out of line. This is surprising, since all indicators can be found in the other standards as well. If any, we would have expected Standard 4 to fall out of line. Standard 4 describes the use of information for a specific purpose, rather than being a part of the acquisition process of information. However, we can only make assumptions about the reason why exactly the classes of Standard 3 are negatively correlated with the classes of the other standards: After information has been accessed, it has to be incorporated into the decision-makers' knowledge base. Based on the definition by the American Library Association, this can be a time intensive process (Information Literacy Competency Standards for Higher Education, 2000). In crisis management decision-making, time is not an unlimited resource. Many experts trust their intuition, knowledge, and expertise, rather than engaging in time intensive thinking processes (van der Hulst et al., 2014). While this assumption is supported by the results depicted in Table 3.8, the results depicted in Table 3.3 do not support it. However, the mean IL scores show a large overlap between classes for Standard 3 (see Table 3.5), contradicting the significant relationships found in Tables 3.6 and 3.7.

In conclusion, the results look promising. While we were not able to develop unobtrusive assessment models that perform well and are supported by the data and all analyses conducted for Standard 3 and Standard 4, we were able to develop well performing unobtrusive assessment models for Standard 1 and Standard 2. These results are a good starting point for developing an adaptive serious game 
that could be used to support the crisis management decision-making training of crisis management organization like VRT.

\section{Sample from expert-level target population}

There are two issues to be discussed regarding the sample in this study. First, due to the rather small number of participants and the fact that the target population is a group of Dutch experts, the results have to be put into perspective. For similar games and similar target populations, we can assume that the results hold. However, if either the game, or the target population deviates from what is described in this study, we advise to not set the results out of context. Second, all results are based on data collected with experts from one safety region in the Netherlands. However, in the Netherlands there are 25 safety regions. These 25 safety regions are all organized differently. In some cases, like in the case of VRT, the individual crisis organizations work closely together, in other cases they cooperate less (Ministerie van Justitie en Veiligheid, 2020). Further, VRT is considered one of the most innovative safety regions: For example, it played a crucial role in setting up the Twente Safety Campus, which serves as an innovative training facility. This Safety Campus is used by crisis responders from all over the Netherlands (Veiligheidsregio Twente, 2015; Twente Safety Campus, 2020).

Therefore, we highlight that this research and its results are just a starting point for making the training of crisis management decision-making more effective and more efficient. The developed unobtrusive assessment models should be further tested and improved by also recruiting participants from other safety regions in the Netherlands.

\section{Follow-up}

To continue research on unobtrusive assessment and the added use of incorporating it in a serious game, our unobtrusive assessment models should be evaluated in practice. Also, as there was no applicable standardized measurement instrument for IL that measures IL in the context of decision-making and is working field independent, the validation of the unobtrusive assessment measure remains a challenge. While our employed IL questionnaire seems to be a wellfunctioning starting point, it needs further evaluation and testing with larger participant numbers. Being able to assess the players' skill level unobtrusively allows game developers to adaptively provide feedback or introduce instructional interventions. As Wouters and van Oostendorp (2013) discussed, such an instructional intervention that has been found useful in training adults, is selfreflection. Regarding crisis management decision-making it would be interesting to investigate the effect of offering self-reflection moments, either adaptively, or at fixed moments with the added information obtained using our unobtrusive 
assessment. This would also be a way to match the current training program even closer: After finishing one of their current training sessions, the professionals of VRT take part in discussion sessions, where they also reflect on their own performance. As this is a crucial learning moment for the professionals, a similar functionality only makes sense in a digital serious game aiming to support the training process of these crisis management decision-makers. 


\section{REFERENCES}

Akogul, S., \& Erisoglu, M. (2017). An approach for determining the number of clusters in a model-based cluster analysis. Entropy, 19, 452. https://doi.org/10.3390/e19090452

Bellotti, F., Kapralos, B., Lee, K., Moreno-Ger, P., \& Berta, R. (2013). Assessment in and of serious games: An overview. Advances in Human-Computer Interaction, 2013. https://doi.org/10.1155/2013/136864

Cesta, A., Cortellessa, G., \& De Benedictis, R. (2014). Training for crisis decision making - An approach based on plan adaptation. Knowledge-Based Systems, 58, 98-112. https://doi.org/10.1016/j.knosys.2013.11.011

Cocea, M., \& Weibelzahl, S. (2007). Eliciting motivation knowledge from log files towards motivation diagnosis for adaptive systems. In C. Conati, K. McCoy, \& G. Paliouras (Eds.), User modeling 2007 (pp. 197-206). Springer. https://doi.org/10.1007/978-3540-73078-1_23

Connolly, T. M., Boyle, E. A., MacArthur, E., Hainey, T., \& Boyle, J. M. (2012). A systematic literature review of empirical evidence on computer games and serious games. Computers \& Education, 59, 661-686. https://doi.org/10.1016/j.compedu.2012.03.004

Crichton, M. T., \& Flin, R. (2001). Training for emergency management: Tactical decision games. Journal of Hazardous Materials, 88, 255-266. https://doi.org/10.1016/s0304-3894(01)00270-9

Crichton, M. T., Flin, R., \& Rattray, W. A. R. (2000). Training decision makers - Tactical decision games. Journal of Contingencies and Crisis Management, 8, 208-217. https://doi.org/10.1111/1468-5973.00141

Endsley, M. R. (2000). Theoretical underpinnings of situation awareness: A critical review. In M. R. Endsley \& D. J. Garland (Eds.), Situation awareness analysis and measurement (pp. 3-32). Erlbaum Associates.

Information Literacy Competency Standards for Higher Education. (2000). https://alair.ala.org/bitstream/handle/11213/7668/ACRL\%20Information\%20Liter acy\%20Competency\%20Standards\%20for\%20Higher\%20Education.pdf

Kippers, W. B., Poortman, C. L., Schildkamp, K., \& Visscher, A. J. (2018). Data literacy: What do educators learn and struggle with during a data use intervention? Studies in Educational Evaluation, 56, 21-31. https://doi.org/10.1016/j.stueduc.2017.11.001

Lopes, R., \& Bidarra, R. (2011). Adaptivity challenges in games and simulations: A survey. IEEE Transactions on Computational Intelligence and AI in Games, 3, 85-99. https://doi.org/10.1109/TCIAIG.2011.2152841

Mandinach, E. B., \& Gummer, E. S. (2016). What does it mean for teachers to be data literate: Laying out the skills, knowledge, and dispositions. Teaching and Teacher Education, 60, 366-376. https://doi.org/10.1016/j.tate.2016.07.011

Mezey, G. (2004). Crisis management decision making. AARMS, 3, 267-288. 
Ministerie van Justitie en Veiligheid. (2020, February 19). Veiligheidsregio's. https://www.rijksoverheid.nl/onderwerpen/veiligheidsregios-encrisisbeheersing/veiligheidsregios

Oberski, D. (2016). Mixture models: Latent profile and latent class analysis. In J. Robertson \& M. Kaptein (Eds.), Modern statistical methods for HCI (pp. 275-287). Springer. https://doi.org/10.1007/978-3-319-26633-6_12

Rosenberg, J. M., Beymer, P. N., Anderson, D. J., Van Lissa, C. J., \& Schmidt, J. A. (2018). TidyLPA: An R package to easily carry out latent profile analysis (LPA) using open-source or commercial software. Journal of Open Source Software, 3, https://doi.org/10.21105/joss.00978

Smale, M. A. (2011). Learning through quests and contests: Games in information literacy instruction. Journal of Library Innovation, 2(2), 36-55.

Shute, V. J. (2011). Stealth assessment in computer-based games to support learning. Computer games and instruction, 55, 503-524.

Shute, V. J., \& Kim, Y. J. (2014). Formative and stealth assessment. In J. M. Spector, M. D. Merrill, J. Elen, \& M. J. Bishop (Eds.), Handbook of research on educational communications and technology (pp. 311-321). Springer. https://doi.org/10.1007/978-1-4614-3185-5

Shute, V. J., Wang, L., Greiff, S., Zhao, W., \& Moore, G. (2016). Measuring problem solving skills via stealth assessment in an engaging video game. Computers in Human Behavior, 63, 106-117. https://doi.org/10.1016/j.chb.2016.05.047

Sniezek, J. A., Wilkins, D. C., \& Wadlington, P. L. (2001, Jan). Advanced training for crisis decision making: Simulation, critiquing, and immersive interfaces. In Proceedings of the 34th Annual Hawaii International Conference on System Sciences. https://doi.org/10.1109/HICSS.2001.926337

Steinrücke, J., Veldkamp, B. P., \& de Jong, T. (2019). Determining the effect of stress on analytical skills performance in digital decision games towards an unobtrusive measure of experienced stress in gameplay scenarios. Computers in Human Behavior, 99, 144-155. https://doi.org/10.1016/j.chb.2019.05.014

Stonebraker, I. (2016). Toward informed leadership: Teaching students to make better decisions using information. Journal of Business \& Finance Librarianship. 21, 229-238. https://doi.org/10.1080/08963568.2016.1226614

Susi, T., Johanneson, M., \& Backlund, P. (2007). Serious games - An overview (Tech. Rep.). School of Humanities and Informatics, University of Skövde. http://urn.kb.se/resolve?urn=urn:nbn:se:his:diva-1279

Twente Safety Campus. (n.d.). Twente Safety Campus. Retrieved March 10, 2020, from https://www.twentesafetycampus.nl/en/about-us/

T-Xchange. (2018). Mayors Game. Retrieved February 15, 2018, from http://www.txchange.nl/portfolio-item/mayors-game/

T-Xchange. (2020). Dilemma. Retrieved February 21, 2020, from https://www.txchange.nl/dilemma/. 
van der Hulst, A. H., Muller, T. J., Buiel, E., Gelooven, D. V., \& Ruijsendaal, M. (2014). Serious gaming for complex decision making: Training approaches. International Journal of Technology Enhanced Learning, 6, 249-264. https://doi.org/10.1504/IJTEL.2014.068364

van de Ven, J. G. M., Stubbé, H., \& Hrehovcsik, M. (2014). Gaming for policy makers: It's serious! In A. De Gloria (Eds.), Games and learning alliance: Second international conference, GALA 2013 (pp. 376-382). Springer. https://doi.org/10.1007/978-3-31912157-4_32

Veiligheidsregio Twente. (2015). Beleidsplan VRT. https://www.vrtwente.nl/media/1175/ beleidsplan-vrt-2016-2019-definitief-ab-29062015.pdf

Veiligheidsregio Twente. (2016). Regionaal Crisisplan Veiligheidsregio Twente - Deel 1. http://www.vrtwente.nl/media/227908/regionaal-crisisplan-veiligheidsregiotwente-deel-1.pdf

Veiligheidsregio Twente. (2018). Overview 2017: Veiligheidsregio Twente. https://www.vrtwente.nl/sharepoint/Vergaderstukken\%20Algemeen\%20Bestuur/ Archief/20181203\%20Vergadering\%20AB\%20VRT\%203\%20december\%202018/2 0181203\%20E03b\%20Overview\%20crisisorganisatie\%20VRT\%202017_DEF.pdf

Wouters, P., \& van Oostendorp, H. (2013). A meta-analytic review of the role of instructional support in game-based learning. Computers \& Education, 60, 412425. https://doi.org/10.1016/j.compedu.2012.07.018 


\section{APPENDIX 3.A}

Table 3.A.1

Example dilemma translated from Dutch to English

Dilemma Text

"Public buildings"

Dilemma

Information

\section{Item}

Question Text

Ministry of public
Because the synagogue is centrally located in Trouveen, there are several public buildings in the vicinity. The crisis team will discuss whether you are going to close them. Are you going to close the public buildings near the synagogue? affairs (OM)

It is not at all certain if anyone else is a fugitive.

That would only interfere with the normal course of events.

Strategic communi- On Twitter, people write that they have seen cations advisor (SC) a suspicious person walking in the direction of the city center.

I do not have any new information.

Policy advisor (BA) In the vicinity of the synagogue there are schools and the hospital, not everyone here is self-reliant.

It is better to close the buildings preventively.

Operational leader We do not have enough crisis staff to protect (OL) all public buildings.

The initial investigation shows there is a good chance it was a terroristic attack.

Spokesman synagogue It is enough that we were hit.

(SY) of the other religious buildings in Trouveen. 


\section{APPENDIX 3.B}

\section{Translated Information Literacy Questionnaire}

\section{Questionnaire Information Literacy}

\section{Participant-ID:}

The next four question are about your background information. This information remains anonymous and will only be used in combination with your participant-ID.

Age:

Sex:

Organization / Function / Experience (in years): I

\section{Questionnaire Information Literacy:}

The following 20 statements are intended to measure your level of Information Literacy proficiency. The questions are formulated in such a way that they are in the context of decision-making situations. This concerns the approach you use to make a decision. The search for information, which you will encounter in several questions, is intended in a broad sense. It may be that you ask colleagues, use the internet, or other ways to gather information. In short, it is about your attitude and handling of information (information literacy proficiency) Please complete the questionnaire as honestly as possible. All your answers are completely anonymized.

Mark the box that best describes your answer/behavior for the next 20 statements.

1) In order to be able to make a good decision, I name/define important key concepts of the situation and actively search for information based on these key concepts.

$\begin{array}{ccccccc}\text { Completely } & \text { Slightly } & \text { Neither agree } & \text { Slightly } & & \text { Completely } \\ \text { disagree } & \text { Disagree } & \text { disagree } & \text { nor disagree } & \text { agree } & \text { Agree } & \text { agree } \\ \circ & \circ & 0 & 0 & 0 & \circ & 0\end{array}$

2) If the information collected is insufficient, I know why and how I need to change my information search strategy in order to achieve the goal.

$\begin{array}{ccccccc}\text { Completely } & \text { Slightly } & \text { Neither agree } & \text { Slightly } & & \text { Completely } \\ \text { disagree } & \text { Disagree } & \text { disagree } & \text { nor disagree } & \text { agree } & \text { Agree } & \text { agree } \\ 0 & 0 & 0 & 0 & 0 & 0 & 0\end{array}$

3) It is important to communicate well how I came to a decision.

$\begin{array}{ccccccc}\text { Completely } & \text { Slightly } & \text { Neither agree } & \text { Slightly } & \text { Completely } \\ \text { disagree } & \text { Disagree } & \text { disagree } & \text { nor disagree } & \text { agree } & \text { Agree } & \text { agree } \\ 0 & 0 & 0 & 0 & 0 & 0 & 0\end{array}$

4) I make a distinction between sources that are important to the situation and sources that are not.

$\begin{array}{ccccccc}\text { Completely } & \text { Slightly } & \text { Neither agree } & \text { Slightly } & & \text { Completely } \\ \text { disagree } & \text { Disagree } & \text { disagree } & \text { nor disagree } & \text { agree } & \text { Agree } & \text { agree } \\ 0 & 0 & 0 & 0 & 0 & 0 & 0\end{array}$


5) I can adapt my decision-making process to any new information about the situation.

$\begin{array}{ccccccc}\text { Completely } & \text { Slightly } & \text { Neither agree } & \text { Slightly } & \text { Completely } \\ \text { disagree } & \text { Disagree } & \text { disagree } & \text { nor disagree } & \text { agree } & \text { Agree } & \text { agree } \\ \circ & \circ & \circ & \circ & \circ & \circ & 0\end{array}$

6) I only use sources I already know to collect information.

$\begin{array}{ccccccc}\text { Completely } & \text { Slightly } & \text { Neither agree } & \text { Slightly } & \text { Completely } \\ \text { disagree } & \text { Disagree } & \text { disagree } & \text { nor disagree } & \text { agree } & \text { Agree } & \text { agree } \\ \circ & \circ & 0 & 0 & 0 & 0 & 0\end{array}$

7) I always look at individual pieces of information in relation to another.

$\begin{array}{ccccccc}\text { Completely } & \text { Slightly } & \text { Neither agree } & \text { Slightly } & \text { Completely } \\ \text { disagree } & \text { Disagree } & \text { disagree } & \text { nor disagree } & \text { agree } & \text { Agree } & \text { agree } \\ \circ & \circ & \circ & 0 & 0 & 0 & 0\end{array}$

8) I always look critically at incoming information.

$\begin{array}{ccccccc}\text { Completely } & \text { Slightly } & \text { Neither agree } & \text { Slightly } & & \text { Completely } \\ \text { disagree } & \text { Disagree } & \text { disagree } & \text { nor disagree } & \text { agree } & \text { Agree } & \text { agree } \\ 0 & 0 & 0 & 0 & 0 & 0 & 0\end{array}$

9) If the information viewed has no added value for the decision-making process, I sometimes still make a decision.

$\begin{array}{ccccccc}\text { Completely } & \text { Slightly } & \text { Neither agree } & \text { Slightly } & \text { Completely } \\ \text { disagree } & \text { Disagree } & \text { disagree } & \text { nor disagree } & \text { agree } & \text { Agree } & \text { agree } \\ 0 & 0 & 0 & 0 & 0 & 0 & 0\end{array}$

10) Instead of searching for information, I rely on my experience and intuition when I know little about the situation, even when there is plenty of time.

$\begin{array}{ccccccc}\text { Completely } & \text { Slightly } & \text { Neither agree } & \text { Slightly } & \text { Completely } \\ \text { disagree } & \text { Disagree } & \begin{array}{c}\text { disagree } \\ \text { nor disagree }\end{array} & \text { agree } & \text { Agree } & \text { agree } \\ 0 & 0 & 0 & 0 & 0 & 0 & 0\end{array}$

11) I always take notes when collecting information and I summarize it.

$\begin{array}{ccccccc}\text { Completely } & \text { Slightly } & \text { Neither agree } & \text { Slightly } & & \text { Completely } \\ \text { disagree } & \text { Disagree } & \text { disagree } & \text { nor disagree } & \text { agree } & \text { Agree } & \text { agree } \\ \circ & \circ & 0 & 0 & 0 & 0 & 0\end{array}$

12) When I make a decision, I always include my previous experiences from similar situations, in addition to new information.

\begin{tabular}{|c|c|c|c|c|c|c|}
\hline $\begin{array}{c}\text { Completely } \\
\text { disagree }\end{array}$ & Disagree & $\begin{array}{l}\text { Slightly } \\
\text { disagree }\end{array}$ & $\begin{array}{c}\text { Neither agree } \\
\text { nor disagree }\end{array}$ & $\begin{array}{l}\text { Slightly } \\
\text { agree }\end{array}$ & Agree & $\begin{array}{c}\text { Completely } \\
\text { agree }\end{array}$ \\
\hline 0 & o & o & 0 & 0 & 0 & 0 \\
\hline
\end{tabular}

13) I think twice about available information before making a decision.

$\begin{array}{ccccccc}\text { Completely } & \text { Slightly } & \text { Neither agree } & \text { Slightly } & \text { Completely } \\ \text { disagree } & \text { Disagree } & \text { disagree } & \text { nor disagree } & \text { agree } & \text { Agree } & \text { agree } \\ \circ & \circ & 0 & 0 & 0 & 0 & 0\end{array}$


14) Even if it can take a lot of time, I still ask for extra information.

$\begin{array}{ccccccc}\text { Completely } & \text { Slightly } & \text { Neither agree } & \text { Slightly } & & \text { Completely } \\ \text { disagree } & \text { Disagree } & \text { disagree } & \text { nor disagree } & \text { agree } & \text { Agree } & \text { agree } \\ 0 & 0 & 0 & 0 & 0 & 0 & 0\end{array}$

15) To make a decision, I use both new information and my own experience.

$\begin{array}{ccccccc}\text { Completely } & \text { Slightly } & \text { Neither agree } & \text { Slightly } & & \text { Completely } \\ \text { disagree } & \text { Disagree } & \text { disagree } & \text { nor disagree } & \text { agree } & \text { Agree } & \text { agree } \\ 0 & 0 & 0 & 0 & 0 & 0 & 0\end{array}$

16) I check whether different sources of information contradict each other.

$\begin{array}{ccccccc}\text { Completely } & \text { Slightly } & \text { Neither agree } & \text { Slightly } & & \text { Completely } \\ \text { disagree } & \text { Disagree } & \text { disagree } & \text { nor disagree } & \text { agree } & \text { Agree } & \text { agree } \\ \circ & 0 & 0 & 0 & 0 & 0 & 0\end{array}$

17) Some sources I never use, even when I know they have knowledge of the situation.

$\begin{array}{ccccccc}\text { Completely } & \text { Slightly } & \text { Neither agree } & \text { Slightly } & & \text { Completely } \\ \text { disagree } & \text { Disagree } & \text { disagree } & \text { nor disagree } & \text { agree } & \text { Agree } & \text { agree } \\ 0 & 0 & 0 & 0 & 0 & 0 & 0\end{array}$

18) If I get information from different sources (Google, newspapers, social media), I know I have to value them differently.

$\begin{array}{ccccccc}\text { Completely } & \text { Slightly } & \text { Neither agree } & \text { Slightly } & & \text { Completely } \\ \text { disagree } & \text { Disagree } & \text { disagree } & \text { nor disagree } & \text { agree } & \text { Agree } & \text { agree } \\ 0 & 0 & 0 & 0 & 0 & 0 & 0\end{array}$

19) Once I have chosen a strategy to gather information, I stick with it, even if I notice that it does not yield good results.

\begin{tabular}{|c|c|c|c|c|c|c|}
\hline $\begin{array}{c}\text { Completely } \\
\text { disagree }\end{array}$ & Disagree & $\begin{array}{l}\text { Slightly } \\
\text { disagree }\end{array}$ & $\begin{array}{c}\text { Neither agree } \\
\text { nor disagree }\end{array}$ & $\begin{array}{l}\text { Slightly } \\
\text { agree }\end{array}$ & Agree & $\begin{array}{c}\text { Completely } \\
\text { agree }\end{array}$ \\
\hline 0 & 0 & 0 & o & o & 0 & o \\
\hline
\end{tabular}

20) I summarize the common meaning of several pieces of information for myself.

$\begin{array}{ccccccc}\text { Completely } & \text { Slightly } & \text { Neither agree } & \text { Slightly } & & \text { Completely } \\ \text { disagree } & \text { Disagree } & \text { disagree } & \text { nor disagree } & \text { agree } & \text { Agree } & \text { agree } \\ 0 & 0 & 0 & 0 & 0 & 0 & 0\end{array}$




\section{APPEndIX 3.C}

Table 3.C.1

BIC values of model candidates for final operationalization

\begin{tabular}{|c|c|c|c|c|c|c|}
\hline $\begin{array}{l}\text { Dilemmas } \\
\text { used }\end{array}$ & Model settin & & $\begin{array}{l}\text { AIC / BIC } \\
\text { Standard 1 }\end{array}$ & $\begin{array}{l}\text { AIC / BIC } \\
\text { Standard } 2\end{array}$ & $\begin{array}{l}\text { AIC / BIC } \\
\text { Standard } 3\end{array}$ & $\begin{array}{l}\text { AIC / BIC } \\
\text { Standard } 4\end{array}$ \\
\hline \multirow{4}{*}{2} & $\begin{array}{l}\text { Classes } \\
\text { Variances } \\
\text { Covariances }\end{array}$ & $\begin{array}{l}3 \\
\text { Equal } \\
\text { Fixed to } 0\end{array}$ & $415.004 / 445.404$ & $393.827 / 424.227^{*}$ & $291.786 / 315.430 *$ & $433.053 / 436.452 *$ \\
\hline & $\begin{array}{l}\text { Classes } \\
\text { Variances } \\
\text { Covariances }\end{array}$ & $\begin{array}{l}3 \\
\text { Equal } \\
\text { Equal }\end{array}$ & $415.192 / 455.725$ & $403.560 / 444.093$ & $289.884 / 318.595$ & $438.618 / 479.151$ \\
\hline & $\begin{array}{l}\text { Classes } \\
\text { Variances } \\
\text { Covariances }\end{array}$ & $\begin{array}{l}4 \\
\text { Equal } \\
\text { Fixed to } 0\end{array}$ & $361.217 / 400.061^{*}$ & 394.559 / 433.403 & 287.896 / 318.295 & $450.158 / 489.002$ \\
\hline & $\begin{array}{l}\text { Classes } \\
\text { Variances } \\
\text { Covariances }\end{array}$ & $\begin{array}{l} \\
\text { Equal } \\
\text { Equal }\end{array}$ & $420.511 / 469.489$ & $381.492 / 430.469$ & $282.886 / 318.352^{*}$ & $455.645 / 504.622$ \\
\hline \multirow{4}{*}{$2-3$} & $\begin{array}{l}\text { Classes } \\
\text { Variances } \\
\text { Covariances }\end{array}$ & $\begin{array}{l}3 \\
\text { Equal } \\
\text { Fixed to } 0\end{array}$ & $419.343 / 449.743^{*}$ & 413.412 / 443.811 & 310.277 / 333.921 & $444.440 / 474.840^{*}$ \\
\hline & $\begin{array}{l}\text { Classes } \\
\text { Variances } \\
\text { Covariances }\end{array}$ & $\begin{array}{l}3 \\
\text { Equal } \\
\text { Equal }\end{array}$ & $424.242 / 464.775$ & $391.635 / 432.168$ & 307.776 / 336.487 & $450.795 / 491.328$ \\
\hline & $\begin{array}{l}\text { Classes } \\
\text { Variances } \\
\text { Covariances }\end{array}$ & $\begin{array}{l}4 \\
\text { Equal } \\
\text { Fixed to } 0\end{array}$ & $427.537 / 466.382$ & $373.965 / 412.809^{*}$ & 304.699 / 335.099* & $449.200 / 488.044$ \\
\hline & $\begin{array}{l}\text { Classes } \\
\text { Variances } \\
\text { Covariances }\end{array}$ & $\begin{array}{l}4 \\
\text { Equal } \\
\text { Equal }\end{array}$ & 423.332 / 472.309 & $394.137 / 443.114$ & $317.194 / 352.661$ & $456.801 / 505.779$ \\
\hline
\end{tabular}


Information literacy

\begin{tabular}{|c|c|c|c|c|c|c|}
\hline $\begin{array}{l}\text { Dilemmas } \\
\text { used }\end{array}$ & Model settir & & $\begin{array}{l}\text { AIC / BIC } \\
\text { Standard } 1\end{array}$ & $\begin{array}{l}\text { AIC / BIC } \\
\text { Standard } 2\end{array}$ & $\begin{array}{l}\text { AIC / BIC } \\
\text { Standard } 3\end{array}$ & $\begin{array}{l}\text { AIC / BIC } \\
\text { Standard } 4\end{array}$ \\
\hline \multirow{4}{*}{$2-4$} & $\begin{array}{l}\text { Classes } \\
\text { Variances } \\
\text { Covariances }\end{array}$ & $\begin{array}{l}3 \\
\text { Equal } \\
\text { Fixed to } 0\end{array}$ & $421.971 / 452.371$ & 363.533 / $393.933^{*}$ & $287.820 / 311.464$ & $440.951 / 471.351^{*}$ \\
\hline & $\begin{array}{l}\text { Classes } \\
\text { Variances } \\
\text { Covariances }\end{array}$ & $\begin{array}{l}3 \\
\text { Equal } \\
\text { Equal }\end{array}$ & $416.991 / 457.524$ & $405.429 / 445.962$ & 339.994 / 368.705 & $437.070 / 477.603$ \\
\hline & $\begin{array}{l}\text { Classes } \\
\text { Variances } \\
\text { Covariances }\end{array}$ & $\begin{array}{l}4 \\
\text { Equal } \\
\text { Fixed to } 0\end{array}$ & 366.346 / 405.191* & $372.188 / 411.032$ & $278.156 / 308.555^{*}$ & $446.696 / 485.540$ \\
\hline & $\begin{array}{l}\text { Classes } \\
\text { Variances } \\
\text { Covariances }\end{array}$ & $\begin{array}{l}4 \\
\text { Equal } \\
\text { Equal }\end{array}$ & $376.211 / 425.188$ & $370.155 / 419.132$ & $294.057 / 329.523$ & $434.292 / 483.269$ \\
\hline \multirow{4}{*}{$2-5$} & $\begin{array}{l}\text { Classes } \\
\text { Variances } \\
\text { Covariances }\end{array}$ & $\begin{array}{l}3 \\
\text { Equal } \\
\text { Fixed to } 0\end{array}$ & $397.808 / 428.208$ & $387.968 / 418.368$ & $281.551 / 305.195$ & $438.322 / 468.722 *$ \\
\hline & $\begin{array}{l}\text { Classes } \\
\text { Variances } \\
\text { Covariances }\end{array}$ & $\begin{array}{l}3 \\
\text { Equal } \\
\text { Equal }\end{array}$ & $399.220 / 439.753$ & $354.468 / 395.001 *$ & 282.986 / 311.697 & $437.355 / 477.888$ \\
\hline & $\begin{array}{l}\text { Classes } \\
\text { Variances } \\
\text { Covariances }\end{array}$ & $\begin{array}{l}4 \\
\text { Equal } \\
\text { Fixed to } 0\end{array}$ & $326.660 / 365.505 *$ & 386.617 / 425.462 & $275.139 / 305.539^{*}$ & $435.568 / 474.412$ \\
\hline & $\begin{array}{l}\text { Classes } \\
\text { Variances } \\
\text { Covariances }\end{array}$ & \begin{tabular}{|l}
4 \\
Equal \\
Equal \\
\end{tabular} & $334.047 / 383.025$ & $351.449 / 400.427$ & $278.359 / 313.826$ & $437.031 / 486.008$ \\
\hline
\end{tabular}


Chapter 3

\begin{tabular}{|c|c|c|c|c|c|c|}
\hline $\begin{array}{l}\text { Dilemmas } \\
\text { used }\end{array}$ & Model setti & & $\begin{array}{l}\text { AIC / BIC } \\
\text { Standard } 1\end{array}$ & $\begin{array}{l}\text { AIC / BIC } \\
\text { Standard } 2\end{array}$ & $\begin{array}{l}\text { AIC / BIC } \\
\text { Standard } 3\end{array}$ & $\begin{array}{l}\text { AIC / BIC } \\
\text { Standard } 4\end{array}$ \\
\hline \multirow{4}{*}{$2-6$} & $\begin{array}{l}\text { Classes } \\
\text { Variances } \\
\text { Covariances }\end{array}$ & $\begin{array}{l}3 \\
\text { Equal } \\
\text { Fixed to } 0\end{array}$ & 418.959 / 449.359 & $385.003 / 415.403$ & $308.863 / 332.507$ & 428.969 / 459.368* \\
\hline & $\begin{array}{l}\text { Classes } \\
\text { Variances } \\
\text { Covariances }\end{array}$ & \begin{tabular}{|l|}
3 \\
Equal \\
Equal
\end{tabular} & $425.632 / 466.165$ & $344.604 / 385.137$ * & $332.206 / 360.917$ & $422.359 / 462.892$ \\
\hline & $\begin{array}{l}\text { Classes } \\
\text { Variances } \\
\text { Covariances }\end{array}$ & $\begin{array}{l}4 \\
\text { Equal } \\
\text { Fixed to } 0\end{array}$ & $392.147 / 430.991^{*}$ & 389.546 / 428.390 & $296.491 / 326.891^{*}$ & 434.808 / 473.652 \\
\hline & $\begin{array}{l}\text { Classes } \\
\text { Variances } \\
\text { Covariances }\end{array}$ & $\begin{array}{l}4 \\
\text { Equal } \\
\text { Equal }\end{array}$ & $397.632 / 446.609$ & $357.533 / 406.511$ & $299.259 / 334.725$ & 419.755 / 468.733 \\
\hline \multirow{4}{*}{$2-7$} & $\begin{array}{l}\text { Classes } \\
\text { Variances } \\
\text { Covariances }\end{array}$ & $\begin{array}{l}3 \\
\text { Equal } \\
\text { Fixed to } 0\end{array}$ & $421.762 / 452.162$ * & $371.279 / 401.679$ & $297.858 / 321.503$ & 425.062 / 455.462 \\
\hline & $\begin{array}{l}\text { Classes } \\
\text { Variances } \\
\text { Covariances }\end{array}$ & $\begin{array}{l}3 \\
\text { Equal } \\
\text { Equal }\end{array}$ & $420.101 / 460.634$ & $375.294 / 415.827$ & $321.101 / 349.812$ & $400.585 / 441.118^{*}$ \\
\hline & $\begin{array}{l}\text { Classes } \\
\text { Variances } \\
\text { Covariances }\end{array}$ & $\begin{array}{l}4 \\
\text { Equal } \\
\text { Fixed to } 0\end{array}$ & 422.366 / 461.210 & 359.147 / 397.991 & $280.343 / 310.743^{*}$ & $413.926 / 452.770$ \\
\hline & $\begin{array}{l}\text { Classes } \\
\text { Variances } \\
\text { Covariances }\end{array}$ & \begin{tabular}{|l|}
4 \\
Equal \\
Equal \\
\end{tabular} & $421.806 / 470.783$ & $334.973 / 383.950$ * & $283.453 / 318.919$ & 398.842 / 447.820 \\
\hline
\end{tabular}

Note. * model used in subsequent analysis. 


\section{4}

\section{Self-reflection}

The effect of self-reflection on information usage and information literacy in a digital serious gam

This chapter is based on:

Steinrücke, J., Veldkamp, B. P., \& de Jong, T. (submitted). The effect of self-reflection on information usage and information literacy in a digital serious game. 


\section{Abstract}

In this study we examined the effect of self-reflection through social comparison, on the information usage and information literacy of players of a digital serious game for training decision-making. An experiment was conducted with two conditions: All participants played two gameplay scenarios in fixed order. Participants in the control condition received no intervention between playing the two scenarios. Participants in the experimental condition, in between the two scenarios, saw a dashboard displaying their own as well as previous players' ingame behavior up to that point. We were able to observe significant betweencondition differences for multiple in-game indicators in the second gameplay scenario and in the change in in-game behavior from the first to second gameplay scenario; these findings were mostly backed up by additionally computed Bayes factors. There were no significant between-condition differences regarding information literacy. Results indicate that in-game behavior can be influenced by letting players self-reflect on their own in-game behavior in comparison to ingame behavior of other players. However, results also suggest that the dashboard should display more specific indicators of the players' in-game behavior, with possible suggestions on what they could improve, rather than simply offering a complete overview of their in-game behavior. 


\section{INTRODUCTION}

In a variety of decision-making situations, it is important for decision-makers to use contextual data as well as their own experience: A purely experience based approach to decision-making could unintentionally be based on biases, therefore leading to suboptimal decisions (Mezey, 2004). In contrast, when decision-makers thoroughly interpret and analyze all data, they can run into issues regarding time. Particularly in quickly developing situations, where decision-makers have only limited time and data, it is critical that they work with this data effectively and efficiently. Since access to more data does not necessarily imply having more or better information (Endsley, 2000), we can argue that in a decision-making context available, raw data (i.e., information) about the situation at hand has to be selected, analyzed, and interpreted by the decision-maker. They have to do this dependent on the context of the situation and put the raw information into perspective using their own experience, so that it becomes useful information (Stonebraker, 2016). Hence in different situations similar pieces of raw information hold different meanings.

A working context where this interplay of data, context and experience is crucial is crisis management decision-making. Crisis situations and therewith the decision-making process can become complex relatively quickly (van der Hulst et al. 2014). Decision-makers must decide in a short time frame, while still considering available data and the characteristics of the situation. This requires decision-makers to be able to combine their own experience with analytical approaches to decision-making, a competency that is effectively indicated as Information Literacy (IL). Described as a multifaceted concept, being information literate is defined being able to recognize the need of (Standard 1), to access information effectively and efficiently (Standard 2), to critically evaluate information and incorporate information into one's own knowledge base (Standard 3 ), and to effectively use information to reach a certain goal (Standard 4; Information Literacy Competency Standards for Higher Education, 2000).

\section{Information literacy training in crisis management practice}

Given the close interaction between information and its context, training IL in practical domains as crisis management decision-making is a complex task to achieve efficiently (see Steinrücke et al., 2020). Training sessions in crisis management decision-making should be realistic, which means that they should be designed similar to real life crisis situations. However, usually much time, effort, and preparation are needed to create realistic situations during training sessions. Veiligheidsregio Twente (VRT; Twente Safety Region), who collaborates with us in this research, is a crisis management organization in the Dutch region 
Twente that is responsible for making (strategic) decisions and coordinating first responders during crisis situations, trains realistic scenarios monthly, exercising the whole crisis management process from first response to solving the situation. In the situations that are trained decisions must be made based on limited information and time and decisions usually cannot be categorized as correct or incorrect. All possible decision options come with advantages and disadvantages. The trainees must weigh off the available information and decision options to reach a justifiable decision. These trainings are concluded by discussion and reflection sessions between observing and trainee staff, to point out where and what can be improved, and to discuss what went particularly well (Veiligheidsregio Twente, 2016). While this experiential learning approach is beneficial (Cesta et al., 2014), it is also complex and nearly unattainable for the complete staff to train on a relatively frequent basis.

\section{Digital serious games for information literacy training}

Digital serious games offer a possible solution to (partly) replace physical training. As Smale (2011) described, serious games are already popular in IL training in an academic library context, often leading to positive outcomes in both learning gains and skill transferability. Furthermore, serious games can mimic realistic scenarios in various contexts (Connolly et al., 2012), one of which is decisionmaking in crisis management (Crichton \& Flin, 2001; Steinrücke et al., 2019). For example, Steinrücke et al. (2020) showed that a serious game, called the Dilemma Game (T-Xchange, 2018), can be used to infer IL skill levels of crisis management decision-makers based on only their in-game behavior. Another example is described in the context of a serious game about decision-making in triage situations by van der Spek et al. (2011), who found a positive effect on verbal knowledge of experts, supporting the potential that serious games offer even for experts. An additional advantage of digital serious games is that they can improve the learning experience for the individual player by adaptively prompting instructional interventions in the game (Cocea \& Weibelzahl, 2007; Lopes \& Bidarra, 2011).

\section{Self-reflection as instructional intervention in serious games}

In their physical trainings, VRT uses post-training discussion and reflection sessions. Also, digital serious games could provide an opportunity for the players to compare their in-game behavior to other players' in-game behavior and to reflect on this. This kind of self-reflection already has been found to increase learning gains in (digital) serious games, based on a meta-analysis with $N=438$ the weighted mean effect size was $d=0.29$ with standard error $S E=0.10$ (Wouters \& van Oostendorp, 2013, 2017). As Truglio-Londrigan and Lewenson (2008) state, in 
a self-reflection it is essential for decision-makers to be thoughtful about their decision-making approaches. Furthermore, self-reflection was also argued to be a valuable tool in goal setting activities, leading to a more targeted and thoughtful approach in post self-reflection learning activities (Travers et al., 2015).

Applied to (digital) serious games this entails, that a self-reflection should trigger players to critically think about and explain their own in-game behavior. Consequently, the players are expected to reevaluate their own behavior, set goals for improvement, and adjust their own behavior, which should improve learning. To achieve this, the self-reflection process can be supported by a dashboard to be shown to the player, which for example displays general in-game behavior of the player compared to other players' in-game behavior. This social comparison could be used as a source of suggestions for improvement, but also to improve engagement, completion rates and some aspects of the players' in-game behavior (Davis et al., 2017; Jivet et al., 2017; Kollöffel \& de Jong, 2016). Last, such dashboards are crucial for critical self-reflection by enhancing the self-judgment process (Michel et al., 2012).

Given that digital serious games already have been proven to be beneficial in a variety of contexts and that discussion and reflection sessions are a crucial part of the training sessions of the crisis managers in VRT, the main goal of this study is to investigate whether a self-reflection moment triggers changes in in-game behavior, and thereby improves learning. The main research question (RQ 1) is: Does a self-reflection cause any change in in-game behavior? Furthermore, as positive effects of self-reflection and social comparison on the learning process are suggested by the previously reviewed literature, as self-reflection is already used in real-life crisis management training, and as digital serious games can be used to infer IL skill levels, we expect the players' IL to increase because of the offered intervention, which leads to the follow-up research question (RQ 2): Does a selfreflection in the Dilemma Game improve IL of the players?

\section{METHOD}

\section{The Dilemma Game}

In the current study, data was collected using the Dilemma Game (T-Xchange, 2018). The Dilemma Game is a digital serious game that can be used to train decision-making in crisis management and to infer the players' IL skill levels (TXchange, 2018). Rather than offering the player questions that can be answered correctly or incorrectly, the Dilemma Game makes use of dilemmas nested in scenarios, thereby shifting the focus away from the decision itself. 
In the game the player has the option to consult several advisors, who can provide (critical) information, which the player can use to take a decision. Hence, the focus lies on the decision-making process, on the actions the player takes to reach a decision and how this process can be improved. Furthermore, the game could provide useful insight into how the player approached the game and scored on different competency scales. For example, van de Ven et al. (2014) used a former version of the Dilemma Game to provide insight into different leadership styles. In a more recent study, Steinrücke et al. (2020) discuss, that the Dilemma Game can be used to train and assess information literacy. The authors found a clear correlation between styles of in-game behavior and performance on specific facets of information literacy.

We used two gameplay scenarios in this study to collect data. Each gameplay scenario consists of four dilemmas. The first scenario, "Drought", was about dealing with a crisis surrounding a prolonged drought period. The second scenario, "Flooding", was about dealing with a crisis surrounding heavy, prolonged rainfalls and its consequences. In each dilemma participants received ten pieces of information from the advisors, five of which had to be actively 'asked' for. That means, that no indicators appeared to show that information is available. Instead, participants had to click on the advisors first, before they knew that a second piece of information from that advisor is available. To give an impression of the games interface, Figure 4.1 displays the main screen of the Dilemma Game as used in this study.

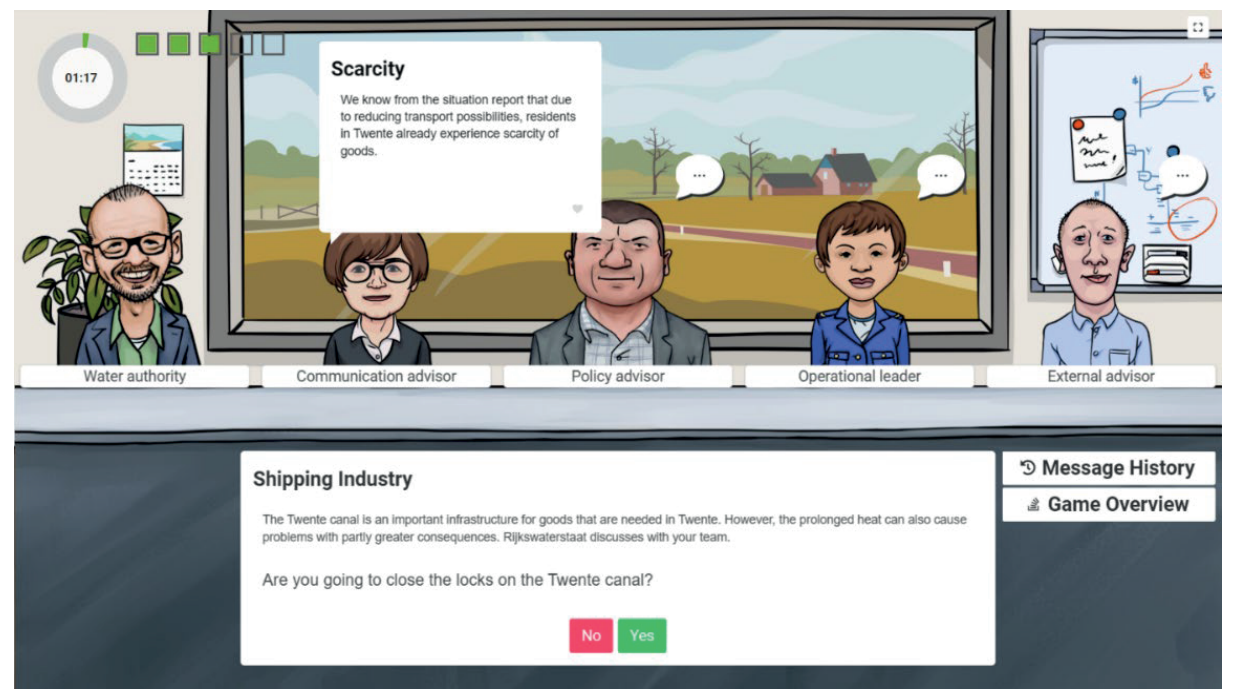

Figure 4.1. Screenshot of Dilemma Game 


\section{Scenario content "Drought"}

As indicated, the gameplay scenario "Drought" consisted of four dilemmas: "Crisis", "Engmelo Marathon", "Shipping Industry" and "Unrest". To accurately exemplify the game, a full text description of the dilemma "Shipping Industry" is given in Appendix 4.A.1.

The first dilemma "Crisis" is about whether it is necessary to raise the official risk level in the region. In doing so, the emergency services would obtain more options to deal with possible problems due to the drought. However, for the civilians that would also come with multiple restrictions and additional guidelines for their everyday life.

The second dilemma "Engmelo Marathon" is about whether the event organizer should be asked to cancel the event beforehand due to the current drought. On the one hand, the marathon is the biggest event of the year in the region, and therefore it is very important to many local businesses. On the other hand, the event is not necessary. Due to the drought, it is important to preserve water, and during a marathon a lot of water is used.

The third dilemma "Shipping Industry" deals with the question whether ships should still be allowed to drive on the local canal. While the local canal is a very important shipping route for many businesses, the water is already too low for ships to drive at full capacity, which might end up damaging the canal.

The fourth dilemma "Unrest" deals with the question how to deal with an announced protest by the local farmers. As the measures taken also restrict the farmers in providing water to some of their crops, they and the locals fear economical damage as well as a lack of locally produced goods. However, not all crops are affected, the measures apply to many more people as well, and the measures are strictly necessary.

\section{Scenario content "Water Nuisance"}

The scenario "Water Nuisance" consisted of four dilemmas as well: "Dike Breach", "Flood", "Emergency Shelter" and "Festival".

The first dilemma "Dike Breach" deals with the question whether the local dikes should be reinforced, given that they might break due to the large amount of water. On the one hand, there is not enough time to reinforce all dikes and the reinforcement should be exercised well, which requires investing a lot of money. On the other hand, being able to prevent a flooding, even if only on certain locations, could help and save many civilians and their belongings.

The second dilemma "Flood" is about whether civilians in the (fictional) village "Dinkelingen" should be evacuated or whether advice is sent out to be careful. 
While evacuating the civilians would keep them safe for sure, extra capacities would still be needed to protect their then empty houses from burglars.

The third dilemma "Emergency Shelter" deals with the question whether the civilians in the (fictional) village "Vechtvelde", which already is partially flooded, should be brought to an emergency shelter. While some fear to get trapped in their houses, the emergency services are already busy trying to solve the situation.

The fourth dilemma "Festival" is about whether a festival in a third village (fictional) "Oldenlutte" should take place or not. With the situation here being less difficult, it theoretically could take place safely. However, the capacities devoted to the festival would be able to help in more troubled regions in case the festival does not take place.

\section{Pre- and posttest measurement instrument}

To measure the intervention effect, we compared in-game behavior from before and after the intervention between the two conditions. Because the first and last dilemma of each scenario also serve to introduce and wrap up the story, we employed the monitored in-game behavior of the second and third dilemma of each gameplay scenario.

\section{In-game behavior}

As stated, we compare in-game behavior from before and after the intervention between the conditions. The Dilemma Game offers to monitor multiple indicators of in-game behavior, which can be used for assessment and analyses purposes. These indicators of in-game behavior describe how players played the game, for example how much information from the advisors they read in each dilemma. We monitored the in-game behavior for each dilemma individually. In Table 4.1, we provide a brief description of the indicator, as well as the label. Furthermore, we differentiate between aggregated and non-aggregated in-game indicators. The indicator Reopened was discarded in further analyses regarding RQ1, because only one participant made use of this functionality.

\section{IL skill level}

To compare the IL skill level from before and after the intervention between the conditions we adapt the unobtrusive assessment models by Steinrücke et al. (2020). In Table 4.2 we display which in-game indicators were used by the authors to assess which IL standard. 
Table 4.1

In-game indicators monitored throughout the game

\begin{tabular}{|c|c|c|}
\hline & Indicator label & Description \\
\hline \multirow{8}{*}{ Aggregated } & InfoCount & Amount of information read \\
\hline & ImpoInf & Amount of information marked as relevant \\
\hline & ResponseTime & Decision time relative to total playtime \\
\hline & StoryTime & Average reading time dilemma introduction story \\
\hline & StoryTimeAfter & $\begin{array}{l}\text { Average reading time dilemma story after } \\
\text { providing answer }\end{array}$ \\
\hline & InfoTime & Average reading time of information per dilemma \\
\hline & AdvNum & Number of advisors consulted \\
\hline & Reopened & Amount of information reopened \\
\hline \multirow{4}{*}{ Non-aggregated } & InfoCount_1 & Amount of 1 st information read \\
\hline & InfoCount_2 & Amount of 2nd information read \\
\hline & InfoTime_1 & Average reading time $1^{\text {st }}$ information per dilemma \\
\hline & Info'Time_2 & Average reading time $2^{\text {nd }}$ information per dilemma \\
\hline
\end{tabular}

Note. Subsequent tables refer to the indicators using the labels in this table.

Table 4.2

In-game indicators used to predict IL skill level

\begin{tabular}{ll}
\hline Standard & In-game indicator \\
\hline Standard 1 & InfoCount_1 \\
& InfoCount_2 \\
& Reopened \\
& AdvNum \\
Standard 2 & InfoCount_2 \\
& InfoTime_2 \\
& ResponseTime \\
& AdvNum \\
Standard 3 & ResponseTime \\
& AdvNum \\
& Reopened \\
Standard 4 & InfoCount_1 \\
& AdvNum \\
& ImpoInf \\
& ResponseTime \\
\hline
\end{tabular}

Note. Adapted from Steinrücke et al. (2020). 


\section{Participants}

In total, 73 professionals participated in this study. Eighteen participants did not complete the serious game and three participants were excluded since they did not follow the guidelines appropriately. Further screening showed that five more participants, four in the control condition and one in the experimental condition, did not fill in their demographic characteristics. That reduced the number of participants to be considered in the data analyses to 47. The control condition included 26 participants and the experimental condition included 21 participants. Participants in this study were professionals working at VRT coming from different backgrounds (i.e., the police, fire department, crisis communication, health care, information management and mental care), who either already work in a higher function or have the perspective to work in a higher function in the (near) future.

The participants mean age was 46.32 years $(\mathrm{SD}=10.04)$. Thirty-nine participants were male (83\%) and eight participants were female (17\%). The participants had 9.62 years $(\mathrm{SD}=8.61)$ experience in the crisis organization on average. Sixteen participants came from the fire department, five from mental care, eight from crisis communication, three from health care, three from information management and twelve from the police. Ten participants were general commandants, two were chief officers, 29 were officers, one was operational leader, two were strategic communication advisors and three had organization specific functions.

\section{Conditions}

Data was collected using an experimental design with two conditions. Participants were randomly assigned to the conditions. Participants in the control condition played a version of the Dilemma Game without being offered a self-reflection phase, participants in the experimental condition were offered a self-reflection phase after completing the first gameplay scenario. In the experimental condition, the self-reflection phase is supported by displaying the in-game behavior of the participant throughout the first gameplay scenario in comparison to other (previous) players' in-game behavior. The previous players in this study were two of our pilot testers, who agreed to participate in a think-aloud protocol. The dashboard is depicted in Figure 2. The data collection took place from September to November 2020. 


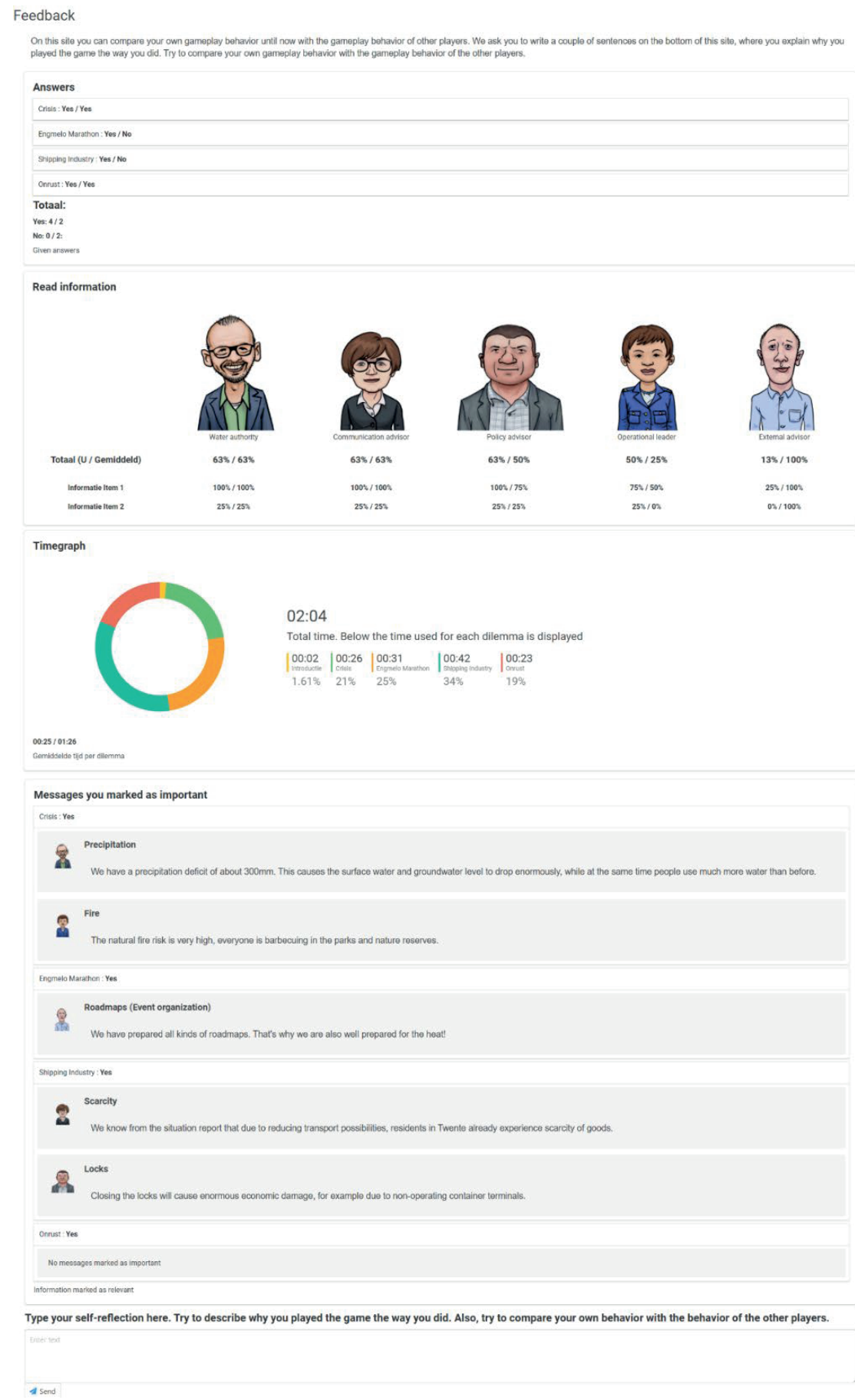

Figure 4.2. Dashboard as used in the experimental condition (translated from Dutch) 


\section{Procedure}

The study was conducted entirely online. First, to familiarize participants with the context of the study and the game to be played, they played through an introductory scenario about the Dilemma Game. Second, the participants provided demographic information and started playing the gameplay scenarios. After completing the first scenario (Drought), participants in the experimental condition were shown the dashboard (see Figure 2). Using this dashboard, the participants were able to gain insight into their own in-game behavior (e.g., amount of information items opened) compared to another person's in-game behavior. After having the opportunity to write a (brief) self-reflection, participants played the second scenario (Water Nuisance). Participants in the control condition were not shown the dashboard, and they were not able to write a brief self-reflection. After completing the final dilemma, all participants were able to provide general feedback on the Dilemma Game, which can be used for future iterations in development. Ethical approval for this research was given by the ethics committee of the University of Twente in May 2020. All participants provided active consent before starting the study. The entire procedure took less than 60 minutes.

\section{Analysis}

To answer RQ1, data was analyzed using multivariate analysis of covariance (MANCOVA), correcting for possible covariates by including the demographic variables in the analyses. By computing the estimated marginal means for condition, between-condition differences were investigated for both gameplay scenarios individually and for the change from the first to the second scenario of the game of the in-game indicators, thereby testing the effect of the instructional intervention. For each indicator we computed the mean values per scenario to be employed in the analyses.

To answer RQ2, we investigated whether the participants were able to increase their IL skill level, employing the unobtrusive assessment models for IL and the corresponding model parameters from Steinrücke et al. (2020), who used latent profile analyses to identify gameplay behavior profiles that are associated with players' IL skill levels. In doing so, we can predict the IL skill level of each participant for each gameplay scenario individually. Here we will perform multivariate multiple linear regression analyses, correcting for possible covariates to investigate the research question.

Given the rather small sample size and that we ran multiple analyses, we performed Bayesian analyses and computed Bayes factors using the brms software package in R (Bürkner, 2017, 2018), which are no subject to multiple testing errors. We computed Bayes factors only for indicators that were significant 
or showed a trend in at least change from first to second gameplay scenario. Bayes factors were computed for the second gameplay scenario and for the change.

To obtain a reliable result for the Bayes factor computations, we computed the Bayes factor 1000 times for each indicator. All Bayes factors compare the marginal likelihood of a model including condition as independent variable (H1) against the marginal likelihood of the same model without condition as independent variables (H0). Bayes factors above one mean that $\mathrm{H} 1$ is more likely than $\mathrm{H} 0$, while Bayes factors below one mean that $\mathrm{H} 0$ is more likely than $\mathrm{H} 1$.

\section{ANALYSIS \& RESULTS}

\section{Effect of self-reflection on in-game behavior (change)}

For the aggregated in-game indicators, as displayed in Table 4.3, no significant between-condition differences were found in the first gameplay scenario. In the second gameplay scenario, we observe that significantly more advisors have been consulted by participants from the experimental condition over participants from the control condition. Further, we see that in the second gameplay scenario participants in the experimental condition read slightly more information than participants in the control condition.

Next, we see that the change of some in-game indicators from the first to second gameplay scenario is significantly bigger in the experimental condition compared to the control condition. This effect is found for both the number of advisors consulted, as well as the number of read information. We also observe a slight between-condition difference for the response time.

With respect to the non-aggregated in-game indicators, as displayed in Table 4.4, we observe that, in the first gameplay scenario, the time spent on reading the second information was significantly longer in the experimental condition than in the control condition. Although the between-condition difference of this indicator was slightly smaller in the second gameplay scenario, it was still noticeable. However, as there was a between-condition difference for this indicator in both gameplay scenarios, this difference is not attributable to the intervention, as confirmed by the non-significant effect in the change from the first to the second gameplay scenario. Only changes in the amount of read first information was attributable to the intervention. We observe a significant between-condition difference in the change from the first to the second gameplay scenario for this indicator.

The full results, including the results of the demographic variables per in-game indicator, are provided in Appendix 4.B.1 and Appendix 4.B.2. 
Table 4.3

Between-condition differences in estimated marginal means of aggregated in-game indicators in the first (Drought) gameplay scenario, second (Water Nuisance) gameplay scenario and over time

\begin{tabular}{|c|c|c|c|c|}
\hline & Indicator & Mean difference (SD) & T-value (df) & p-value \\
\hline \multirow{7}{*}{ Drought } & InfoCount & $0.774(1.069)$ & $0.724(32)$ & 0.474 \\
\hline & ImpoInf & $-0.043(0.055)$ & $-0.772(32)$ & 0.446 \\
\hline & ResponseTime & $-1.301(3.247)$ & $-0.401(32)$ & 0.691 \\
\hline & StoryTime & $0.193(3.675)$ & $0.052(32)$ & 0.959 \\
\hline & StoryTimeAfter & $-0.843(1.106)$ & $-0.762(32)$ & 0.452 \\
\hline & InfoTime & $0.107(0.378)$ & $0.283(32)$ & 0.779 \\
\hline & AdvNum & $0.642(0.643)$ & $0.999(32)$ & 0.325 \\
\hline \multirow{7}{*}{$\begin{array}{l}\text { Water } \\
\text { Nuisance }\end{array}$} & InfoCount & 2.087 (1.037) & $2.012(32)$ & $0.053^{*}$ \\
\hline & ImpoInf & $0.276(0.232)$ & $1.191(32)$ & 0.243 \\
\hline & ResponseTime & $4.041(2.467)$ & $1.638(32)$ & 0.111 \\
\hline & StoryTime & $-0.767(1.700)$ & $-0.451(32)$ & 0.655 \\
\hline & StoryTimeAfter & $-1.074(2.839)$ & $-0.378(32)$ & 0.708 \\
\hline & InfoTime & $0.447(0.343)$ & $1.305(32)$ & 0.201 \\
\hline & AdvNum & $1.484(0.563)$ & $2.634(32)$ & $0.013^{* *}$ \\
\hline \multirow{7}{*}{ Change } & InfoCount & $1.313(0.598)$ & $2.194(32)$ & $0.036^{* *}$ \\
\hline & ImpoInf & $0.319(0.224)$ & $1.421(32)$ & 0.165 \\
\hline & Response'Time & $5.342(2.626)$ & $2.035(32)$ & $0.050^{*}$ \\
\hline & StoryTime & $-0.960(3.944)$ & $-0.243(32)$ & 0.809 \\
\hline & StoryTimeAfter & $-0.231(2.804)$ & $-0.082(32)$ & 0.935 \\
\hline & InfoTime & $0.340(0.399)$ & $0.853(32)$ & 0.400 \\
\hline & AdvNum & $0.841(0.401)$ & $2.098(32)$ & $0.044^{* *}$ \\
\hline
\end{tabular}

Note. ${ }^{*} \mathrm{p}<0.1 ;{ }^{* *} \mathrm{p}<0.05$. 
Table 4.4

Between-condition differences in estimated marginal means of non-aggregated in-game indicators in the first (Drought) gameplay scenario, second (Water Nuisance) gameplay scenario and over time

\begin{tabular}{lllll}
\hline \multirow{4}{*}{ Drought } & Indicator & \multicolumn{1}{c}{ Mean difference (SD) } & T-value (df) & p-value \\
& InfoCount_1 & $0.642(0.642)$ & $0.999(32)$ & 0.325 \\
& InfoCount_2 & $0.132(0.603)$ & $0.219(32)$ & 0.828 \\
& InfoTime_1 & $-0.022(0.400)$ & $-0.055(32)$ & 0.956 \\
& InfoTime_2 & $0.828(0.374)$ & $2.210(32)$ & $0.034^{* *}$ \\
Water & InfoCount_1 & $1.484(0.563)$ & $2.634(32)$ & $0.013^{* *}$ \\
Nuisance & InfoCount_2 & $0.603(0.690)$ & $0.875(32)$ & 0.388 \\
& InfoTime_1 & $0.381(0.355)$ & $1.074(32)$ & 0.291 \\
& InfoTime_2 & $0.579(0.315)$ & $1.837(32)$ & $0.076^{*}$ \\
\hline \multirow{2}{*}{ Change } & InfoCount_1 & $0.841(0.401)$ & $2.098(32)$ & $0.044^{* *}$ \\
& InfoCount_2 & $0.471(0.473)$ & $0.997(32)$ & 0.326 \\
& InfoTime_1 & $0.403(0.398)$ & $1.014(32)$ & 0.318 \\
& InfoTime_2 & $-0.248(0.466)$ & $-0.533(32)$ & 0.598 \\
\hline
\end{tabular}

Note. ${ }^{*} \mathrm{p}<0.1 ; * * \mathrm{p}<0.05$.

\section{Effect of self-reflection on IL skill level}

To predict the IL skill level of each participant for the first and second gameplay scenario, we adapted the model parameters obtained by Steinrücke et al. (2020). We employed data from the second and third dilemma of each gameplay scenario for skill level prediction of the in the original study operationalized IL standards. Further, for each participant we computed the change in their skill level from the first to the second gameplay scenario.

In both gameplay scenarios no significant difference between the conditions can be found for each of the four IL standards, only a trend in favor of the experimental condition can be observed in the second gameplay scenario for IL Standard 2. Regarding the change in skill level from the first to second gameplay scenario, also no significant between-condition differences were found. The results are displayed in Table 4.5 .

A further inspection of the data revealed, that only nine, twelve, two and two participants changed their IL skill level from the first to second gameplay scenario for Standard 1, Standard 2, Standard 3 and Standard 4 respectively (see Table 4.6). As this happened in both directions, this explains why no significant results were found. 
Table 4.5

Between-condition difference of IL skill levels in the first (Drought) gameplay scenario, second (Water Nuisance) gameplay scenario and over time

\begin{tabular}{lllll}
\hline & IL Standard & Estimate (SD) & T-value (df) & p-value \\
\hline \multirow{2}{*}{ Drought } & 1 & $-0.112(0.225)$ & $-0.499(32)$ & 0.621 \\
& 2 & $0.393(0.281)$ & $1.399(32)$ & 0.172 \\
& 4 & $0.102(0.204)$ & $0.501(32)$ & 0.620 \\
\hline \multirow{2}{*}{ Water } & 1 & $0.051(0.102)$ & $0.501(32)$ & 0.620 \\
Nuisance & 3 & $0.138(0.240)$ & $0.575(32)$ & 0.569 \\
& 4 & $0.478(0.237)$ & $2.020(32)$ & $0.052^{*}$ \\
\hline \multirow{2}{*}{ Change } & 1 & $0.237(0.193)$ & $1.228(32)$ & 0.229 \\
& 2 & $0.119(0.097)$ & $1.228(32)$ & 0.229 \\
\hline & 4 & $0.250(0.194)$ & $1.287(32)$ & 0.218 \\
& 4 & $0.085(0.197)$ & $0.433(32)$ & 0.636 \\
& & $0.135(0.144)$ & $0.941(32)$ & 0.354 \\
\hline
\end{tabular}

Note. ${ }^{*} \mathrm{p}<0.1$.

Table 4.6

Change matrix per condition and per IL standard

\begin{tabular}{lcccccc}
\hline \multirow{2}{*}{$\begin{array}{l}\text { IL } \\
\text { Standard }\end{array}$} & \multicolumn{4}{c}{$\begin{array}{c}\text { Experimental } \\
\text { Control condition }\end{array}$} & \multicolumn{2}{c}{ Total } \\
\cline { 2 - 7 } & $\begin{array}{c}\text { Positive } \\
\text { change }\end{array}$ & $\begin{array}{c}\text { Negative } \\
\text { change }\end{array}$ & $\begin{array}{c}\text { Positive } \\
\text { change }\end{array}$ & $\begin{array}{c}\text { Negative } \\
\text { change }\end{array}$ & $\begin{array}{c}\text { Positive } \\
\text { change }\end{array}$ & $\begin{array}{c}\text { Negative } \\
\text { hange }\end{array}$ \\
\hline 1 & 1 & 2 & 2 & 4 & 3 & 6 \\
2 & 1 & 3 & 4 & 4 & 5 & 7 \\
3 & 1 & 1 & 0 & 0 & 1 & 1 \\
4 & 1 & 1 & 0 & 0 & 1 & 1 \\
\hline
\end{tabular}

\section{Bayesian analyses}

Following the guidelines described by Kass and Raftery (1995) the respective Bayes factors of the significant effects found in the second gameplay scenario provide strong evidence for a between-condition effect. The number of consulted advisors was found to have positive evidence only, as opposed to the strong evidence found for response time and amount of information read. With respect to the non-aggregated in-game indicators we found strong evidence for the first information read in the second gameplay scenario and positive evidence for the 
change from the first to the second gameplay scenario. The results of the Bayesian analyses are provided in Table 4.7.

As we only observed a trend for one between-condition difference for the IL skill levels and no significant between-condition effect in change from the first to the second gameplay scenario, we also computed the Bayes factor for IL Standard 2. With a mean Bayes factor of 0.043 and a standard deviation smaller than 0.001 , we found no evidence speaking for a between-condition effect in neither direction.

Table 4.7

Bayes factors of aggregated and non-aggregated indicators

\begin{tabular}{llll}
\hline & Indicator & Bayes factor & SD of Bayes factor \\
\hline \multirow{3}{*}{ Water Nuisance } & InfoCount & 19.130 & 0.346 \\
& ResponseTime & 23.153 & 0.395 \\
& AdvNum & 34.345 & 0.639 \\
& InfoCount_1 & 35.216 & 0.709 \\
\hline \multirow{2}{*}{ Change } & InfoCount & 14.704 & 0.271 \\
& ResponseTime & 49.230 & 0.169 \\
& AdvNum & 8.232 & 0.162 \\
\hline
\end{tabular}

\section{DISCUSSION}

This study aimed to investigate the effect of a self-reflection moment, which utilized social comparison, on the in-game behavior in a digital serious game for decision-making training (RQ1) and on the IL of the player (RQ2). We expected participants in the experimental condition to change their in-game behavior after the self-reflection, as well as the same group of participants to increase their IL in the second gameplay scenario as compared to the first gameplay scenario. Data was analyzed using MANCOVA (RQ1) and multivariate multiple linear regression analyses (RQ2).

\section{Effect of self-reflection on in-game behavior}

First, we examined the effect of self-reflection on the in-game behavior of the participants. We found that participants in the experimental condition consulted more advisors and read more information items in the second gameplay scenario, as compared to participants in the control condition. Furthermore, we observed that the change from the first gameplay scenario to the second gameplay scenario was bigger for participants in the experimental condition. Also, we observe a 
slightly bigger increase in response time relative to total playtime in the experimental condition, which could indicate that participants engage more critically with the information offered.

The Bayes factor analyses widely confirmed the significant results obtained using MANCOVA for the aggregated indicators and non-aggregated indicators. However, we also see that with respect to the change from first to second gameplay scenario, only positive evidence for a between-condition effect was found, which shows that the between-condition effect is not as big as the main analyses might suggest. As shown in Appendix 4.B.1 and Appendix 4.B.2, some demographic characteristics had a significant influence on some in-game indicators. Here a further, more detailed investigation is needed to evaluate possible structural differences that can explain these results.

\section{Effect of self-reflection on IL skill level}

To predict the IL skill level of the player, we also had to derive how often players reopened an information item they already read. However, since only one player reopened an information item in each scenario, we chose not to include it for further analyses regarding RQ1. As the parameters used to predict the IL skill level were obtained using a relatively small sample and a different scenario (in terms of storyline; Steinrücke et al., 2020), the obtained results in terms of IL skill level have to be interpreted with caution. We observed a trend of between-condition difference in the second gameplay scenario for the skill level of IL standard 2, indicating that participants in the experimental condition might have reached a higher IL skill level more often than participants in the control condition. However, the Bayesian analyses revealed that this trend is not generalizable.

The effects of the intervention on the IL skill level and the change in IL skill level should be suspect for further evaluation in a larger sample study, in which a more targeted intervention to promote change in specific in-game behavior indicators associated with the IL standards should be used. This more targeted intervention could also influence the actual IL skill level of the participants, as the participants attention is guided towards specific points of improvement. However, this could also trigger a temporal change only, as the participants in the experimental condition experienced the dashboard only once. To trigger long lasting effects of the selfreflection, it would also be valuable to investigate what happens if the participants are exposed to the intervention more often and over an extended time frame.

\section{Dashboard and game design}

As hinted in the previous section, this study comes with limitations regarding the dashboard that was used as intervention. The dashboard provides a vast overview of in-game behavior, partly in comparison the other players' in-game behavior. 
Displaying all this information could lead to the players not knowing what to focus on. Adapting the displayed information depending on, for example, the IL performance could make the dashboard more effective, by specifically targeting in-game behavior associated with the to be improved skill (Sansom et al., 2020).

As the dashboard was the same for all participants in the experimental condition, we cannot draw specific conclusions whether the displayed behavior being worse or better than the behavior of the current players influences the direction and size of the effect. This could be tackled by testing a more adaptive version of the dashboard, that uses the data of high or low IL players for comparison. By adaptively displaying the respective data, we could investigate whether there are differences based on what data is shown to the participants using a threecondition experimental design, where the control condition again has no dashboard and the two experimental conditions adaptively displays behavior of higher and lower IL players, respectively.

We also noticed that certain options in the game, like reopening an information item, were barely used by the players. While the functionality was given, it was rather complex to use, calling for a slight redesign of the games interface for training purposes in crisis management decision-making. Usually, decisionmakers can take notes or ask the advisors again, allowing decision-makers to read information multiple times. To overcome this issue, the game could be redesigned, such the message history functionality (see Figure 1) is extended by displaying the list of read information continuously. Additionally, a future version of the dashboard could also display if and how often information has been reopened.

\section{Data collection}

As many studies conducted in 2020 and 2021, the experiment was conducted under the conditions of the COVID-19 pandemic. This posed several challenges. Apart from not being able to collect the data in person, it is important to stress that our participants are professionals working for crisis management organizations. Many (prospective) participants were involved in handling the local challenges the pandemic caused. Therefore, participants who joined might not have been able to fully focus on the study. We had to exclude 21 participants who were either not able to finish or who did not follow instructions correctly. Five more participants partly missed to provide demographic characteristics. Furthermore, participants were not able to, or just did not, ask questions about the study in general. Although we offered different contact details, we barely received questions. In a real in-person setting, participants would just have asked in case they needed help with the study. These were issues, that we would not have had if we would have been able to collect the data in person. Furthermore, four participants completed the game, but did not read any information in the first 
gameplay scenario. We also checked the results excluding these people, which did not affect any of the effects found in the main analyses.

In genuine training practice, a finalized serious game would be used during official working hours, and on their working locations. Although participants could do that in our case, many participated after their official working hours, which might have affected the results. Given the combination of the online data collection, the continuous involvement of our target group in the current crisis and the not entirely accurate setting compared to how a finalized serious game would be used, we can argue that the results of our study may have underestimated the true effect of the intervention on the in-game behavior.

\section{Follow-up}

As already suggested, in follow-up research different topics can be explored. Next to exploring a more adaptive and specific dashboard and measuring IL through additional means, follow-up research could also investigate whether the time players take to self-reflect and compare with previous players effects in-game behavior change. Further, if players were encouraged to actively write a reflective text about their own in-game behavior, in comparison to other players, this could be employed to investigate whether the quality of the self-reflection effects the degree of in-game behavior change. Although it was also possible in the current study, participants barely engaged in this activity. However, we should refrain from making this activity mandatory, as that could result in a lack of motivation to seriously engage in the second gameplay scenario. In contrast, when participants were encouraged to engage in writing a self-reflection, and choose to do so from a self-authored, autonomous perspective, that might enhance their engagement and performance (Ryan \& Deci, 2000).

Most of the obtained significant results were further backed up by additional Bayesian analyses. Knowing that some of the computed Bayes factors were rather small, we acknowledge that the study would have benefitted from larger sample sizes. However, as even small changes can be good changes, it might be interesting to investigate the effects of repeated playing, with more different gameplay scenarios, and therefore repeated exposures to the dashboard, on the players' in-game behavior. Last, the results of this study can be used to further develop and research digital serious games for decision-making training, especially eyeing at dashboard-based interventions, with the goal to improve the players' IL through playing these games. 


\section{REFERENCES}

Bürkner P. C. (2017). brms: An R package for Bayesian multilevel models using Stan. Journal of Statistical Software, 80, 1-28. https://doi.org/10.18637/jss.v080.i01

Bürkner P. C. (2018). Advanced Bayesian multilevel modeling with the $\mathrm{R}$ package brms. The R Journal. 10, 395-411. https://doi.org/10.32614/RJ-2018-017

Cesta, A., Cortellessa, G., \& De Benedictis, R. (2014). Training for crisis decision making - An approach based on plan adaptation. Knowledge-Based Systems, 58, 98-112. https://doi.org/10.1016/j.knosys.2013.11.011

Cocea, M., \& Weibelzahl, S. (2007). Eliciting motivation knowledge from log files towards motivation diagnosis for adaptive systems. In C. Conati, K. McCoy, \& G. Paliouras (Eds.), User modeling 2007 (pp. 197-206). Springer. https://doi.org/10.1007/978-3540-73078-1_23

Connolly, T. M., Boyle, E. A., MacArthur, E., Hainey, T. \& Boyle, J. M. (2012). A systematic literature review of empirical evidence on computer games and serious games. Computers \& Education, 59, 661 - 686.

Crichton, M. T. \& Flin, R. (2001). Training for emergency management: Tactical decision games. Journal of Hazardous Materials, 88(2), 255 - 266.

Davis, D., Jivet, I., Kizilcec, R. F., Chen, G., Hauff, C., \& Houben, G.-J. (2017). Follow the successful crowd: Raising MOOC completion rates through social comparison at scale. Proceedings of the Seventh International Learning Analytics \& Knowledge Conference. https://doi.org/10.1145/3027385.3027411

Endsley, M. R. (2000). Theoretical underpinnings of situation awareness: A critical review. In M. R. Endsley \& D. J. Garland (Eds.), Situation awareness analysis and measurement (pp. 3-32). Lawrence Erlbaum Associates.

Information Literacy Competency Standards for Higher Education. (2000). https://alair.ala.org/bitstream/handle/11213/7668/ACRL\%20Information\%20Liter acy\%20Competency\%20Standards\%20for\%20Higher\%20Education.pdf

Jivet, I., Scheffel, M., Drachsler, H. \& Specht, M. (2017). Awareness is not enough: Pitfalls of learning analytics dashboards in the educational practice. In É. Lavoué, H. Drachsler, K. Verbert, J. Broisin, \& M. Pérez-Sanagustín (Eds.), Lecture notes in computer science: Vol. 10474. Data driven approaches in digital education (pp. 8296). Springer. https://doi.org/10.1007/978-3-319-66610-5_7

Kass, R. E., \& Raftery, A. E. (1995). Bayes factors. Journal of the American Statistical Association, 90, 773-795. https://doi.org/10.1080/01621459.1995.10476572

Kollöffel, B., \& de Jong, T. (2016). Can information about peers' performance boost knowledge acquisition? Contrasting criterion-based and social comparison feedback. Interactive Learning Environments, 24, 1428-1438. https://doi.org/10.1080/10494820.2015.1016535

Lopes, R., \& Bidarra, R. (2011). Adaptivity challenges in games and simulations: A survey. IEEE Transactions on Computational Intelligence and AI in Games, 3, 85-99. https://doi.org/10.1109/TCIAIG.2011.2152841. 
Mezey, G. (2004). Crisis management decision making. AARMS, 3, 267-288.

Michel, C., Lavoué, E. \& Pietrac, L. (2012). A dashboard to regulate project-based learning. In A. Ravenscroft, S. Lindstaedt, C. D. Kloos, \& D. Hernández-Leo, Lecture notes in computer science: Vol 7563 (pp. 250-263). Springer. https://doi.org/10.1007/9783-642-33263-0_20

Ryan, R. M., \& Deci, E. L. (2000). Self-determination theory and the facilitation of intrinsic motivation, social development, and well-being. American Psychologist, 55(1), 68-78. https://doi.org/10.1037//0003-066x.55.1.68

Sansom, R. L., Bodily, R., Bates, C. O., \& Leary, H. (2020). Increasing student use of a learner dashboard. Journal of Science Education and Technology, 29(3), 386-398. https://doi.org/10.1007/s10956-020-09824-w

Smale, M. A. (2011). Learning through quests and contests: Games in information literacy instruction. Journal of Library Innovation, 2(2), 36-55.

Steinrücke, J., Veldkamp, B. P., \& de Jong, T. (2019). Determining the effect of stress on analytical skills performance in digital decision games towards an unobtrusive measure of experienced stress in gameplay scenarios. Computers in Human Behavior, 99, 144-155. https://doi.org/10.1016/j.chb.2019.05.014

Steinrücke, J., Veldkamp, B. P., \& de Jong, T. (2020). Information literacy skills assessment in digital crisis management training for the safety domain: Developing an unobtrusive method. Frontiers in Education, 5. https://doi.org/10.3389/feduc.2020.00140

Stonebraker, I. (2016). Toward informed leadership: Teaching students to make better decisions using information. Journal of Business \& Finance Librarianship, 21, 229-238. https://doi.org/10.1080/08963568.2016.1226614

Travers, C. J., Morisano, D., \& Locke, E. A. (2015). Self-reflection, growth goals, and academic outcomes: A qualitative study. British Journal of Educational Psychology, 85, 224-241. https://doi.org/https://doi.org/10.1111/bjep.12059

Truglio-Londrigan, M., \& Lewenson, S. B. (2008). Know yourself: Reflective decisionmaking. In S. B. Lewenson, \& M. Truglio- Londrigan (Eds.), Decision-making in nursing: Thoughtful approaches for practice (pp. 1-11). Jones and Bartlett.

T-Xchange. (2018, December 03). Dilemma. https://www.txchange.nl/dilemma/

van der Hulst, A. H., Muller, T. J., Buiel, E., Gelooven, D. V., \& Ruijsendaal, M. (2014). Serious gaming for complex decision making: Training approaches. International Journal of Technology Enhanced Learning, 6, 249-264. https://doi.org/10.1504/IJTEL.2014.068364

van der Spek, E. D., Wouters, P., \& van Oostendorp, H. (2011). Code red: Triage or cognition-based design rules enhancing decisionmaking training in a game environment. British Journal of Educational Technology, 42, 441-455. https://doi.org/10.1111/j.1467-8535.2009.01021.x 
van de Ven, J. G. M., Stubbé, H. \& Hrehovcsik, M. (2014). Gaming for policy makers: It's serious! In A. De Gloria (Eds.), Games and learning alliance: Second international conference, GALA 2013 (pp. 376-382). Springer. https://doi.org/10.1007/978-3-31912157-4_32

Veiligheidsregio Twente. (2016). Regionaal Crisisplan Veiligheidsregio Twente - Deel 1. http://www.vrtwente.nl/media/227908/regionaal-crisisplan-veiligheidsregiotwente-deel-1.pdf

Wouters, P., \& van Oostendorp, H. (2013). A meta-analytic review of the role of instructional support in game-based learning. Computers \& Education, 60(1), 412-425. https://doi.org/10.1016/j.compedu.2012.07.018

Wouters, P., \& van Oostendorp, H. (2017). Overview of instructional techniques to facilitate learning and motivation of serious games. In P. Wouters, \& H. van Oostendorp (Eds.), Instructional techniques to facilitate learning and motivation of serious games (pp. 1-16). Springer. https://doi.org/10.1007/978-3-319-39298-1_1 


\section{APPENDIX 4.A}

Table 4.A.1

Example dilemma translated from Dutch to English

$\begin{array}{ll}\begin{array}{l}\text { Dilemma Text } \\ \text { "Shipping Industry" }\end{array} & \begin{array}{l}\text { The Twente canal is an important } \\ \text { infrastructure for goods that are needed in } \\ \text { Twente. However, the prolonged heat can also } \\ \text { cause problems with partly greater } \\ \text { consequences. Rijkswaterstaat discusses with } \\ \text { your team. }\end{array} \\ & \begin{array}{l}\text { Are you going to close the locks on the Twente } \\ \text { canal? }\end{array}\end{array}$

Water authority (WS) 1. The water level in the canal is $40 \mathrm{~cm}$ lower than normal, shipping should be stopped to prevent damage to the waterways.

2. The water in the canal is urgently needed for the farmers and production companies in the region.

Strategic communications advisor (SC)

Policy advisor (BA)

Information item
1. We know from the situation report that due to reducing transport possibilities, residents in Twente already experience scarcity of goods.

2. It also shows that some companies fear scarcity.

1. Closing the locks will cause enormous economic damage, for example due to nonoperating container terminals.

2. Many companies cannot continue to produce if they do not receive goods through the canal, a similar situation we already had in Deventer.

Operational leader (OL)

1. Some gas stations already have problems getting enough fuel, most of which is supplied via the canal.

2. Alternatives for transport by road are hardly available.

External advisor (EA) 1. A decrease in shipping will lead to an increase in freight traffic on the roads.

2. The drought has a harmful effect on the locks, we should use them as little as possible. 


\section{APPENDIX 4.B}

Table 4.B.1

MANOVA results aggregated variables.

\begin{tabular}{llccc}
\hline Variable & F-value & $\begin{array}{c}\text { Degrees of Freedom } \\
\text { (num df, den df) }\end{array}$ & p-value \\
\hline \multirow{2}{*}{ Drought } & Gender & 1.550 & 7,26 & 0.195 \\
& Organization & 0.935 & 35,150 & 0.578 \\
& Function & 1.040 & 35,150 & 0.420 \\
& Age & 0.980 & 7,26 & 0.467 \\
& Experience & 0.700 & 7,26 & 0.672 \\
Water & Condition & 1.351 & 7,26 & 0.267 \\
\hline \multirow{2}{*}{ Nuisance } & Gender & 1.455 & 7,26 & 0.227 \\
& Frganization & 0.669 & 35,150 & 0.918 \\
& Function & 0.714 & 35,150 & 0.878 \\
& Experience & 0.715 & 7,26 & 0.190 \\
& Condition & 1.401 & 7,26 & 0.660 \\
\hline \multirow{6}{*}{ Change } & Gender & 3.038 & 7,26 & 0.247 \\
\hline & Organization & 0.882 & 7,26 & $0.018^{* *}$ \\
& Function & 0.667 & 35,150 & 0.659 \\
& Age & 0.326 & 35,150 & 0.919 \\
& Experience & 0.549 & 7,26 & 0.935 \\
& Condition & 1.174 & 7,26 & 0.789 \\
\hline
\end{tabular}

Note. $* * \mathrm{p}<0.05$. 
Table 4.B.2

MANOVA results non-aggregated variables.

\begin{tabular}{|c|c|c|c|c|}
\hline & Variable & F-value & $\begin{array}{l}\text { Degrees of Freedom } \\
\text { (num df, den df) }\end{array}$ & p-value \\
\hline \multirow{6}{*}{ Drought } & Gender & 3.068 & 4,29 & $0.032^{* * *}$ \\
\hline & Organization & 1.646 & 20,128 & $0.052^{*}$ \\
\hline & Function & 0.397 & 20,128 & 0.990 \\
\hline & Gender & 0.556 & 4,29 & 0.696 \\
\hline & Experience & 1.025 & 4,29 & 0.411 \\
\hline & Condition & 1.377 & 4,29 & 0.266 \\
\hline \multirow{6}{*}{$\begin{array}{l}\text { Water } \\
\text { Nuisance }\end{array}$} & Gender & 0.213 & 4,29 & 0.929 \\
\hline & Organization & 1.057 & 20,128 & 0.403 \\
\hline & Function & 0.943 & 20,128 & 0.534 \\
\hline & Age & 1.678 & 4,29 & 0.182 \\
\hline & Experience & 1.384 & 4,29 & 0.264 \\
\hline & Condition & 2.341 & 4,29 & $0.079^{*}$ \\
\hline \multirow{6}{*}{ Change } & Gender & 3.623 & 4,29 & $0.016^{* * *}$ \\
\hline & Organization & 1.272 & 20,128 & 0.210 \\
\hline & Function & 0.603 & 20,128 & 0.905 \\
\hline & Age & 0.413 & 4,29 & 0.798 \\
\hline & Experience & 0.310 & 4,29 & 0.869 \\
\hline & Condition & 2.096 & 4,29 & 0.107 \\
\hline
\end{tabular}

Note. ${ }^{*} \mathrm{p}<0.1 ; * * \mathrm{p}<0.05$. 


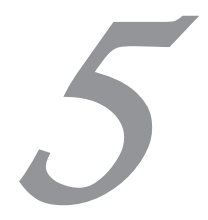

General discussion 


\section{INTRODUCTION}

All studies in this dissertation were conducted in the context of digital game-based learning (DGBL) and crisis management decision-making, as we were working closely together with Veiligheidsregio Twente (VRT; Twente Safety Region), with the goal to develop theory and practices to being able to introduce adaptivity in DGBL environments. In this final chapter we discuss the most important results, conclusions, lessons learned, as well as implications for possible future research based on the three conducted studies.

\section{DISCUSSION OF THE CONDUCTED STUDIES}

In this dissertation, in total three studies were conducted. In all studies, we used different versions of the Mayor Game and the Dilemma Game, which is a further developed version of the Mayor Game. The Mayor (or Dilemma) Game is a serious game, which originally was used by Dutch mayors to train handling crisis situations by answering dilemmas. A key characteristic of the Mayor Game is, that the decisions that can be made are neither correct nor incorrect. For supporting the players decision-making, they can consult different advisors for additional information about the crisis situation (T-Xchange, 2020; van de Ven et al., 2014).

In the following paragraphs, we describe the conducted studies in more detail. Two of these studies investigated unobtrusive ways of assessing important competencies in decision-making, and one study investigated the effect of an instructional intervention.

\section{Approaches to unobtrusive assessment}

\section{Study 1}

At VRT, analytical skills and stress resistance are considered as the two most important competencies in crisis management: Crisis managers have to be able to accurately interpret information, even in stressful situations. To investigate the effect of induced stress on analytical skills in a digital serious game, we conducted an experiment using two versions of the Mayor Game: one paced version to induce stress and one non-paced version. Next to investigating the effect of induced stress on analytical skills, this study aimed to develop an unobtrusive assessment method of experienced stress, by utilizing in-game behavior to predict physiological stress responses like galvanic skin response or heart rate variability, which are widely used to assess experienced stress (Holmgård et al., 2015) and scores on two independent experienced arousal scales: Affect Grid (AG; Russell et al., 1989) and Perceived Arousal Scale (PAS; Anderson, 1995; Anderson et al., 
1995). Although not the target population of this research project, the sample in this study consisted of in total 80 students from the University of Twente. From these 80 participants, twelve were not able to complete the experiment within the available time. Results showed that participants in the paced (the assumed most stressful) condition tended towards following a more intuitive and less accurate decision-making strategy as compared to participants in the non-paced condition, which resulted in a drop in analytical skills performance.

Despite the fact that we saw behavioral differences between the two conditions, only three out of eleven measured physiological features showed (significant) differences between the conditions: The difference between the maximum and minimum skin conductance was significantly bigger, and the maximum skin conductance throughout the gameplay was significantly higher in the paced condition. We found a trend for the minimum skin conductance of the participants, which was lower in the paced condition. In addition, no self-report measures differed between the conditions. Therefore, we could raise the question whether the intervention created only time pressure, rather than actual stress, causing the drop in performance.

Furthermore, out of the five indicators of in-game behavior that we tested (i.e., within-person variance of ability, average time an information item was kept open and its within-person variance, and per dilemma count of opened information items and its within-person variance), only the average time an information item was kept open was related to the participants initial skin conductance and the last measurement of heart rate. Regarding the self-reports, only the average of the per dilemma count of opened information and its within-person variance was significantly correlated to the AG scores, the latter showing a trend in respect to the PAS scores. However, given that a significant relationship was found with only two out of 11 physiological measures, we did not obtain sufficient evidence to use in-game behavior as an unobtrusive measure of experienced stress.

In summary, since we took a top-down approach to unobtrusive assessment, where we based our indicators of experienced stress and the way they are expected to be related to experienced stress on existing literature, we were not able to catch (more complex) relationships between in-game behavior and experienced stress. While this top-down approach is theory-based and, if successful, could be assumed to be valid, it lacks flexibility. To overcome this issue, we could take a bottom-up approach to unobtrusive assessment, where we can employ more log-data and more sophisticated tools of analyses, thereby taking a more exploratory angle to find differences and relationships in the data.

\section{Study 2}

In the previous study, we measured analytical skills, such as finding and evaluating information and its sources, of in a serious game in a straightforward, 
not unobtrusive manner. This skillset that VRT describes as analytical skills, is well described by the concept of information literacy (IL), which the Information Literacy Competency Standards for Higher Education (2000) define as a multifaceted competency of being able to recognize the need of information (Standard 1), being able to locate and access information (Standard 2), to evaluate information and its sources (Standard 3), to interpret and use the information (Standard 4) and to understand economic, legal, and social issues surrounding the use of information (Standard 5). Therefore, in our second study, we aimed to develop an unobtrusive assessment method to measure information literacy (IL) in a digital serious game.

Apart from Standard 5, which cannot be associated with measurable in-game behavior, all standards were operationalized in the Dilemma Game (an updated version of the Mayor Game), which we employed in this study. Like in decisionmaking processes in real crisis management situations, in the Dilemma Game it is crucial for the players to find and use available in-game information effectively and correctly, following the idea that more data does not necessarily mean more information, and in turn that more information does not automatically lead to better decisions (Stonebraker, 2016). The initial sample in this study consisted of 48 professionals working at VRT, due to missing data and violations of the study protocol the sample size for the analysis was reduced to 40 .

Using latent profile analyses (LPA) in a bottom-up analysis, unobtrusive assessment models for IL standards 1 to 4 were generated, identifying three (standards 1 and 4), respectively four (standards 2 and 3), skill levels for each operationalized standard. That means that, for example, with respect to IL standard 1 the unobtrusive assessment model can classify players in one out of three skill levels describing the players' in-game IL performance based on their in-game behavior. For validation, these models were correlated to the participants scores on a self-report measure of IL. As result, the unobtrusive assessment models for standards 1, 2 and 3 were found to perform well. However, our analyses did not result in an appropriate unobtrusive assessment model for Standard 4. Given the definition of the individual standards, this result is not entirely surprising: Standard 1, Standard 2, and Standard 3 all are about acquiring information, which is what the participants did in the game. In contrast, Standard 4 is about using the already acquired information for a specific purpose, which is more difficult to measure using the logged in-game indicators. Last, we computed correlations between class memberships of participants for the unobtrusively assessed standards. Results showed that IL class memberships of Standard 3 correlated negatively with the other standards, which is contradictory to the correlations found using the questionnaire data, where all standards were positively intercorrelated. Considering the large overlap of IL scores for Standard 
3, see Table 3.5, we should continue searching for a more discriminative in-game indicator, which is able to capture smaller differences in IL scores.

Therefore, we concluded that the unobtrusive assessment models for Standard 1 and Standard 2 are well performing and supported by all our conducted analyses, while the unobtrusive assessment models of standards 3 and 4 were less performant. Last, because the employed self-report of IL is not yet validated in a large-scale study, the results of this study should only be interpreted as a wellfunctioning starting point.

Combining Study 1 and Study 2 - Top-down approaches vs. bottom-up approaches

A major distinction and choice for the design of an unobtrusive assessment is whether it should be approached top-down (i.e., more confirmatory like in Study 1) or bottom-up (i.e., more exploratory like in Study 2). In a top-down approach, possible evidence to measure a skill would be chosen based on theory and the way the interactions a player can make are related to this theory. In a bottom-up approach, the idea is to search for correlations, relationships and patterns in the data that can be used to explain the (via an external instrument) measured skill, for example by using machine learning methods. While bottom-up approaches are more flexible and capable of finding accurate models and are less time consuming for the researcher in terms of assigning in-game behavior to performance, these models need to be tested using external measures regarding their convergent validity (i.e., to measures that are supposed to measure the same are highly correlated). Consequently, top-down approaches lead to better models in terms of interpretability, while bottom-up approaches lead to more flexible and possibly more accurate models (Hothorn, 2018).

In Study 1 (Chapter 2) we aimed to unobtrusively assess experienced stress during a gameplay scenario using a top-down approach to assessment with rather simple regression analyses. Using this top-down approach, the conducted analyses did not result in consistent findings about unobtrusively assessing experienced stress. As already mentioned in the respective discussion, more extensive analyses, also considering bottom-up approaches, should be conducted to overcome this issue and catch more (complex) relationships between gameplay and physiological data. These more extensive analyses could involve, for example, latent profile analyses as employed in Study 2 (Chapter 3). Next to performing more sophisticated analyses to assess experienced stress, we could build predictive models for the measured analytical skills using gameplay behavior only. By utilizing a variety of in-game indicators, which are all logged automatically, we could examine whether certain patterns of gameplay behavior result in higher analytical skills and whether other patterns result in lower accuracy. However, as the sample in Study 
1 consisted of university students, the study should be replicated with participants working at VRT.

In contrast, in Study 2 (Chapter 3) a bottom-up approach to unobtrusive assessment delivered quite promising results. Furthermore, as we tested our unobtrusive assessment models using a self-report measure on IL, we can be certain that our models measure IL. Although our approach was labelled as promising by Hahnel et al. (2020), we also must acknowledge their valid criticism: While we were able to show that unobtrusive assessment of rather complex competencies is feasible using DGBL environments, our unobtrusive assessment models could profit from validating and testing the employed self-report measure more extensively. However, by unobtrusively assessing the player, we already can draw valuable conclusions about the player's current skill level, which we could further translate into (adaptive) instructional interventions.

\section{Instructional intervention}

\section{Study 3}

After developing unobtrusive assessment models for IL, we focused on investigating the effect of an instructional intervention in the Dilemma Game as the final study of this dissertation. In this final study, we employed the in Study 2 developed unobtrusive assessment measures for measuring IL performance. For professionals in crisis management, it is important to learn from their previous experiences. Through post-training discussion and reflection sessions after completing real-life training sessions, professionals at VRT regularly do just that. Furthermore, reflecting on your own behavior has shown to be valuable in DGBL environments (Wouters \& van Oostendorp, 2013). Therefore, together with the developer of the Dilemma Game at HBA-Lab (formerly T-Xchange, renamed in 2018), a dashboard displaying the players' own in-game behavior in comparison to other players' in-game behavior was developed and implemented in the game. As a self-reflection through social comparison, this dashboard was used to support the players' self-reflection process.

An experimental design with two conditions was used: In the control condition, participants played through two gameplay scenarios of four dilemmas each. These participants played the second gameplay scenario right after finishing the first gameplay scenario. Participants in the experimental condition were shown the dashboard, as described in the previous paragraph, right after finishing the first gameplay scenario. In total 73 participants participated in this study. However, due to not following experiment protocol, not completing the study, or providing incomplete demographic information, twenty-six participants had to be excluded 
from the data analysis. Due the COVID-19 pandemic, this third study was conducted entirely online.

Results indicated that participants in the experimental condition consulted significantly more information and significantly more advisors in the second half of the game compared to the first half of the game. Furthermore, participants in the experimental condition also took slightly more time to reach a decision, which is logical, given that they consult more information and more advisors. However, a long-lasting change (i.e., transition of IL class membership as estimated using the unobtrusive assessment models developed in the second study) was not observed.

The results of this study have shown that self-reflection, guided by a dashboard giving a rather general overview of in-game behavior, influences information usage in subsequent dilemmas of the game. A more targeted intervention focusing on specific aspects of in-game behavior might be more beneficial, especially in combination with more exposures to the intervention. However, as small changes in information usage are favorable over no changes at all, the self-reflection implemented in its current form (i.e., guided by a rather general dashboard) can be concluded to be beneficial.

In conclusion, rather than abandoning a dashboard-guided self-reflection due to absence of long-lasting change in our study, we should continue developing the dashboard that was used to foster the self-reflection. Moreover, since participants were exposed to the intervention only once, the fact that a long-lasting change was not observed is not entirely unexpected, as it might take more exposures to trigger a long-lasting behavior change.

\section{UNOBTRUSIVE ASSESSMENT IN DIGITAL GAME-BASED LEARNING}

The field of adaptive digital serious games is still in its early stages, especially regarding the use of analytics for adaptivity (Ninaus \& Nebel, 2021). Unobtrusive assessment methods might help advance the field, because they can utilize in-game behavior (i.e., data about the process of playing the game) and perhaps physiological measures to measure the players' competency state (i.e., current skill or ability level). Since unobtrusive assessment measures in DGBL can be used for summative (e.g., grades) and also formative assessment, they can be helpful in providing players insight into their own learning processes, instead of providing grades only (Schildkamp et al., 2014; Steinrücke et al., (submitted)). Hence, when properly integrated, unobtrusive assessment measures can utilize a variety of process data, which we can use to point to specific points of improvement for the individual players and, therefore, to provide feedback at process level. In other words, instead of displaying raw numbers (i.e., raw information) about learners performance or behavior, which is how learning analytics are often implemented, 
unobtrusive assessment measures can be used to give meaning to these raw numbers (Georgiadis et al., 2019). Consequently, it might be easier for learners to understand what they can change to improve and why they have to change it.

To further popularize the use of unobtrusive assessment methods in serious games, generic tools like the stealth assessment (SA) tool T-Mon (AlonsoFernández et al., 2021) or the SA tool by Georgiadis et al. (2020) can be developed and used, allowing for widespread integration of unobtrusive assessments into digital serious games. Although users would still have to perform some manual work, these tools make unobtrusive assessment methods more accessible. To further ease the use of generic tools for unobtrusive assessment, bottom-up approaches could be employed. By additionally leveraging self-regulated learning techniques, such as letting players produce a written reflection on their in-game behavior, these approaches can be utilized to find accurate predictive models of players' skill levels, especially if combined with data analyses techniques such as text analysis (Geden et al., 2021).

So far, the unobtrusive assessment measures discussed in this dissertation mostly employed in-game behavior, such as response times or clicking frequencies during a specific task or over a certain period of time. By adding sequential data, such as change in response times or clicking frequencies over time, as variables to the unobtrusive assessment models, it might be possible to sketch an even more accurate picture of players' skill levels and in-game behavior, such that instructional interventions can be customized to focus on more specific points of improvement (Henderson et al., 2020). Finally, unobtrusive assessment cannot only be used assess learning (processes), but also to measure other psychometric properties. For example, Afroza et al. (2021) unobtrusively measured personality traits like Neuroticism using players' in-game behavior in a serious game. This assessment could further be employed in subsequent unobtrusive assessments of learning, such that instructional interventions (or other tools) can be customized to the player even better.

To further support unobtrusive assessment measures and their applications, we could make use of physiological measures, which we already scraped upon in Chapter 2. While we aimed to predict these physiological measures using gameplay data, we can also approach the use of physiological measures the opposite way. Next to assessing the players' skill level in an unobtrusive manner using the gameplay data, we could employ physiological measures to add more detail and additional depth to the assessment (Noroozi et al., 2019). For example, while players do not change their in-game behavior, it could very well be that they experience less or more stress over time. This could be measured using physiological measures such as heart rate (HR) and galvanic skin response (GSR). For an adaptive serious game that could mean, that in order to adjust to players 
physiological state, different characteristics of the game like game pace, the amount of information, the complexity of information provided to the players or other relevant game characteristics could be adjusted (Darzi et al., 2019; Mavromoustakos Blom et al., 2019, 2020a; Mavromoustakos Blom et al., 2020b; Yannakakis \& Hallam, 2008).

Next to measuring the players' experienced stress and use it to adapt the game, we could also make use of the experienced cognitive workload measured through brain-sensing or neuro-imaging techniques like functional near-infrared spectroscopy (fNIRS). Yuksel et al. (2016) described that adaptations based on cognitive workload measured through fNIRS might be more effective compared to adaptations based on HR or GSR measurements, because fNIRS is not affected by different levels of respiration, mouse or keyboard clicks, or even heartbeat. An adaptive brain-computer system for learning piano that used fNIRS was demonstrated by the same authors. Their brain-computer system can dynamically adjust the task difficulty (i.e., complexity of the pieces the learner was supposed to play) based on the learners' cognitive workload measured by a sensor that is attached to the forehead through a simple headband. Learners using the braincomputer system showed increased note accuracy and playing speed.

Another physiological measure to consider for supporting (unobtrusive) assessments is eye-movement, which could be measured unobtrusively through webcam-based technologies (e.g., Park et al., 2020). Utilizing eye-movement data, which is an indicator of (visual) attention (e.g., Lee et al., 2019; Mason et al., 2016), could enrich unobtrusive assessments. For example, less fixations (i.e., how often the eyes focus on specific parts of the screen) indicate that less time was spent on the actual task (Frutos-Pascual \& Garcia-Zapirain, 2015). Therefore, we might be able to retrieve the actual attention time of a player, that is the response time based on log-data corrected for the number of fixations. As a result, compared to using response time based on log-data only, we could improve the unobtrusive assessment models to sketch a more accurate representation of the players' behavior, which consequently translates to a more accurate assessment of the players' skill level.

Last, to give players insight into their own physiological state, all physiological data could be incorporated in a dashboard as described in Chapter 4. For successful implementation, it is crucial to display the physiological information in an understandable manner: Instead of displaying (raw) numbers, we must give meaning to the information. For example, instead of saying that their heart rate increased by a certain number, we should give the players an interpretation of what this increase means, accompanied by a suggestion what they could do to tackle this issue (Mavromoustakos Blom et al., 2019). 


\section{KEEPING LEARNERS MOTIVATED}

Motivation is a key factor in learning and training through serious games: More motivated players are expected to be more engaged, better performing, and learn more effectively (Rahimi et al., 2021). Unfortunately, in our study described in Chapter 4, we observed a relatively high non-completion rate. Out of 73 initial participants, only 47 completed the study ( $35.6 \%$ did not complete the study). In contrast to Chapter 3, where nearly all participants completed the study, albeit only because of the researcher's presence, we were not able to collect the data in person in Chapter 4. Consequently, participants could choose themselves when they would participate. Once they chose to participate, it was more likely for them to have gotten distracted due to the at-home setting, and consequently, as they were not observed by colleagues and/or researchers, they might have been less motivated to still complete the study.

However, we also must acknowledge that serious games like the Dilemma Game can soon feel repetitive. Participants had to play through a total of eight dilemmas, which, especially if you do it individually at home, can feel rather lengthy. Arguably, professionals have to stay concentrated much longer in real crises and real-life training sessions, but that does not mitigate the feeling of repetitiveness and lengthiness they might experience in serious games like the Dilemma Game. Therefore, the game should be reevaluated regarding its length, whether it should be played individually or (optionally) cooperatively and even whether it might be more useful in a group setting, where players can discuss their approaches once they completed the game or a predefined number of dilemmas.

As training of decision-making situations also benefits from the relevance and timeliness of the scenarios presented to trainees, serious games could be advanced even further by generating scenario texts, information, or dilemmas dependent on real recent events. For example, van Stegeren and Theune (2018) presented a natural language generation system capable of generating possible in-game information based on predefined keywords, which could be used to assure feelings of relevance and timeliness to the players.

Next to adjusting the displayed texts in the game to real recent events, we could adjust the game to the individual player, for example with respect to task complexity. Although research in the context of computerized adaptive testing (CAT) has shown contradicting results (Ling et al., 2017; Martin \& Lazendic, 2018; Ortner et al., 2014; Ross et al., 2018), presenting players with tasks fitted to their individual skill level, to challenge them just enough, might still be beneficial for player's motivation when implemented in DGBL environments.

Furthermore, incentive systems like earned badges or points can be useful to keep players motivated (Rahimi et al., 2021). These incentive systems could even be 
linked to the unobtrusive assessment measures, such that a badge is earned whenever a specific gameplay behavior that is positively associated with the skill of interest is observed. Rahimi et al. (2021) also discuss the additional use of learning supports, which should be used to clarify the connection between the game and its levels (i.e., dilemmas in the Dilemma Game), the gameplay behavior and the to be trained skill, such that players see added value in playing the game.

According to Self-Determination theory (SDT; Ryan \& Deci, 2000), a crucial factor influencing people's motivation is autonomy. In the Dilemma Game, the degree of autonomy is rather restricted. While players can choose which information to read for each dilemma, the general degree of autonomy is rather low in the game. While this might be an accurate representation of real crises, where decision-makers cannot fully influence what information is available or how long the crises last, a low degree of autonomy is rather demotivating in digital games in general.

\section{CONCLUDING NOTES}

The synopsis of the studies conducted in this dissertation demonstrate clearly, that with the proper tools and validation, unobtrusive assessment measures can be beneficial for serious games and their application in real-life settings. Furthermore, with the proper integration of unobtrusive assessment measures in learner dashboards, unobtrusive assessment measures might also be beneficial for learning analytics, by providing an additional level of detail and meaning to the usually displayed raw numbers.

Despite finding well performing models and significant effects, our results should be considered rather conservative. In combination with the high non-completion rate in Study 3, we argue that it is important to also consider the motivational factor before putting serious games for crisis management decision-making training into practice. While some professionals might not see added value in using digital serious games in their training, the participants in our studies were in general positive and open about new forms of training, because they want to stay competent in their profession.

In real crises, crisis management decision-makers cannot thoroughly evaluate all information the context provides. All actions and choices of the decision-makers can have real consequences. While real-life training settings might be able to simulate this to some degree of reality, serious games like the Dilemma Game fail to do so. Whenever professionals are playing serious games, there are no real consequences. For example, evaluating all information in real crises can lead to a decision being made too late, leading to serious consequences. In serious games however, they can evaluate all available information without having to fear these consequences.

While professionals do not have to fear serious consequences in real-life training sessions as well, in contrast to serious games, they do not have the option to explore different courses of actions afterwards, and thereby "fixing" their 
mistakes. Therefore, serious games should never be implemented with the goal to replace the real-life trainings, serious games should rather be an addition that can provide further insight into the professionals approaches to decision-making and other relevant competencies.

Lastly, crisis management decision-making at VRT is a complex task, where clear roles within the crisis organization help to make it more structured. The close cooperation with municipalities, between the different emergency services and associated organizations, offers plenty of options for researching and developing (adaptive) digital serious games, (unobtrusive) assessment methods and instructional interventions. When crisis organizations like VRT choose to implement serious games in their training practice, these serious games can be used not only for actual training of crisis management decision-makers, but also for giving civilians the opportunity to experience complex crises from the decisionmakers point of view. 


\section{REFERENCES}

Afroza, A., Murray, K., Wünsche, B. C., \& Denny, P. (2021). Who am I? - Development and analysis of an interactive 3D game for psychometric testing. 2021 Australasian Computer Science Week Multiconference. https://doi.org/10.1145/3437378.3442688

Akogul, S., \& Erisoglu, M. (2017). An approach for determining the number of clusters in a model-based cluster analysis. Entropy, 19, 452. https://doi.org/10.3390/e19090452

Alonso-Fernández, C., Calvo-Morata, A., Freire, M., Martínez-Ortiz, I. \& FernándezManjón, B. (2021, April 21-23). Data science meets standardized game learning analytics. IEEE Global Engineering Education Conference (EDUCON). https://pubman.e-ucm.es/drafts/e-UCM_draft_364.pdf

Anderson, C. A. (1995). Perceived arousal scale. http://public.psych.iastate.edu/caa/scales/ PerArous.pdf

Anderson, C. A., Deuser, W. E., \& DeNeve, K. M. (1995). Hot temperatures, hostile affect, hostile cognition, and arousal: Tests of a general model of affective aggression. Personality and Social Psychology Bulletin, 21, 434-448. https://doi.org/10.1177/0146167295215002

Darzi, A., Wondra, T., McCrea, S., \& Novak, D. (2019). Classification of multiple psychological dimensions in computer game players using physiology, performance, and personality characteristics. Frontiers in Neuroscience, 13, 1278. https://www.frontiersin.org/article/10.3389/fnins.2019.01278

Frutos-Pascual, M., \& Garcia-Zapirain, B. (2015). Assessing visual attention using eye tracking sensors in intelligent cognitive therapies based on serious games. Sensors, 15, 11092-11117. https://www.mdpi.com/1424-8220/15/5/11092

Geden, M., Emerson, A., Carpenter, D., Rowe, J., Azevedo, R., \& Lester, J. (2021). Predictive student modeling in game-based learning environments with word embedding representations of reflection. International Journal of Artificial Intelligence in Education, 31, 1-23. https://doi.org/10.1007/s40593-020-00220-4

Georgiadis, K., van Lankveld, G., Bahreini, K., \& Westera, W. (2019). Learning analytics should analyse the learning: Proposing a generic stealth assessment tool. 2019 IEEE Conference on Games (CoG), 1-8. https://doi.org/10.1109/CIG.2019.8847960

Georgiadis, K., Lankveld, G. V., Bahreini, K., \& Westera, W. (2020). On the robustness of stealth assessment. IEEE Transactions on Games, 1-1. https://doi.org/10.1109/TG.2020.3020015

Hahnel, C., Eichmann, B., \& Goldhammer, F. (2020). Evaluation of online information in university students: Development and scaling of the screening instrument EVON. Frontiers in Psychology, 11. https://doi.org/10.3389/fpsyg.2020.562128

Henderson, N. L., Kumara, V., Min, W., Mott, B. W., Wu, Z., Boulden, D. C., Lord, T., Reichsman, F., Dorsey, C., Wiebe, E., \& Lester, J. C. (2020). Enhancing student competency models for game-based learning with a hybrid stealth assessment framework. Proceedings of the 13th International Conference on Educational Data Mining (EDM 2020). 
Holmgård, C., Yannakakis, G. N., Martínez, H. P., Karstoft, K.-I., \& Andersen, H. S. (2015). Multimodal PTSD characterization via the StartleMart Game. Journal on Multimodal User Interfaces, 9, 3-15. https://doi.org/10.1007/s12193-014-0160-5

Information Literacy Competency Standards for Higher Education. (2000). https://alair.ala.org/bitstream/handle/11213/7668/ACRL\%20Information\%20Liter acy\%20Competency\%20Standards\%20for\%20Higher\%20Education.pdf

Hothorn, T. (2018). Top-down transformation choice. Statistical Modelling, 18, 274-298. https://doi.org/10.1177/1471082x17748081

Lee, J. Y., Donkers, J., Jarodzka, H., \& van Merriënboer, J. J. G. (2019). How prior knowledge affects problem-solving performance in a medical simulation game: Using game-logs and eye-tracking. Computers in Human Behavior, 99, 268-277. https://doi.org/https://doi.org/10.1016/j.chb.2019.05.035

Ling, G., Attali, Y., Finn, B., \& Stone, E. A. (2017). Is a computerized adaptive test more motivating than a fixed-item test? Applied Psychological Measurement, 41, 495511. https://doi.org/10.1177/0146621617707556

Martin, A. J., \& Lazendic, G. (2018). Computer-adaptive testing: Implications for students' achievement, motivation, engagement, and subjective test experience. Journal of Educational Psychology, 110, 27-45. https://doi.org/10.1037/edu0000205

Mason, L., Pluchino, P., \& Tornatora, M. C. (2016). Using eye-tracking technology as an indirect instruction tool to improve text and picture processing and learning. British Journal of Educational Technology, 47, 1083-1095. https://doi.org/https://doi.org/10.1111/bjet.12271

Mavromoustakos Blom P., Bakkes S., Spronck P. (2019). Andromeda: A personalised crisis management training toolkit. In A. Liapis, G. Yannakakis, M. Gentile, \& M. Ninaus (Eds.), Games and learning alliance. GALA 2019 (pp 139-147). Springer. https://doi.org/10.1007/978-3-030-34350-7_14

Mavromoustakos Blom, P., Bakkes, S., \& Spronck, P. (2020a, September 23-25). Multimodal study of the effect of information complexity in a crisis management game [Paper presentation]. GAME-ON 2020 - Aveiro, Portugal. https://www.researchgate.net/publication/348383411_Multimodal_Study_of_the_Effect_of_Information_Complexity_in_a_Crisis_Manageme nt_Game

Mavromoustakos Blom, P., Bakkes, S., \& Spronck, P. (2020b). Multi-modal study of the effect of time pressure in a crisis management game. International Conference on the Foundations of Digital Games, Bugibba, Malta. https://doi.org/10.1145/3402942. 3403006

Ninaus, M., \& Nebel, S. (2021). A systematic literature review of analytics for adaptivity within educational video games. Frontiers in Education, 5. https://doi.org/10.3389/feduc.2020.611072

Noroozi, O., Alikhani, I., Järvelä, S., Kirschner, P. A., Juuso, I., \& Seppänen, T. (2019). Multimodal data to design visual learning analytics for understanding regulation of learning. Computers in Human Behavior, 100, 298-304. https://doi.org/10.1016/j.chb.2018.12.019 
Ortner, T. M., Weißkopf, E., \& Koch, T. (2014). I will probably fail: Higher ability students' motivational experiences during adaptive achievement testing. European Journal of Psychological Assessment, 30, 48-56. https://doi.org/10.1027/1015-5759/a000168

Park, S., Aksan, E., Zhang, X., \& Hilliges, O. (2020). Towards end-to-end video-based eyetracking. In A. Vedaldi, H. Bischof, T. Brox, \& J.-M. Frahm (Eds), Computer vision - ECCV 2020 (pp. 747-763). Springer. https://doi.org/10.1007/978-3-030-58610$2 \_44$

Rahimi, S., Shute, V., Kuba, R., Dai, C.-P., Yang, X., Smith, G., \& Fernández, C. A. (2021). The use and effects of incentive systems on learning and performance in educational games. Computers \& Education, 165, 104135. https://doi.org/10.1016/j.compedu.2021.104135

Ross, B., Chase, A.-M., Robbie, D., Oates, G., \& Absalom, Y. (2018). Adaptive quizzes to increase motivation, engagement and learning outcomes in a first year accounting unit. International Journal of Educational Technology in Higher Education, 15, 30. https://doi.org/10.1186/s41239-018-0113-2

Russell, J. A., Weiss, A., \& Mendelsohn, G. A. (1989). Affect grid: A single-item scale of pleasure and arousal. Journal of Personality and Social Psychology, 57, 493-502. https://psycnet.apa.org/doi/10.1037/0022-3514.57.3.493

Ryan, R. M., \& Deci, E. L. (2000). Self-determination theory and the facilitation of intrinsic motivation, social development, and well-being. American Psychologist, 55, 68-78. https://doi.org/10.1037/0003-066X.55.1.68

Schildkamp, K., Heitink, M. C., van der Kleij, F., Hoogland, I., Dijkstra, A. M., Kippers, W. B., \& Veldkamp, B. P. (2014). Voorwaarden voor effectieve formatieve toetsing: Een praktische review [Requirements for effective formative assessment: A practical review]. Universiteit Twente.

Steinrücke, J., Veldkamp, B. P., \& de Jong, T. (submitted). The effect of self-reflection on information usage and information literacy in a digital serious game.

Stonebraker, I. (2016). Toward informed leadership: Teaching students to make better decisions using information. Journal of Business \& Finance Librarianship, 21, 229-238. https://doi.org/10.1080/08963568.2016.1226614

T-Xchange. (2020, February 21). Dilemma. https://www.txchange.nl/ dilemma/

van de Ven, J. G. M., Stubbé, H., \& Hrehovcsik, M. (2014). Gaming for policy makers: It's serious! In A. De Gloria (Eds.), Games and learning alliance: Second international conference, GALA 2013 (pp. 376-382). Springer. https://doi.org/10.1007/978-3-31912157-4_32

van Stegeren, J., \& Theune, M. (2018). Towards generating textual game assets from realworld data. Proceedings of the 13th International Conference on the Foundations of Digital Games. https://doi.org/10.1145/3235765.3235809

Wouters, P., \& van Oostendorp, H. (2013). A meta-analytic review of the role of instructional support in game-based learning. Computers \& Education, 60, 412425. https://doi.org/10.1016/j.compedu.2012.07.018 
Yannakakis, G. N., \& Hallam, J. (2008). Entertainment modeling through physiology in physical play. International Journal of Human-Computer Studies, 66, 741-755. https://doi.org/10.1016/j.ijhcs.2008.06.004

Yuksel, B. F., Oleson, K. B., Harrison, L., Peck, E. M., Afergan, D., Chang, R., \& Jacob, R. J. (2016). Learn piano with BACh: An adaptive learning interface that adjusts task difficulty based on brain state. Proceedings of the 2016 CHI Conference on Human Factors in Computing Systems. https://doi.org/10.1145/2858036.2858388 
General discussion 
English summary 


\section{INTRODUCTION}

In digital game-based learning (DGBL), adaptivity allows for a more efficient and effective learning experience. That means, that the game can change dependent on, for example, the current performance of the players regarding a certain skill. For example, if a player performs badly, the game can adapt to become easier, and therefore more appropriate for the player's skill level. However, to be truly adaptive, the game also needs to know the current performance level of a player. To achieve this, we need to assess the players regarding the skill we want to measure and train. One way to do this, would be to interrupt the game and to administer some kind of test, like a multiple-choice test. Unfortunately, this rather obtrusive method of assessment would break the flow of the gameplay and would keep the players aware of the fact that they are being assessed. Alternatively, we can try to assess the players without them noticing it. In doing so, players would remain in their flow state and could fully focus on playing the game. This is called unobtrusive assessment.

By unobtrusively assessing the players' current skill levels, games can adapt to the players needs and offer instructional interventions. Which intervention is offered, depends on the context of the game, on the target skill and on the target population. While it could be argued that flow is interrupted even with an unobtrusive assessment, that would be done without the player noticing it and only to trigger a change in the players' in-game behavior.

The goal of this dissertation has been to investigate the potential use of unobtrusive assessment measures in a DGBL environment, as well as the potentially beneficial effect of one specific instructional intervention, namely selfreflection through social comparison. Self-reflection not only fitted the DGBL environment that we used, but it also fits the natural way of crisis management decision-making training of Veiligheidsregio Twente (VRT; Twente Safety Region), whose members are used to critically reflect on their own approaches in real- life training sessions.

\section{OVERVIEW OF CONDUCTED STUDIES}

In the context of this dissertation, we conducted three studies. While the first study was conducted with university students from University of Twente, the other two studies were conducted with professionals in crisis management at VRT. We focused on three important competencies in the context of crisis management decision-making: Analytical skills, stress resistance, and information literacy (IL). In the different studies, we used various evolutionary stages of the Mayor Game, later on referred to as the Dilemma Game. In the first study, the original Mayor 
Game was slightly modified to fit the goal of the study. In the second study, the Mayor Game lost its original name, and was revised and further developed to become the Dilemma Game. These two versions ran on the flash-based SDM and DDM game engines from T-Xchange by Thales respectively. In Study 3, the Dilemma Game used their newest HTML5 based game engine, ensuring compatibility on most devices. As in real-life crisis management decision-making situations, the Mayor Game, or Dilemma Game, makes use of dilemmas, where there is no correct decision to take. The only thing that matters, is how players reach a decision.

\section{Study 1}

In the first study, we investigated the effect of induced stress on analytical skills, which we measured within the Mayor Game, using a control and an experimental condition. We aimed to develop an unobtrusive assessment method of experienced stress using participants gameplay behavior. Although participants in the experimental condition tended towards a more intuitive and less accurate decision-making strategy, in-game indicators of gameplay behavior only partially predicted the through self-reports and physiological sensors collected measures of stress. More powerful analysis tools and a more targeted method of inducing stress could help to gain more insight into the unobtrusive assessment of stress in digital serious games.

\section{Study 2}

As finding and evaluating information and its sources is crucial in crisis management decision-making, we aimed to develop an unobtrusive assessment method to measure IL in a digital serious game in our second study. To validate our unobtrusive assessment method, we employed a self-report measure of IL. Using latent profile analyses (LPA) in a data-driven bottom-up analysis, we were able to adequately relate different patterns of gameplay behavior to higher or lower IL skill levels. Although the employed self-report measure still needs to be validated in future research, this study and its results are a starting point for making the training of crisis management decision-making more effective and efficient.

\section{Study 3}

In the third study of this dissertation, we focused on investigating whether a selfreflection through social comparison influences the in-game behavior of participants and subsequently on the in-game IL skill level, as unobtrusively measured using the in the previous study obtained results. In contrast to participants in the control condition, participants who were shown a dashboard facilitating this self-reflection after completing half of the game, increased the 
amount of information and number of consulted advisors in the second half of the game. Further, these participants also took slightly more time to reach a decision, which only makes sense if they consult more advisors and read more information. However, no meaningful between-condition differences regarding the in-game IL skill levels could be found in terms of change from first to second half of the game.

\section{CONCLUSION}

Real adaptivity in DGBL environments is hard to achieve. Especially in decisionmaking situations where all decision options are equally viable, we cannot base adaptive elements on a directly observable outcome. Therefore, in-game behavior of players has to be used, such that DGBL environments can assess players continuously and adapt accordingly. With the research presented in this dissertation, we set some valuable starting points to further develop DGBL environments that can be used for crisis management decision-making training.

We observed that players who were less stress resistant, lost accuracy in evaluating information. Furthermore, we found that unobtrusive assessment of skills like IL is feasible using players' in-game behavior. This allows for further development of instructional interventions that can be incorporated in DGBL environments. Last, we observed that self-reflection through social comparison can be a valuable tool in triggering change in players in-game behavior. However, to trigger long lasting behavior change that is reflected in the actual skill level, we conclude that the dashboard used to guide the self-reflection should be more targeted and more specific. In an optimal case, interpretations on the in-game behavior, supported by specific suggestions for improvement can be displayed to the player. Then can players effectively use the information to critically evaluate their own in-game behavior and adjust it accordingly. 
Nederlandse samenvatting 


\section{INTRODUCTIE}

Digital game-based learning (DGBL; digitaal spel-gebaseerd leren) biedt mogelijkheden om games te adapteren op de speler, hetgeen kan resulteren in meer efficiënte en effectieve leerervaring. Dit betekent dat de game kan veranderen op basis van een spelers' prestatie in termen van een bepaalde vaardigheid. Als de speler bijvoorbeeld relatief slecht presteert, kan de game worden vergemakkelijkt en daarmee toegankelijker worden omdat het dan beter aansluit op de vaardigheden van desbetreffende speler. Om de game daadwerkelijk volledig aanpasbaar te maken, moet het wel bekend zijn met de huidige prestatie van een speler. Om dit te kunnen doen, moeten wij de speler op de vaardigheid, die we willen meten en trainen, toetsen. Enerzijds kunnen we hiervoor testen gebruiken zoals bijvoorbeeld meerkeuze toetsen. Helaas zou deze best ingrijpende methode van toetsen de flow van het gameplay breken and daardoor de spelers bewust houden van het feit dat ze worden beoordeeld. Aan de andere kant kunnen we ook proberen om spelers te toetsen zonder dat ze dit door hebben. Op deze wijze zal de game niet onderbroken worden en zullen spelers zich volledig kunnen concentreren op de game. Deze wijze wordt onopvallend toetsen ('unobtrusive assessment') genoemd.

Bij onopvallend toetsen kan de game worden aangepast op basis van het vaardigheidsniveau van de speler en kunnen instructie interventies worden aangeboden. Welke interventies worden aangeboden is afhankelijk van de context van de game, de vaardigheid die wordt gemeten en getraind, en de doelgroep. Terwijl er kan worden gesteld dat de flow op deze manier wel wordt onderbroken, zal dit gebeuren zonder dat de spelers het doorhebben en enkel om het gedrag van de speler binnen de game te veranderen.

Deze dissertatie richt zich op het onderzoeken van het potentiële gebruik van onopvallend toetsen binnen een DGBL-omgeving. Daarnaast richt de dissertatie zich op het onderzoeken van de mogelijke voordelen bij het inzetten van specifieke instructie interventies, specifiek zelfreflectie door sociaal vergelijk. Zelfreflectie past binnen de DGBL-context die we gebruiken. Daarnaast past zelfreflectie ook bij de wijze waarop besluitvorming bij crisismanagement wordt getraind binnen Veiligheidsregio Twente (VRT). Voor de leden van VRT is het gebruikelijk om kritisch te reflecteren op het eigen handelen bij real-life trainingssessies.

\section{OVERZICHT VAN DE UITGEVOERDE STUDIES}

Deze dissertatie bestaat uit drie studies. De eerste studie is uitgevoerd met studenten van de Universiteit van Twente. De andere twee studies zijn uitgevoerd met crisismanagement experts van VRT. We concentreren ons met name op drie 
belangrijke competenties in de context van besluitvorming bij crisismanagement: analytische vaardigheden, stressbestendigheid, en information literacy (IL; informatievaardigheden).

In de verschillende studies hebben we gebruik gemaakt van verschillende evolutionaire fasen van de Mayor Game, later naar gerefereerd als de Dilemma game. In de eerste studie is de originele Mayor game ietwat aangepast om aan te sluiten bij het doel van de studie. In de tweede studie is de Mayor Game verder ontwikkeld en is de naam gewijzigd in Dilemma game. Deze eerste twee versies draaiden eerst op respectief de SDM en DDM-game engine van T-Xchange bij Thales. In Studie 3, draaide de Dilemma Game op de nieuwe HTML5 game engine voor betere compatibiliteit met de meeste apparaten. Net zoals in echte besluitvormingssituaties in crisismanagement, maken de Mayor Game en Dilemma Game gebruik van dilemma's, waar er geen correct of incorrect besluit kan worden genomen en waar het juist om de wijze waarop men tot een besluit komt gaat.

\section{Studie 1}

In de eerste studie hebben we de invloed van stress op analytische vaardigheden onderzocht door middel van de Mayor Game. We hebben dit gedaan middels controle en experimentele condities. Ons doel was om een onopvallende analysemethode te ontwikkelen van de stress die spelers ervaarde tijdens de game op basis van het gebruiksgedrag. Ondanks het feit dat spelers blootgesteld aan de experimentele conditie de neiging hebben om meer intuïtieve en minder accurate besluitvorming strategieën te hanteren, voorspellen in-game indicators van spelgedrag de mate van stress, gemeten door zelfrapportage en fysiologische sensoren, alleen gedeeltelijk. Krachtigere analysetools en specifiekere methoden voor het veroorzaken van stress, zouden kunnen helpen om inzichten rondom onopvallende analysemethodes in digitale serious games te vergroten.

\section{Studie 2}

Het vinden en evalueren van informatie en informatiebronnen is cruciaal binnen besluitvorming in crisismanagement. Daarom is het doel van de tweede studie om een onopvallende analysemethode van informatievaardigheden te ontwikkelen. Om onze onopvallende analysemethode te valideren, hebben we gebruik gemaakt van een informatievaardigheden zelfrapportage. Door gebruik te maken van latent profile analyses (LPA; latente profielanalyse) in een data gedreven bottomup analyse, hebben we verschillende patronen van spelgedrag gevonden die te relateren zijn aan hoge of lage niveaus van informatievaardigheden. Ongeacht het feit dat de zelfrapportage instrument verder moet worden gevalideerd in toekomstige studies, biedt de studie een goed startpunt om besluitvormingstraining in crisismanagement meer effectief en efficiënt te maken. 


\section{Studie 3}

In de derde studie hebben we onderzocht of zelfreflectie door sociaal vergelijk het spelgedrag van spelers beïnvloed en als gevolg ook het in-game ILvaardigheidsniveau, onopvallend gemeten met behulp van de resultaten uit te vorige studie. In tegenstelling tot deelnemers blootgesteld aan de controle conditie, nam de hoeveelheid informatie en geconsulteerde adviseurs toe bij deelnemers die halverwege de game werden blootgesteld aan een dashboard die zelfreflectie faciliteert. Daarnaast gebruikten deze deelnemers ook meer tijd bij het nemen van beslissingen hetgeen logischerwijs aangeeft dat zij meer informatie en adviseurs hebben geconsulteerd. Desondanks zijn er geen verschillen gevonden tussen de condities in in-game IL-vaardigheidsniveau tussen het eerste en tweede deel van de game.

\section{Conclusie}

Volledige adaptiviteit in DGBL-omgevingen is moeilijk te bereiken. Vooral in besluitvormingssituaties waar elke beslissing even haalbaar is, is het moeilijk om adaptieve elementen te baseren op een direct waarneembaar resultaat. Daarom moet het gamegedrag van spelers worden gebruikt, daarmee DGBL-omgevingen spelers continue kunnen toetsen en op basis hiervan aan te passen. Deze dissertatie biedt een aantal belangrijke startpunten voor het verder ontwikkelen van DGBL-omgevingen die kunnen worden gebruikt bij besluitvormingstraining in crisismanagement.

We hebben geobserveerd dat spelers die minder stressbestendig zijn, minder accuraat zijn in het evalueren van informatie. Daarnaast hebben we geconstateerd dat voor het onopvallend toetsen van vaardigheden zoals IL mogelijk is door het spelgedrag van spelers te gebruiken. Deze inzichten maken het mogelijk om instructie interventies verder te ontwikkelen en te integreren in DGBL-omgevingen. Ten slotte, hebben we geconstateerd dat zelfreflectie door sociaal vergelijk een waardevolle tool kan zijn om verandering in het spelgedrag van deelnemers te stimuleren. Maar om lange termijn gedragsveranderingen, die zichtbaar zijn in het vaardigheidsniveau, is het belangrijk om het dashboard, wat zelfreflectie faciliteert, specifieker en doelgerichter te maken. Dat wil zeggen, gedrag wat wordt gereflecteerd in het niveau van vaardigheden. In optima forma, zou de interpretatie van het spelgedrag van spelers kunnen worden getoond aan de spelers met daarbij specifieke suggesties voor ontwikkeling. Op deze manier zouden spelers effectief gebruik kunnen maken van de getoonde informatie om het eigen spelgedrag kritisch te evalueren en het hierop te veranderen. 


\section{Deutsche Zusammenfassung}




\section{EINLEITUNG}

Beim digital game-based learning (DGBL; digitales spielbasiertes Lernen) ermöglicht die Adaptivität eine effizientere und effektivere Lernerfahrung. Das bedeutet, dass sich das Spiel z. B. in Abhängigkeit von der aktuellen Leistung der Spieler:innen in Bezug auf eine bestimmte Fähigkeit verändert. Wenn die Spieler:innen z. B. eine eher schlechte Leistung erbringen, kann das Spiel so angepasst werden, dass es einfacher wird und somit besser zum Leistungsniveau der Spieler:innen passt. Um jedoch wirklich adaptiv zu sein, muss das Spiel auch die aktuelle Leistung der Spieler:innen kennen. Um dies zu erreichen, müssen wir die Spieler:innen hinsichtlich der Fähigkeit, die wir messen und trainieren wollen, einschätzen. Einerseits können wir eine Art Test verabreichen, z. B. einen Multiple-Choice-Test. Leider würden diese eher auffälligen AssessmentMethoden den Spielfluss unterbrechen und den Spieler:innen stets bewusst machen, dass sie bewertet werden. Andererseits können wir versuchen die Spieler:innen zu bewerten ohne dass sie es aktiv bemerken. Dabei würden die Spieler:innen in ihrem Flow-Zustand bleiben und könnten sich voll auf das Spiel konzentrieren. Dies wird als unauffälliges Assessment bezeichnet.

Durch das unauffällige Assessment des aktuellen Fähigkeitsniveaus der Spieler:innen können sich Spiele an die Bedürfnisse der Spieler:innen anpassen und instruktive Interventionen anbieten. Welche Intervention angeboten wird, hängt vom Kontext des Spiels, von der Zielfähigkeit und von der Zielgruppe ab. Man könnte folglich zwar argumentieren, dass der Spielfluss auch bei einem unauffälligen Assessment unterbrochen wird, aber das würde geschehen, ohne dass die Spieler:innen es bemerken, und nur, um eine Änderung des Verhaltens der Spieler:innen im Spiel auszulösen.

Das Ziel dieser Dissertation war es, den potentiellen Einsatz von unauffälligen Assessments in einer DGBL-Umgebung zu untersuchen, sowie den potentiell positiven Effekt einer spezifischen instruktiven Intervention, nämlich Selbstreflexion durch sozialen Vergleich. Selbstreflexion fügt sich nicht nur in die von uns verwendete DGBL-Umgebung, sondern auch in die natürliche Art und Weise des Trainings von Entscheidungsprozessen im Krisenmanagement der Veiligheidsregio Twente (VRT; Sicherheitsregion Twente), deren Mitglieder:innen gewohnt sind, ihre eigenen Vorgehensweisen in realen Trainingseinheiten kritisch zu reflektieren.

\section{ÜBERSICHT ÜBER DIE DURCHGEFÜHRTEN STUDIEN}

Im Rahmen dieser Dissertation haben wir drei Studien durchgeführt. Während die erste Studie mit Student:innen der Universität Twente durchgeführt wurde, 
wurden die beiden anderen Studien mit Fachleuten im Krisenmanagement der VRT durchgeführt. Wir konzentrierten uns auf drei wichtige Kompetenzen im Zusammenhang mit der Entscheidungsfindung im Krisenmanagement: Analytische Fähigkeiten, Stressresistenz und Information Literacy (IL; Informationskompetenz).

In den verschiedenen Studien verwendeten wir verschiedene Evolutionsstufen des Mayor Game, das später als Dilemma Game bezeichnet wurde. In der ersten Studie wurde das ursprüngliche Mayor Game leicht modifiziert, um es an das Ziel der Studie anzupassen. In der zweiten Studie verlor das Mayor Game seinen ursprünglichen Namen und wurde zum Dilemma Game überarbeitet und weiterentwickelt. Während diese beiden Versionen auf den Flash-basierten SDMbzw. DDM-Game-Engines von T-Xchange by Thales liefen, wurde das Dilemma Game für die dritte Studie auf deren neueste HTML5-basierte Game-Engine portiert, um Kompatibilität auf den meisten Geräten zu gewährleisten. Wie in realen Entscheidungssituationen im Krisenmanagement nutzt das Mayor Game beziehungsweise Dilemma Game Dilemmasituationen, in denen es keine richtige Entscheidung zu treffen gibt. Das Einzige, was zählt, ist, wie die Spieler zu einer Entscheidung kommen.

\section{Studie 1}

In der ersten Studie untersuchten wir die Auswirkung von induziertem Stress auf die analytischen Fähigkeiten, die im Mayor Game gemessen wurden, unter Verwendung einer Kontroll- und einer experimentellen Bedingung. Unser Ziel war es, ein unauffälliges Assessment für erlebten Stress anhand des Spielverhaltens der Teilnehmer:innen zu entwickeln. Obwohl die Teilnehmer:innen in der experimentellen Bedingung zu einer intuitiveren und weniger genauen Entscheidungsstrategie tendierten, sagten die spielinternen Indikatoren des Gameplay-Verhaltens nur teilweise die durch Selbstberichte und physiologische Sensoren erhobenen Stressindikatoren voraus. Leistungsfähigere Analysewerkzeuge und eine gezieltere Methode der Stressinduktion könnten helfen, mehr Erkenntnisse über das unauffällige Assessment von Stress in digitalen Serious Games zu gewinnen.

\section{Studie 2}

Da das Finden und Bewerten von Informationen und deren Quellen für die Entscheidungsfindung im Krisenmanagement von entscheidender Bedeutung sind, wollten wir in unserer zweiten Studie ein unauffälliges Assessment zur Messung der IL in einem digitalen Serious Game entwickeln. Um unser unauffälliges Assessment $\mathrm{zu}$ validieren, benutzten wir ein ILSelbstberichtsinstrument. Mit Hilfe von latenten Profilanalysen (LPA) in einer 
datengetriebenen Bottom-Up-Analyse konnten wir verschiedene Muster des Spielverhaltens adäquat mit höheren oder niedrigeren IL-Fähigkeitsstufen in Beziehung setzen. Obwohl das verwendete Selbstberichtsinstrument in zukünftigen Forschungen noch validiert werden muss, sind diese Studie und ihre Ergebnisse ein Ansatzpunkt, um das Training von Entscheidungsfindung im Krisenmanagement effektiver und effizienter zu gestalten.

\section{Studie 3}

In der dritten Studie dieser Dissertation konzentrierten wir uns auf die Untersuchung, ob eine Selbstreflexion durch sozialen Vergleich das In-GameVerhalten der Teilnehmer:innen und in der Folge auf das In-Game-ILFähigkeitsniveau beeinflusst, wie es unauffällig mit den in der vorherigen Studie gewonnenen Ergebnissen gemessen wurde. Im Gegensatz $\mathrm{zu}$ den Teilnehmer:innen in der Kontrollbedingung, nahmen Teilnehmer:innen denen nach der Hälfte des Spiels ein Dashboard gezeigt wurde das diese Selbstreflexion ermöglichte in der zweiten Spielhälfte mehr Informationen auf und konsultierten mehr Berater:innen. Außerdem brauchten diese Teilnehmer:innen auch etwas mehr Zeit, um eine Entscheidung zu treffen, was nur Sinn macht, wenn sie mehr Berater:innen konsultieren und mehr Informationen lesen. Es konnten jedoch keine bedeutsamen Unterschiede zwischen den Bedingungen hinsichtlich der ILFähigkeiten im Spiel gefunden werden, was die Veränderung von der Ersten zur zweiten Spielhälfte betrifft.

\section{FAZIT}

Echte Adaptivität in DGBL-Umgebungen ist schwer zu erreichen. Besonders in Entscheidungssituationen, in denen alle Entscheidungsoptionen gleichwertig sind, können wir adaptive Elemente nicht auf ein direkt beobachtbares Ergebnis stützen. Daher muss das In-Game-Verhalten der Spieler:innen herangezogen werden, so dass DGBL-Umgebungen die Spieler kontinuierlich bewerten und sich entsprechend anpassen können. Mit den in dieser Dissertation vorgestellten Untersuchungen haben wir einige wertvolle Ansatzpunkte für die Weiterentwicklung von DGBL-Umgebungen gesetzt, die für das Training von Entscheidungsfindungen im Krisenmanagement eingesetzt werden können.

Wir beobachteten, dass Spieler:innen, die weniger stressresistent waren, bei der Bewertung von Informationen an Genauigkeit verloren. Darüber hinaus fanden wir heraus, dass ein unauffälliges Assessment von Fähigkeiten wie IL anhand des Verhaltens der Spieler:innen im Spiel möglich ist. Dies ermöglicht die weitere Entwicklung von didaktischen Interventionen, die in DGBL-Umgebungen integriert werden können. Schließlich haben wir festgestellt, dass Selbstreflexion 
durch sozialen Vergleich ein wertvolles Werkzeug sein kann, um eine Veränderung im Spielverhalten der Spieler:innen auszulösen. Um jedoch eine dauerhafte Verhaltensänderung auszulösen, die sich in der tatsächlichen Spielstärke widerspiegelt, folgern wir, dass das Dashboard, das zur Anleitung der Selbstreflexion verwendet wird, gezielter und spezifischer sein sollte. Im optimalen Fall können den Spieler:innen Interpretationen zum In-GameVerhalten, unterstützt durch spezifische Verbesserungsvorschläge, angezeigt werden. Folglich können die Spieler:innen die Informationen effektiv nutzen, um ihr eigenes Spielverhalten kritisch zu bewerten und entsprechend anzupassen. 

Digital game-based learning can be a valuable training tool in, for example, crisis management decision-making. In this dissertation it is investigated whether learners' skills can be assessed unobtrusively and whether a dashboard-guided self-reflection can lead to in-game behavior changes.

Two studies were conducted investigating unobtrusive assessment measures for important skills in crisis management decision-making: Analytical skills, stress resistance and information literacy. Additionally, one study was conducted investigating the effect of using a dashboard for self-reflection on players' gameplay behavior.

Results showed that induced stress influences in-game performance, that different patterns of gameplay behavior can be associated with different skill levels of information literacy, and that a dashboard-guided self-reflection can be used to influence learners' gameplay behavior. 